\title{
ESTUDIO COMPARATIVO DE LA REPARACIÓN DEL SISTEMA NERVIOSO PERIFÉRICO CON TÉCNICAS MICROQUIRÚRGICAS EXPERIMENTALES DE SUTURA EPINEURAL EN CONDICIONES DE DISTINTOS GRADOS DE TENSIÓN
}

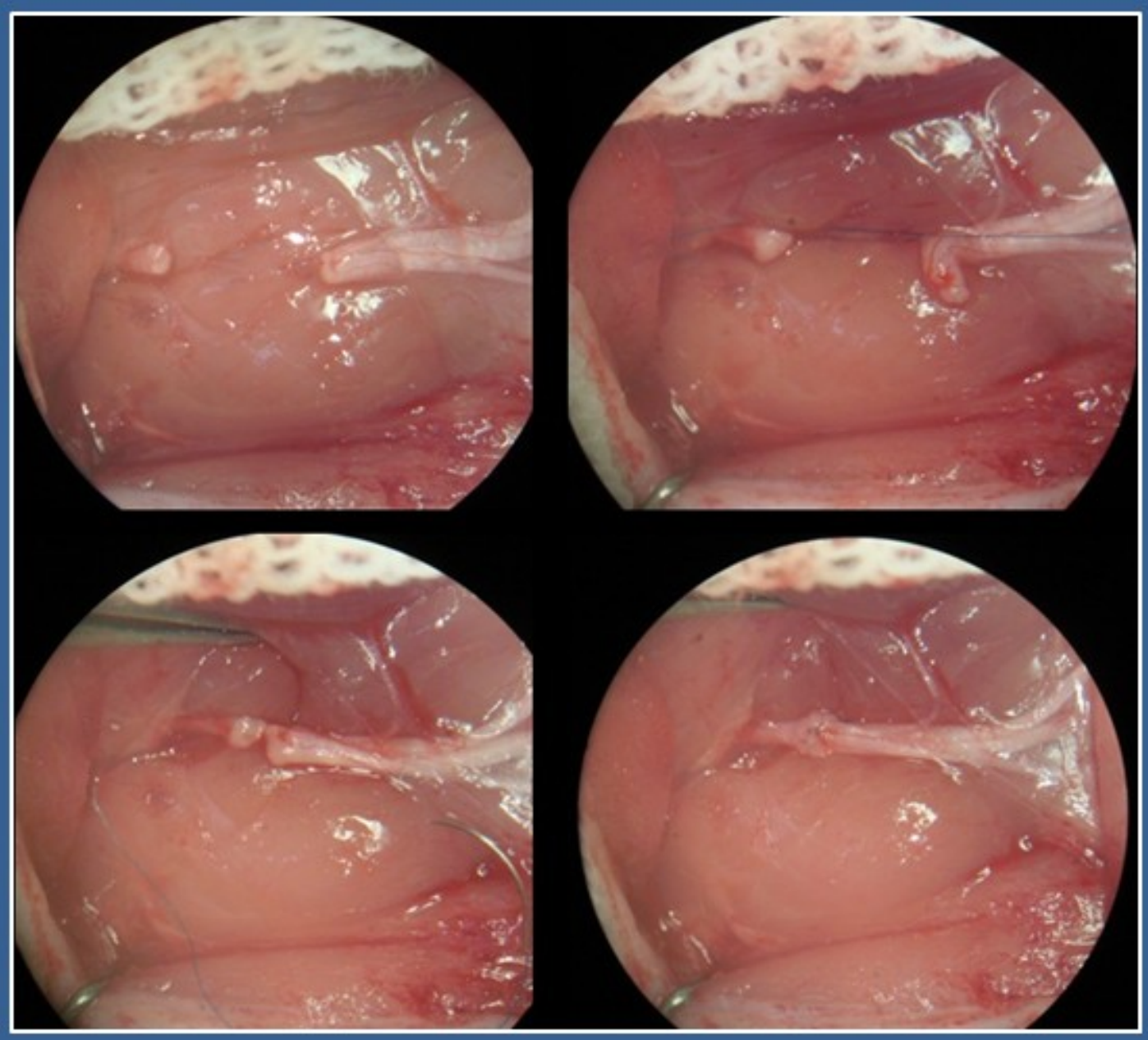

Jorge Luis Bustamante

Tesis de Doctorado en Ciencias Médicas

Universidad Nacional de La Plata $2012-2015$ 



\title{
ESTUDIO COMPARATIVO DE LA REPARACIÓN DEL SISTEMA NERVIOSO PERIFÉRICO CON TÉCNICAS MICROQUIRÚRGICAS EXPERIMENTALES DE SUTURA EPINEURAL EN CONDICIONES DE DISTINTOS GRADOS DE TENSIÓN
}

\author{
Jorge Luis Bustamante \\ Director de Tesis: Dr. Mariano P. Socolovsky
}

Co Directora de Tesis: Dra MV Natalia R. Lausada

Jurados: Prof. Dr. Antonio Carrizo, Prof. Dr. Juan José Mezzadri, Prof. Dr. Osvaldo Fournes

Carrera de Doctorado en Ciencias Médicas

Facultad de Ciencias Médicas

Universidad Nacional de La Plata

Presentación año 2015 



\section{Índice}

Resumen

Aprobación de Comité, Beca y Premio de Tesis II

Abreviaturas Utilizadas _III

$\begin{array}{ll}\text { Introducción } & 1\end{array}$

Antecedentes y marco teórico

Reseña histórica 3

Histología del sistema nervioso periférico $\quad \mathbf{5}$

$\begin{array}{ll}\text { Anatomía funcional del nervio ciático de la rata } & \mathbf{6}\end{array}$

Fisiopatología de la lesión del sistema nervioso periférico $\quad \mathbf{8}$

Clasificación de las lesiones nerviosas $\quad 12$

Técnicas de reparación del sistema nervioso periférico $\quad 13$

$\begin{array}{lr}\text { Diseño experimental general } & 20\end{array}$

$\begin{array}{ll}\text { Hipótesis } & 21\end{array}$

$\begin{array}{ll}\text { Objetivos } & 21\end{array}$

Materiales y métodos

Animales, instrumental quirúrgico $\quad 22$

Microscopio, anestesia, preparación quirúrgica $\quad \mathbf{2 2}$

Abordaje $\quad 24$

Técnica quirúrgica $\quad 26$

Determinaciones

Evaluación funcional mediante huellas plantares $\quad 29$

Electrofisiología $\quad 31$

Histopatología 33

Análisis estadístico $\quad 36$

Resultados $\quad 36$

Evaluación funcional mediante huellas plantares $\quad 37$

Electrofisiología $\quad 40$

Histopatología $\quad 41$

$\begin{array}{ll}\text { Discusión } & 43\end{array}$

$\begin{array}{ll}\text { Conclusiones } & 51\end{array}$

$\begin{array}{ll}\text { Bibliografía } & 52\end{array}$

$\begin{array}{ll}\text { Agradecimientos } & 61\end{array}$ 


\section{Resumen}

Traumatismos con heridas contusas y avulsiones por impacto de alta cinética que involucran al sistema nervioso periférico, pueden producir carencia de tejido nervioso o la formación de un neuroma que amerita su resección, donde muchas veces resulta imposible la realización de una sutura primaria. Asimismo, la sutura simple de un nervio seccionado que se efectúe con tensión entre los cabos distal y proximal irá irremediablemente al fracaso.

Para reparar un nervio periférico que tiene pérdida de sustancia, clásicamente este defecto se suple por un injerto autólogo. Sin embargo, se produce comorbilidad en el sitio dador, como pérdida de sensibilidad, aumento del tiempo operatorio, neuromas dolorosos, entre otros; y sus resultados siempre son inferiores a la sutura directa sin tensión. Existe una opción para evitar el uso de injertos cuando el defecto es escaso, colocando puntos epineurales distales (PED) a la neurorrafia, eliminando así la tensión en dicha unión.

La propuesta general del presente trabajo es analizar en forma prospectiva la viabilidad de una reparación nerviosa en un modelo experimental, mediante técnicas microquirúrgicas con diferentes grados crecientes de pérdida de tejido nervioso periférico. Asimismo consensuar el límite de pérdida de tejido nervioso que pueda ser reparado con técnica de PED exitosamente.

Se utilizarán 40 ratas Wistar adultas, dividiéndose aleatoriamente en 4 grupos. Bajo anestesia general se le realizó el abordaje al nervio ciático y se efectuó sección trasversal y sutura simple con nylon 10.0 bajo magnificación con microscopio quirúrgico al grupo $A$ (control). Se realizó exéresis de $2 \mathrm{~mm}$ de nervio al grupo $B$, de $4 \mathrm{~mm}$ al grupo $C$ y de $6 \mathrm{~mm}$ al grupo $D$; para luego realizar su reparación mediante la técnica de PED.

Se realizó registro de la marcha mediante las impresiones de las huellas plantares a los 30, 60 y 90 días, que nos permitió una evaluación funcional y evolutiva del miembro con lesión sin la necesidad de exploración quirúrgica.

A los 90 días se realizó el análisis por electrofisiología de la velocidad de conducción nerviosa en ambos miembros inferiores, que nos permitió analizar cuantitativamente la viabilidad de la neurorrafia mediante su conducción eléctrica y la comparación con su par. Posteriormente se extrajo el segmento nervioso reparado y su contralateral para su análisis histológico por coloraciones con hematoxilinaesosina, como también inmunohistoquímica con anticuerpo primario (S100) para células de Schwann.

Se realizó el conteo de axones por técnicas de microfotografías, estableciendo el índice de regeneración, y de esta manera el número de axones que cruzan el sitio reparado.

Se confrontó a los diferentes grupos planteados con análisis de la varianza, considerando significativo un valor de $p<0.05$. 


\section{Aprobación de Comité de Ética}

La presente tesis de doctorado contó con la aprobación del protocolo experimental por el Comité Institucional para el Cuidado y Uso de Animales de Laboratorio (CICUAL) dependiente de la Secretaría de Ciencia y Técnica de la Facultad de Ciencias Médicas de la Universidad Nacional de La Plata. ( $N^{\circ}$ T01-03-2015).

\section{Beca}

El presente trabajo fue beneficiario del "Programa de becas para la finalización de tesis de postgrado para docentes de universidades nacionales" (PROFITE). Resolución № 2775SPU. Ministerio de Educación de la Nación Argentina. Agosto 2014.

\section{Premio}

Esta tesis fue premiada en el Congreso Anual de la Sociedad de Cirugía Neurológica de Buenos Aires. Decisión unánime del jurado. Noviembre de 2014. 


\section{Abreviaturas Utilizadas}

SNP - Sistema Nervioso Periférico

PED - Puntos Epineurales Distales

Fig. - Figura

et ál. - (et álii) Y otros

v. g. - (verbi gratia) Por Ejemplo

cm - Centímetros

mm - Milímetros

G - Gauge

mA - Miliamperios

PAM - Potencial de Acción Motor

LATM - Latencia Máxima

AMPTM - Amplitud Máxima

VCM - Velocidad de Conducción Nerviosa
Ms - Milisegundos

IFC - Índice de Función Ciático

LH - Longitud de Huella

D 1-5 - Distancia entre el primer y el quinto dedo

D 2-4 - Distancia entre el segundo y el cuarto dedo

DPO - Distancia de la Pata Opuesta 



\section{Introducción}

La afectación traumática del sistema nervioso periférico (SNP) es una patología que afecta predominantemente a personas jóvenes de sexo masculino en edad económicamente activa. Generalmente dicho trauma es producido en accidentes de tránsito de vehículos a motor, aunque en menor medida se puede atribuir al trauma penetrante, caídas de altura y accidentes industriales. Se estima que las lesiones de nervios periféricos en las extremidades se encuentran entre un 2 o $3 \%$ de las admisiones en centros de trauma, ascendiendo al $5 \%$ si se incluyen a los plexos nerviosos. ${ }^{1}$

El miembro superior es el mayoritariamente afectado, siendo el nervio radial el dañado con más frecuencia, seguido por el cubital y luego el nervio mediano. Dentro del miembro inferior, con mayor asiduidad de daño se encuentra al nervio ciático, seguido por el peroneo y en mucha menor frecuencia el tibial y el femoral.

Las fracturas óseas suelen asociarse a injuria de los nervios que se encuentran en íntima relación con ellos, como es el caso del daño del nervio radial en las fracturas humerales.

Las lesiones del sistema nervioso periférico se encuentran hasta en un $60 \%$ asociadas a politrauma, y entre un 10 a 34\% del trauma encefalocraneano se asocia a lesión del SNP. Ello representa un desafío diagnóstico, ya que la evaluación de los nervios periféricos resulta muy dificultosa en un paciente que no se encuentre lúcido, entendiendo como esto al grado máximo de nivel de conciencia. Asimismo un daño en el sistema nervioso central puede solapar o confundir la interpretación diagnóstica de una injuria en el SNP. ${ }^{1}$

En la práctica médica diaria se tratan pacientes con lesiones en nervios periféricos que están lejos de reunir las condiciones ideales para realizar una sutura primaria del nervio dañado. El campo más propicio para una reparación nerviosa consistiría en una herida cortante limpia que involucre solo al nervio, cuyo tratamiento sería la sutura simple. ${ }^{2}$ Heridas contusas y avulsiones por impacto de alta cinética se observan frecuentemente en las guardias hospitalarias por la magnitud de los accidentes de tránsito. La afectación de los nervios periféricos redunda en discapacidades que impiden o demoran el regreso a las actividades laborales luego de un traumatismo. Asimismo conlleva un riesgo elevado de nuevos traumatismos como caídas o accidentes domésticos. ${ }^{1}$ El sexo donde más frecuentemente se presenta es el masculino, y del grupo etario es el de adultos jóvenes, lo que no solo implica discapacidad personal sino que también influye directamente en la economía de una sociedad en lo referente a la pérdida de productividad, el lucro cesante y los grandes costos que poseen los tratamientos prolongados de rehabilitación y cirugías reconstructivas o paliativas. ${ }^{3-7}$ La falta de tejido nervioso producto del trauma o la formación de un neuroma que amerita su resección, nos deja frente a una situación médico-quirúrgica en la que se debe reparar un segmento nervioso en el cual muchas veces resulta imposible la realización de una sutura primaria. Un concepto abundantemente descripto y probado en la literatura médica, es que la sutura simple de un nervio seccionado que se efectúe con

tensión entre los cabos distal y proximal irá irremediablemente al fracaso. ${ }^{8-10}$ El mecanismo mediante el cual la tensión interfiere con el pasaje axoplasmático a través del sitio de la sutura, es la ausencia de un 
marco estable que permita al brote axonal atravesar la zona dañada, siguiendo la quimiotaxia positiva que le genera el cabo distal. ${ }^{10,11}$

Innumerables mecanismos han sido probados y desarrollados en los últimos 100 años para evitar dicha tensión, incluyendo las flexiones articulares ${ }^{12}$, las transposiciones ${ }^{13-15}$, los injertos nerviosos ${ }^{16-19}$, los expansores tisulares $^{20,21}$, las mallas sintéticas ${ }^{22}$, y hasta los modernos neurotubos ${ }^{2,4,23-26}$, por sólo citar algunos ejemplos. La flexión articular presenta como complicación habitual la rigidez articular, y si bien décadas atrás había caído en desuso, actualmente ha resurgido como alternativa terapéutica ${ }^{18}$. Las transposiciones son un recurso utilizado habitualmente, pero limitado a determinados nervios en sitios también determinados de su recorrido (típicamente el nervio cubital en el codo ${ }^{27,28}$ ). Los neurotubos han demostrado ser exitosos pero sólo cuando el intervalo es pequeño, de hasta 3 centímetros, lo cual limita mucho su utilización, lo que se suma a su elevado costo. ${ }^{23,24}$ La técnica de elección para unir dos extremos de un nervio cuando hay pérdida de sustancia entre ellos es la neurorrafia con injertos autólogos interpuestos. Actualmente este método ha demostrado ser el más apropiado. ${ }^{17,26}$ Sin embargo, el empleo de injertos no está exento de complicaciones, como la pérdida de sensibilidad en el territorio inervado por el nervio dador (generalmente el sural o safeno externo), el incremento del tiempo operatorio, el dolor por neuroma o la infección. ${ }^{2}$ Sin embargo, tal vez el punto más importante a tener en cuenta al valorar la sutura mediante injerto, es que sus resultados siempre son inferiores en cuanto a reinervación a los de la sutura directa sin tensión (neurorrafia término-terminal). ${ }^{26,29}$

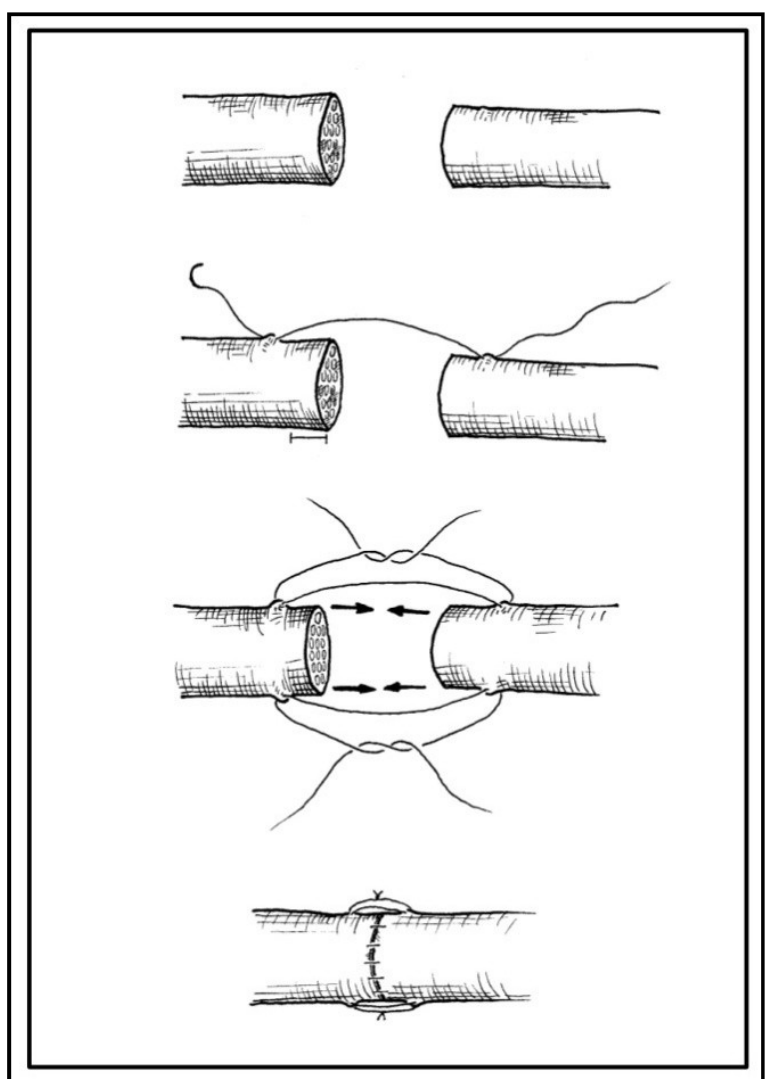

Fig. 1: Técnica de Puntos Epineurales Distales
En las condiciones en las cuales la pérdida de tejido es limitante para la realización de una sutura términoterminal, pero no lo es tanto como para requerir un injerto, se puede desarrollar una tercera opción colocando puntos epineurales distales (PED) al sitio de anastomosis nerviosa, eliminando así la tensión en dicha unión. De esta manera está comprobado que esta técnica favorece la irrigación de la zona dañada y así su correcta reparación. ${ }^{8}$ Mediante esta técnica se aprovecha la elasticidad natural que posee un nervio, que al ser traccionado puede desplazarse una cierta distancia sin generar lesiones en su interior. (Fig. 1) En trabajos publicados por nuestro grupo se ha logrado reparar en la rata pérdidas de hasta $4 \mathrm{~mm}$ de nervio ciático con PED, siendo sus resultados alentadores y demostrando una clara mejoría de la conducción nerviosa, aún bajo cierta tensión, en comparación con el uso de injertos interpuestos. ${ }^{9}$ No obstante, no existe un consenso acerca de la mayor extensión de pérdida de tejido nervioso periférico que puede ser reparada con PED, ni la que requiere de un injerto. 


\section{Antecedentes y marco teórico}

\section{Reseña Histórica}

Las primeras escrituras sobre nervios periféricos fueron de Hipócrates en el siglo cuatro antes de Cristo (460-375), si bien existía confusión en la diferenciación entre nervios y tendones, se creía que el frio era malo para el nervio y el calor bueno. ${ }^{30}$ Asimismo el estudio de la reparación de los nervios periféricos también data de tiempos antiguos, una de las primeras descripciones se remonta al segundo siglo después de Cristo, que fueron realizadas por Galeno (129-200), quien describió con detalles la anatomía desde la médula espinal hasta los nervios digitales, y creía que una vez que los nervios eran seccionados no se regeneraban ${ }^{31}$, y que la manipulación de un nervio dañado causaba convulsiones y dolor, ya que se encontraba en continuidad con el cerebro y por lo tanto eran irreparables. ${ }^{30}$ Trabajos sobre suturas nerviosas fueron reportadas por Paul von Aegina en el siglo séptimo y por los persas Avicenna y Rahzes a finales del primer milenio, este último escribió extensivamente sobre neuroanatomía y logró distinguir nervios motores y sensitivos, y que si un nervio se encontraba comprimido se podía restablecer su función si se lo trataba, pero si era seccionado nunca recuperaría su función. ${ }^{30,31}$ Fue Gabriele Ferrara quien realizó una detallada descripción de la técnica de sutura entre los extremos separados de un nervio en el año $1608 .^{32,33}$

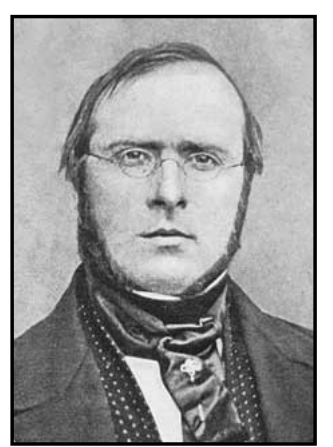

Durante el siglo diecinueve hubo grandes adelantos en lo referente a la reparación de nervios gracias a la introducción de nuevas técnicas histológicas que permitieron dilucidar más detalladamente las estructuras de tejidos y células. El potencial de regeneración de los nervios periféricos y las estrategias para su reparación surgieron de las observaciones de Augustus Waller, quien describió por primera vez la degeneración axónica que acontece en el cabo distal luego de una sección de un nervio, quedando el cabo proximal intacto. ${ }^{30,32}$

\section{Augustus Waller}

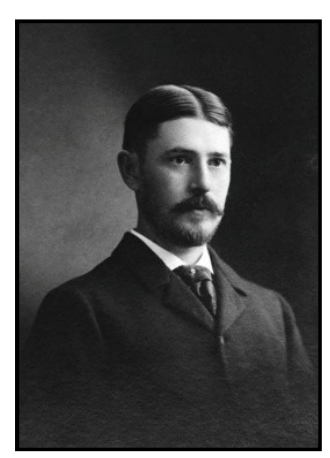

Durante el siglo veinte los avances en la reconstrucción de los nervios periféricos siguieron de cerca las lesiones nerviosas producidas en las guerras mundiales (1914-1918 y 1939-1945). Carl Huber (1887-1934) estuvo relacionado con la primera guerra mundial, donde realizó investigaciones sobre el uso de injertos nerviosos de distintas fuentes (del propio paciente, de cadáveres y hasta de animales) donde observó que los extraídos del mismo paciente tenían los mejores resultados en el laboratorio, aunque sus resultados clínicos tuvieron escasa funcionalidad.

\section{Carl Huber}

Uno de los colaboradores de Huber fue Byron Stookey (1887-1966), quien publicó Surgical and Mechanical Treatment of Peripheral Nerves, libro utilizado como texto de consulta durante décadas. Otro cirujano que trabajó con Huber fue Charles Elsberg, quien estableció grandes principios que continúan hasta el día de hoy, como la sección de los neuromas de los cabos nerviosos hasta evidenciar 
axones sanos, sin fibrosis, y el principio de realizar suturas epineurales para disminuir la formación de tejido de fibrosis que impida el crecimiento axonal. ${ }^{33}$

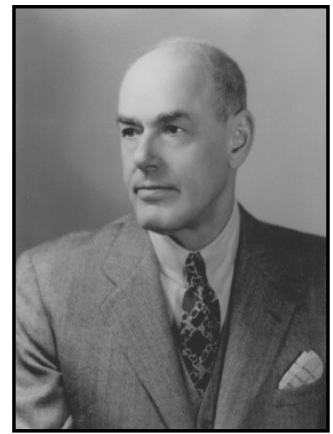

Byron Stookey

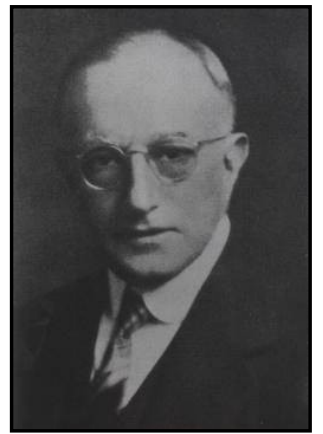

Charles Elsberg

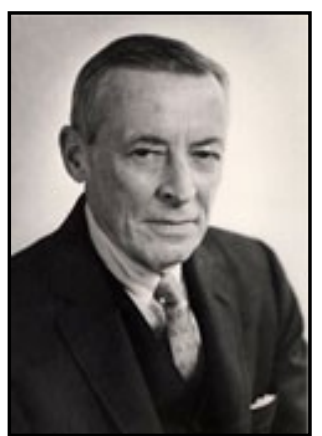

Barnes Woodhall

En la segunda guerra mundial y los tiempos venideros, lo referente a las lesiones nerviosas y su reparación, estuvo ligado a Barnes Woodhall (1905-1984), cuyo estudio titulado Peripheral Nerve Regeneration: A Follow-up Study of 3656 World War Injuries fue una completa base de datos utilizada como estandarte del tema. En esta época Guttmann demostró que cualquier tipo de sutura que se empleara en una neurorrafia produciría fibrosis y por ende impediría el crecimiento axonal. ${ }^{30}$ Uno de los cirujanos de nervios más importante en tiempos de guerra fue Herbert Seddon (1903-1977). Inicialmente cirujano ortopedista, Seddon se dedicó a la cirugía de nervios, atendiendo 669 casos en la segunda guerra mundial. A su vez no solo realizó una de las clasificaciones de lesiones de nervios más utilizadas en nuestros tiempos, sino que ligado a ella determinó el momento adecuado en el que un nervio traumatizado debe ser reparado por una vía quirúrgica. Asimismo estimó que los axones humanos se regeneran a una velocidad de $0.5 \mathrm{~mm}$ por día. La clasificación de Seddon ${ }^{34,35}$ divide en tres grados a la lesión de un nervio periférico, mientras que otro gran cirujano de nervios, el australiano Sidney Sunderland, agrega otros dos grados a la clasificación precedente, conformando una clasificación de cinco grados. Introduce también el concepto de aguardar unos meses antes de operar una lesión nerviosa, las cuales hasta el momento eran operadas lo antes posible luego de la lesión. Del mismo modo pregonó que si durante la exploración quirúrgica era encontrado un neuroma en continuidad, este no debía seccionarse, esperando su recuperación espontánea, y si esto no fuera así, realizar una nueva exploración en tiempo diferido. ${ }^{30,33,36}$

En las últimas décadas y hasta la actualidad, los avances científicos sobre la biología molecular han desarrollado cuantiosos progresos en la comprensión de la fisiopatología de los nervios periféricos ${ }^{37}$ y la posibilidad del tratamiento de las lesiones de los mismos; ejemplo de ello son materiales experimentales de verdadera bioingeniería. ${ }^{38-40}$ No obstante la mejor opción para reparar un nervio sigue siendo tema de controversias. 


\section{Histología del sistema nervioso periférico}

La evaluación histológica, sin ahondar en la biología molecular, de los nervios periféricos de la rata de laboratorio es indistinguible del mismo tejido humano. ${ }^{41}$

Los axones periféricos, estructura de prolongación distal de la neurona cuyo soma se encuentra dentro del sistema nervioso central o en diferentes ganglios, se rodean de una vaina de células de Schwann. En los axones periféricos mayores estas células desarrollan además una capa de mielina, la vaina de mielina, quedando conformadas fibras nerviosas mielínicas y amielínicas. Estas últimas se componen de varios axones que son envueltos grupalmente por una sola célula de Schwann, mientras que en las denominadas fibras mielínicas se encuentra un axón rodeado individualmente por una célula de Schwann. Cada axón "mielínico" es envuelto a lo largo de su recorrido por múltiples células de Schwann que contactan unas con otras en sentido longitudinal, denominándose internodo a la porción axónica rodeada por una única célula de Schwann. La pequeña porción axónica amielínica resultante entre dos células de Schwann que envuelven longitudinalmente al nervio se denomina nódulo de Ranvier. En las fibras mielínicas el potencial de acción se transmite "saltando" entre cada nódulo de Ranvier, lo que se conoce como conducción saltatoria, por lo cual dichas fibras poseen mayor velocidad de transmisión del impulso axonal. ${ }^{11,42}$

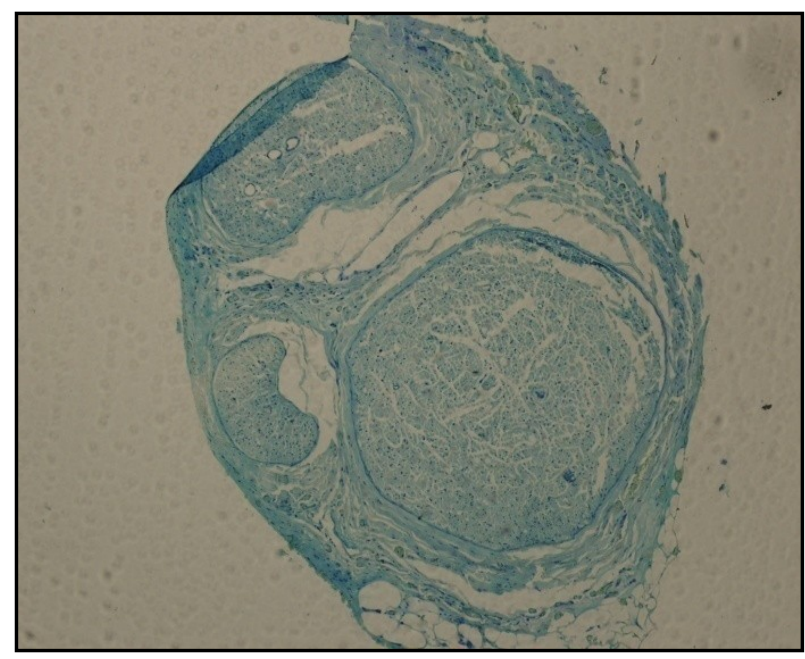

Fig. 2: Corte transversal de nervio ciático de la rata Wistar. 4X Azul de Toluidina.
Los nervios periféricos poseen una estructura dividida en capas, con tejido conectivo que protege y sostiene a los delicados axones. Todo el nervio se encuentra rodeado por una gruesa capa de tejido conectivo denso irregular denominado epineuro, que lo separa de otros tejidos del organismo, constituyendo aproximadamente el $50 \%$ del total de la superficie de un nervio en un corte transversal. $^{42}$ Las fibras nerviosas suelen encontrarse agrupadas en fascículos diferenciados por prolongaciones del epineuro. Dichos fascículos se encuentran rodeados por el perineuro, compuesto por tejido conectivo menos denso que el epineuro. ${ }^{43}$ (Fig. 2)

Dentro del perineuro, los espacios entre cada fibra nerviosa se encuentran ocupados por tejido conectivo laxo, el endoneuro, que puede agrupar tanto axones mielínicos como a grupos de axones amielínicos. ${ }^{42}$ Cuando el nervio se va dividiendo en ramificaciones progresivamente más finas, el epineuro desaparece y el perineuro se fusiona con el endoneuro. ${ }^{43}$

Importantes funciones pueden atribuirse al perineuro, entre ellas la de mantener la presión intrafascicular y regular a modo de barrera selectiva las sustancias de su interior. Asimismo, es el encargado de proteger los axones de los microorganismos infecciosos, pudiendo así los nervios aún mantener su función en trayectos piógenos. ${ }^{42}$ En lo referente al epineuro, sus principales funciones 
residen en proteger los fascículos y mantener la continuidad estructural del nervio. El epineuro interfascicular facilita la movilidad individual de cada fascículo, por lo que su fibrosis puede resultar en una compresión crónica de las estructuras nerviosas.

Finalmente rodeando al epineuro se encuentra un tejido areolar laxo conocido como mesoneuro, que funciona como nexo entre el tejido circundante y el epineuro.

La vascularización nerviosa, también conocida como vasa nervorum, se compone de una porción extrínseca y una intrínseca. Esta última se encuentra en extensión y abarca al epineuro, perineuro y endoneuro. Se encuentran vasos longitudinales tanto en el epineuro como en el endoneuro, mientras que los capilares sanguíneos sólo son hallados en el endoneuro. Los vasos arriban al nervio a través del mesoneuro. (Fig. 3)

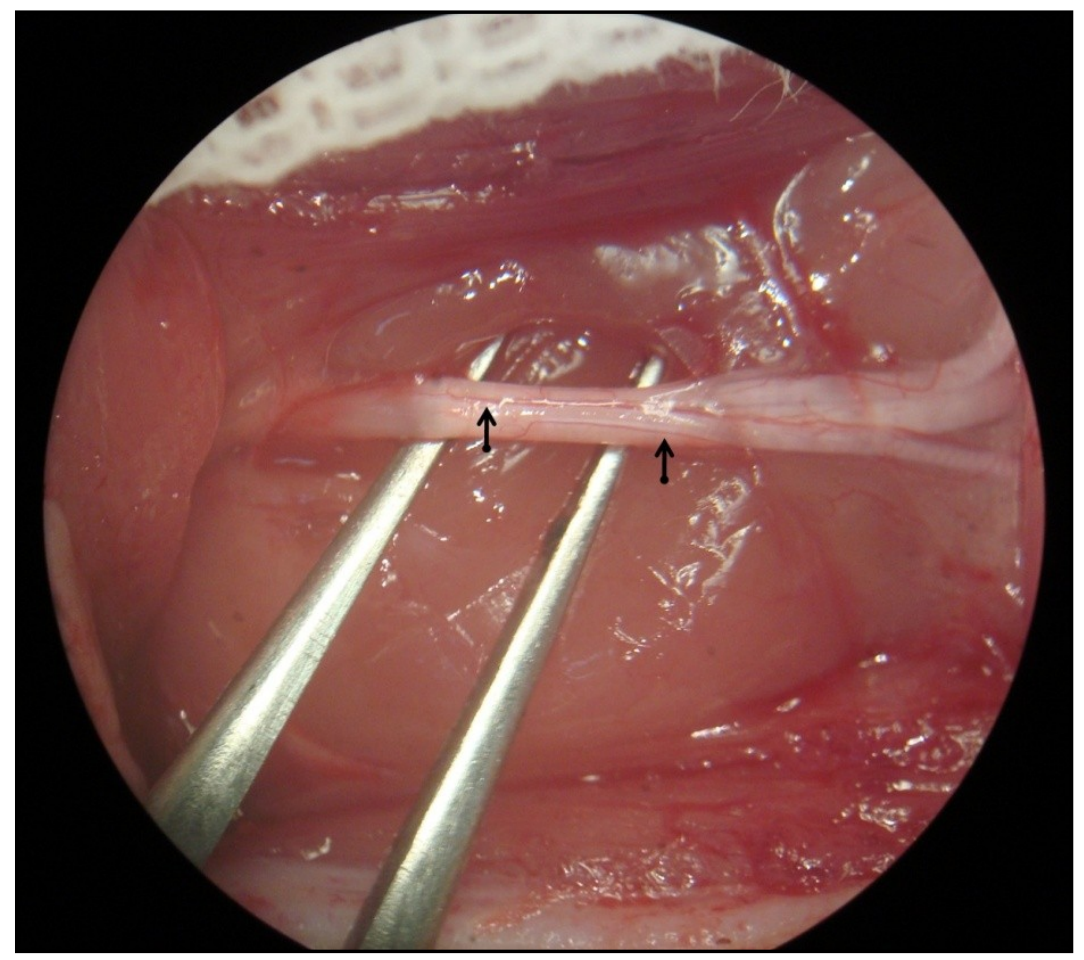

Fig. 3: Nervio Ciático de la rata Wistar evidenciando la vasa nervorum.(Flechas)

\section{Anatomía funcional del nervio ciático de la rata}

Si bien el nervio ciático de la rata es uno de los modelos mayoritariamente utilizados en la investigación de los nervios periféricos, existen pocas descripciones e ilustraciones que detallen su anatomía y distribución. ${ }^{44}$ 
El nervio ciático de la rata se forma principalmente de las raíces lumbares cuarta y quinta, aunque suele recibir anastomosis de las raíces contiguas, tanto de la superior como en mayor medida de la raíz inferior, como demuestra en su estudio Asato et ál. ${ }^{44} \mathrm{El}$ tronco principal tiene una extensión aproximada de $25 \mathrm{~mm}$ antes de ramificarse, siendo éste el sitio donde se realizan la mayoría de los experimentos de SNP en la rata. ${ }^{45-51}$ Posteriormente se divide en tres principales ramas, los nervios peroneo, tibial y safeno. $^{52}$ (Fig. 4)

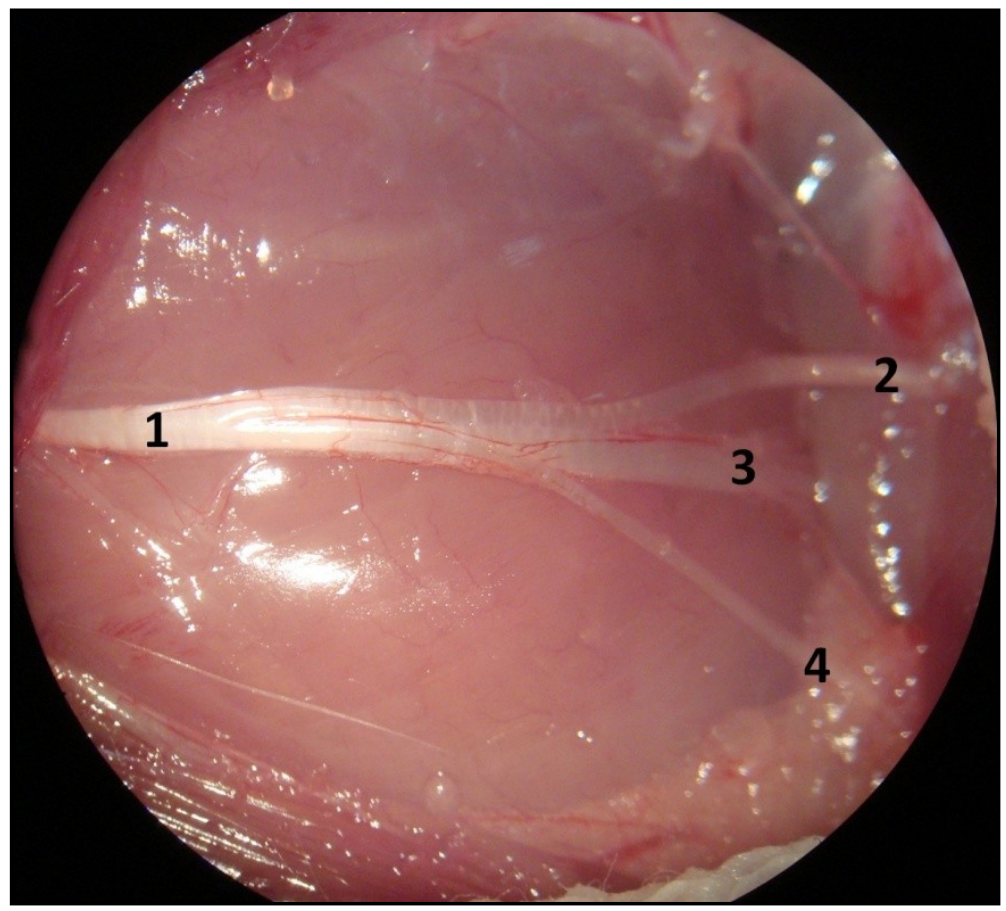

Fig. 4: Ramas terminales del Nervio Ciático de la rata Wistar. 1.Nervio ciático 2.Nervio peroneo 3.Nervio tibial 4.Nervio safeno.

El nervio peroneo inerva los extensores de los dedos del miembro inferior y determina la dorsiflexión del pie, por lo cual una lesión del mismo producirá un acortamiento en la impresión de la huella plantar en el análisis de la marcha (ver evaluación observacional de la marcha en materiales y métodos) debido al predominio de los músculos flexores.

El nervio tibial determina la flexión plantar del tobillo y de los dedos, así como la movilidad intrínseca del pie, por lo que su lesión produce una significativa dificultad para la marcha: al predominar la acción extensora del nervio peroneo el animal camina apoyando toda la región plantar. La pérdida de la acción de los músculos intrínsecos del pie determina una menor impresión de la huella del pie, aunque de mayor longitud por lo anteriormente expuesto. ${ }^{41}$

El nervio safeno es puramente sensitivo, recibiendo estímulos de gran parte del miembro inferior de la rata. 


\section{Fisiopatolología de la lesión del sistema nervioso periférico}

Luego de una injuria al sistema nervioso periférico, se produce una compleja y regulada serie de eventos destinados a su reparación, con remoción del tejido dañado y restauración de la continuidad axonal. A diferencia de la reparación celular en otras áreas del organismo, en los nervios periféricos dañados no ocurre mitosis, ya que el tejido injuriado, el axón, es una prolongación celular que generalmente se encuentra muy distante al núcleo. No obstante, el complejo proceso de reparación involucra indefectiblemente al soma neuronal, localizado en ganglios nerviosos o dentro del sistema nervioso central. Varias células juegan un papel primordial en la correcta reconstrucción de la conducción nerviosa, como las células de Schwann, macrófagos y otras células de respuesta inflamatoria. Asimismo, son de vital importancia en el sitio de la lesión los factores neurotróficos. ${ }^{11,37}$

El cabo proximal también sufre desmielinización hasta el nódulo de Ranvier más proximal si la injuria es leve. ${ }^{53}$ Todos los cambios neuronales y su posterior regeneración se corresponden con la magnitud del trauma. Si la injuria fue de gran cuantía, la recuperación será escasa o nula.

Posterior al daño nervioso, la desmielinización del axón es subsanada con la progresiva reconstitución de la vaina mielínica, la cual puede ser utilizada como un indicador de severidad de la injuria y como pronóstico de la recuperación del nervio. El grado de regeneración de la mielina se correlaciona directamente con la recuperación funcional nerviosa. En la actualidad no existe manera no invasiva de evaluar la remielinización axonal, aunque se encuentran en desarrollo experimental diferentes métodos. ${ }^{53,54}$

La organización intraneural sufre cambios luego de la injuria y la posterior reparación nerviosa; el epineuro se encontrará adelgazado, con diferentes grados de fasciculación y proliferación. A su vez, en el interior del nervio se evidenciará tejido de fibrosis, dependiendo su cuantía en relación a la importancia del trauma. ${ }^{55}$

\section{Mecanismos de injuria}

Se reconocen tres tipos básicos de mecanismos lesionales en el SNP, no obstante muchas veces en la práctica clínica se encuentran asociaciones de los mismos, siendo raro observar formas puras.

El tipo más común de lesión es la producida por estiramiento, ocasionada cuando las fuerzas de tracción sobrepasan la capacidad de estiramiento fisiológica del nervio, pudiendo ocurrir desde una lesión en continuidad, lo cual es más frecuente, hasta una sección nerviosa como ocurre por ejemplo en las avulsiones de plexo braquial. Estas lesiones pueden ser únicas o asociadas a fracturas donde los nervios y los huesos se encuentran en íntima relación (como ocurre con el nervio radial en las fracturas de húmero).

Las laceraciones nerviosas, comúnmente producidas por armas blancas, constituyen otro tipo de lesión y representan hasta el $30 \%$ en algunas series. Si bien el nervio puede encontrarse en una situación de sección completa, generalmente es más frecuente hallar una lesión en continuidad. ${ }^{37}$ 
La injuria por compresión incluye la "parálisis de sábado por la noche" ${ }^{56,57}$ que se produce cuando un individuo, bajo efectos de alcohol o drogas, permanece apoyado sobre una extremidad (usualmente el miembro superior) durante un período de varias horas sin moverse, presionando a un nervio adyacente a un hueso largo. El nervio mayormente afectado por este mecanismo es nuevamente el radial. Este es el clásico ejemplo de neurapraxia de la clasificación de H. Seddon. (Ver clasificación de las lesiones nerviosas)

\section{Respuesta celular a la lesión}

Luego de la injuria se desencadenan procesos degenerativos previos a la regeneración nerviosa. Esta degeneración del nervio es proporcional a la magnitud del daño producido, por lo cual es muy discreta o nula en la neurapraxia, se intensifica en la axonotmesis y es excelsa en la neurotmesis.

Los cambios celulares se producen en las primeras horas, donde se fragmentan los axones y la mielina que los envuelve, neurotubos y neurofilamentos pierden su orden natural y el contorno axonal se vuelve irregular por el edema. Entre las 48 y las 96 horas posteriores, se pierde la continuidad axonal y por ende la conducción nerviosa de los impulsos es inasequible. La desintegración mielínica es posterior a la axónica, no obstante se encuentra en estado avanzado entre las 36 a las 48 horas.

Las células de Schwann incrementan su actividad luego de las $24 \mathrm{hs}$ del daño: su núcleo y citoplasma se observan alargados y aumenta su actividad mitótica. Esta activación celular produce cambios moleculares (precedidos de activación génica) que mediarán inicialmente la remodelación nerviosa. Asimismo se produce una posterior migración de macrófagos que fagocitarán restos celulares, y en conjunto con las células de Schwann "despejarán" el sitio dañado. ${ }^{2}$ Este complejo proceso se extiende entre una semana y varios meses. Los mastocitos endoneurales producen histamina y serotonina aumentando la permeabilidad capilar y facilitando la migración de los macrófagos. Luego de cinco a ocho semanas el proceso degenerativo suele estar completo y el segmento distal se compone solo de células de Schwann con una vaina endoneural. ${ }^{37,42}$

Si la lesión ha sido de importante magnitud, se observa abundante edema y hemorragia, lo que condiciona una vigorosa respuesta inflamatoria. Se produce gran proliferación de fibroblastos y se genera una cicatriz densa que dificultará la correcta neurotización.

\section{Cambios postraumáticos en el segmento proximal a la lesión}

En el segmento proximal y cerca del lugar de la injuria, las células de Schwann degeneran, lo cual se asocia a una disminución del diámetro del axón y de la vaina de mielina. Si la lesión primaria fue leve, la degeneración mielínica se produce hasta el nódulo de Ranvier más próximo, mientras que si el trauma fue de magnitud importante, los cambios degenerativos pueden abarcar hasta el mismo soma neuronal, y cuando esto ocurre, todo el segmento proximal sufre degeneración Walleriana y es fagocitado. 
Concomitante a la reducción del diámetro axonal, también se produce una reducción de la velocidad de conducción nerviosa. Estos cambios retrogradan, aunque nunca hasta parámetros previos, con el restablecimiento de las conexiones axonales.

El núcleo neuronal no escapa a los cambios generados por una lesión distante en su axón. Ya a las 6 horas luego de la injuria el núcleo migra hacia la periferia y los corpúsculos de Nissl se rompen y dispersan, proceso conocido como cromatolisis. ${ }^{37,42}$ Los principales cambios metabólicos producidos consisten en un incremento de la síntesis de ARN, de proteínas y lípidos, así como un incremento de la glucosa-6-fosfato deshidrogenasa y enzimas hidrolíticas; todas estas modificaciones son producidas con el objetivo de reconstruir el axón dañado para el restablecimiento de la conducción de impulsos. El lugar físico donde ocurren estos cambios varía si se trata de un axón sensitivo o motor, siendo el ganglio dorsal sensitivo en el primer caso, o el asta anterior de la médula espinal en el segundo.

Estos cambios no solo afectan a la neurona, ya que las células gliales también sufren un incremento de su actividad, posiblemente generado por la cromatolisis, interrumpiendo las sinapsis neuronales, lo cual probablemente constituye un proceso previo a la regeneración neuronal propiamente dicha.

En traumas severos se observa apoptosis neuronales en los ganglios de las raíces dorsales entre un 20 y un $50 \%$. La apoptosis se produce más frecuentemente si: se trata de neuronas sensitivas, de pares craneales, o el trauma es más cercano al soma neuronal. Todos estos complejos procesos son escasamente comprendidos en la actualidad.

\section{Cambios postraumáticos en el segmento distal a la lesión (Degeneración Walleriana)}

A este nivel se produce una reducción de tamaño de los tubos endoneurales denervados que alcanza su máximo hacia los tres o cuatro meses luego de la injuria. Asimismo, se produce un depósito de colágeno en la cara externa de la membrana basal de las células de Schwann que engrosa las vainas endoneurales. Si los tubos endoneurales no reciben finalmente un axón en regeneración, terminan por obliterarse por fibrosis progresiva. ${ }^{37}$

Las células de Schwann también sufren cambios en el segmento distal, formando columnas conocidas como bandas de Büngner que son la guía para los axones durante su regeneración. Esta constituye una importante función de dichas células formadoras de mielina, ya que conducirán el proceso de neurotización. Los axones que no ingresan a las bandas de Büngner lo hacen al espacio endoneural ocupado por tejido conectivo, lo que provoca que rápidamente detengan su crecimiento y nunca aborden al órgano blanco. ${ }^{11}$

Justamente también en el órgano blanco se producen cambios luego de la denervación de manera rápida: al cabo de dos meses el músculo sufre una atrofia del $70 \%$ en el corte transversal. El núcleo del miocito, normalmente periférico, se torna central. Los pliegues sinápticos de las placas neuromusculares se mantienen al menos por un año luego de la denervación. El músculo experimenta abundante 
proliferación de fibroblastos, y las fibras de colágeno se depositan en el endo y el perimisio. ${ }^{37}$ Estos cambios limitan la recuperación funcional final. ${ }^{42}$

\section{Regeneración nerviosa}

Así como fue descripto anteriormente en los cambios neuronales luego de la injuria, la posterior regeneración nerviosa puede ser dividida histológicamente en regiones. A nivel del soma, el núcleo retorna al centro de la célula, y las nucleoproteínas se reagrupan en corpúsculos de Nissl compactos. Un concepto muy importante a remarcar, consiste en que las neuronas que componen al SNP humano poseen la capacidad de regenerar hasta 12 meses luego de la injuria. Los axones amielínicos pueden crecer en tubos endoneurales mielínicos y también puede ocurrir lo contrario. Hasta el momento no se conocen factores neurotróficos que puedan guiar al brote axonal a encontrarse con su correspondiente tubo endoneural distal. ${ }^{37}$

El axón que regenera posee como primer obstáculo la fibrina generada en el sitio de lesión, y si logra atravesar dicha barrera puede ocurrir que no llegue al órgano blanco por una disrupción posterior del tubo endoneural, o porque el tubo endoneural no es el indicado. Puede acontecer además que varios brotes axonales se introduzcan en un mismo endotubo, observándose más de un axón en su interior en una sección transversal distal. Luego de 4 meses de la injuria, el endotubo distal generalmente se reduce tres micrómetros o menos, lo que dificulta al brote axonal encontrarlo. No obstante, una vez que se encuentra dentro del mismo este escaso diámetro no impide el crecimiento del axón, presumiblemente por la elasticidad propia del endoneuro.

Si el axón no logra atravesar el anteriormente mencionado obstáculo de fibrina e ingresar a las bandas de Büngner, sus brotes axonales crecerán de manera aleatoria en varias direcciones, lo que puede derivar en la formación de un neuroma. ${ }^{2,11}$

Aún cuando se logre una buena recuperación motora, la sensibilidad puede continuar con déficit, particularmente la propiocepción. Los receptores sensitivos tienen una mejor recuperación si la continuidad axonal se reinstaura antes del año, y al igual que la porción motora, si la injuria fue de gran magnitud, la recuperación será menos auspiciosa y nunca será completa. ${ }^{37}$ Luego de un tiempo variable para cada nervio y para cada organismo, ya no existirán chances de reinervación por crecimiento axonal en el segmento distal, incluso con la más prolija técnica quirúrgica.

Existen diferencias tanto respecto a la respuesta a la injuria como a la regeneración según se trate de fibras sensitivas o motoras. Las primeras poseen una tasa de muerte celular mucho más elevada que las fibras motoras: se cree que hasta un $40 \%$ de las neuronas sensitivas ubicadas en el ganglio dorsal de la médula realizan apoptosis luego de un trauma severo si el nervio no es reparado. ${ }^{4}$

Se ha instaurado como referencia clásica una velocidad de crecimiento ponderada en $1 \mathrm{~mm}$ por día, aunque existen variaciones en lo referente a la literatura y al nervio lesionado. ${ }^{42}$ Se cree que la variabilidad de la velocidad de crecimiento depende de varios factores, como la distancia entre el soma 
neuronal y el sitio de lesión axonal: a mayor distancia, menor velocidad de crecimiento. Asimismo juegan un papel cardinal la severidad del daño primario, el tiempo de denervación y el estado de los órganos diana y tejidos periféricos, razones por las cuales resulta de fundamental importancia una correcta rehabilitación kinesiológica.

Dentro del complejo mecanismo de degeneración y reparación de una lesión nerviosa confluyen numerosos factores especializados en la comunicación dentro de la neurona y entre ésta y otras células. Uno de los más importantes es el factor de crecimiento nervioso, el cual fue el primer factor conocido y por tal motivo el mejor caracterizado. Su función se encuentra relacionada con el mantenimiento de la supervivencia celular y de las estructuras luego de la lesión axonal. Asimismo los macrófagos intervinientes en la fagocitosis estimularían la producción de este factor de crecimiento, y las propias células de Schwann lo producirían en el sitio de la injuria, así como el incremento de su receptor en las bandas de Büngner posteriores al daño. ${ }^{42} \mathrm{El}$ factor de crecimiento nervioso es tomado por el propio axón dañado y conducido en forma retrógrada, constituyendo un estímulo constante para el brote axonal en su avance. ${ }^{11,37}$

\section{Clasificación de las Lesiones Nerviosas}

La clasificación de las lesiones de los nervios periféricos en la actualidad responde a dos grandes autores Herbert Seddon y Sidney Sunderland.

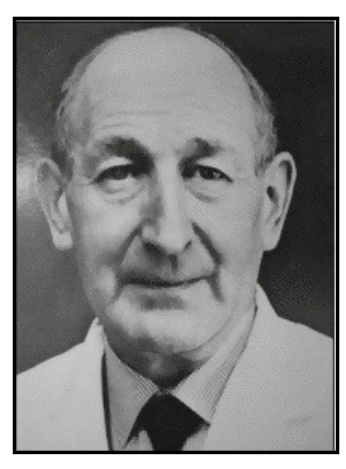

Herbert Seddon

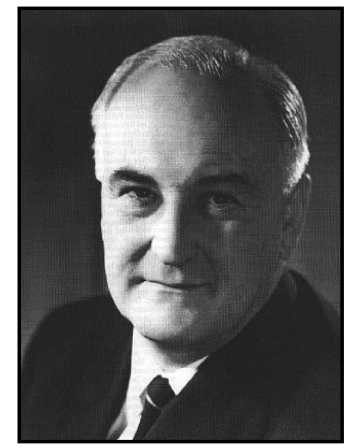

Sidney Sunderland

La clasificación de Seddon realizada entre los años 1942 y $1943^{34,35}$, ordena de manera creciente al daño que puede sufrir un nervio y pronostica su recuperación. El primer Grado de lesión corresponde a la neurapraxia y consta del bloqueo de la conducción nerviosa de manera local sin afectación axonal. La recuperación es completa y se produce en forma rápida, máximo un par de semanas. El segundo grado es la axonotmesis, en la cual se encuentra dañado el axón produciéndose degeneración Walleriana del cabo distal. Como no hay daño de las coberturas nerviosas (perineuro, epineuro) la regeneración axonal sigue su curso natural hasta el órgano blanco, por lo que es regla la recuperación a pesar de producirse en un mayor lapso de tiempo, hasta 6 meses. El grado máximo de lesión lo constituye la neurotmesis, en la cual se produce la sección completa de los axones y sus envolturas, y macroscópicamente el nervio se observa con discontinuidad. La pérdida de función nerviosa es completa y permanente, y requerirá de su tratamiento para la posibilidad de restitución de su función.

Posteriormente Sunderland en $1951^{51}$ agregó dos estadios a la clasificación precedente. Los grados primero y segundo son idénticos a lo realizado por Seddon, el tercer grado consta de una lesión del axón y del endoneuro, lo cual conllevará a una recuperación espontánea de la función nerviosa aunque sin restitución ad integrum, ya que algunos axones no podrán atravesar el sitio de 
lesión. Mientras que el cuarto grado se observa cuando ambos extremos seccionados del nervio se hallan unidos por tejido cicatrizal, aunque no por tejido nervioso. El quinto grado es idéntico al tercer grado, o grado máximo descripto por Seddon.

En la práctica diaria la clasificación más utilizada es la realizada por Herbert Seddon, ya sea por su simpleza o por la dificultad de distinguir clínicamente el grado 4 de Sunderland, solo posible de manera intraquirúrgica.

\begin{tabular}{cccc}
\hline $\begin{array}{c}\text { Clasificación de } \\
\text { Seddon }\end{array}$ & $\begin{array}{c}\text { Clasificación de } \\
\text { Sunderland }\end{array}$ & Daño Nervioso & Recuperación \\
\hline $\mathbf{1}$ & $\mathbf{1}$ & Mielina que rodea al axón & Completa en días \\
\hline $\mathbf{2}$ & $\mathbf{3}$ & Axón & Completa en meses \\
& $\mathbf{4}$ & Axón y Endoneuro & Incompleta en meses \\
& $\mathbf{5}$ & Solo intacto Epineuro & Nula \\
\hline
\end{tabular}

\section{Técnicas de reparación del sistema nervioso periférico}

Existen diferentes técnicas al momento de realizar una reparación nerviosa. La condición ideal de reparación luego de una sección nerviosa es la sutura epineural sin injerto interpuesto.

Luego de una lesión con sección nerviosa, nos enfrentamos a un complejo escenario donde la intención de restablecer la función nerviosa se ve obstaculizada por la magnitud de la injuria. La existencia o no de pérdida de sustancia nerviosa y sobre todo su extensión, nos plantea la necesidad de utilizar injertos interpuestos como se discutirá más adelante.

En el humano se puede realizar la reparación primaria de un nervio o realizar una transferencia nerviosa, es decir tomar un nervio que normalmente cumple una función determinada y "reconducirlo" hacia un cabo distal de un nervio dañado, con el objetivo de refuncionalizar una región deseada. En ambos casos las técnicas de coaptación nerviosas son las mismas, y si bien son variadas, el cirujano debe elegir el mejor modo para lograr el objetivo de reinervación.

El procedimiento de transferencia nerviosa es frecuentemente utilizado en las cirugías de plexo braquial, donde el cirujano posee a su alcance nervios aledaños de los que puede sacrificar su función primaria para lograr restablecer capacidades, como por ejemplo, la flexión de codo en una transferencia de nervios intercostales al musculocutáneo. Esta técnica es particularmente utilizada cuando no existe cabo proximal viable para reinervar al segmento distal, por lo cual la complejidad del cerebro utiliza su plasticidad neuronal para reconocer y utilizar su nueva función. 4,59,60 
Una adecuada planificación quirúrgica, con la ayuda de diagnóstico por imágenes y electrofisiología, debe preceder indefectiblemente a todo acto quirúrgico, ya que gran parte del éxito del procedimiento depende de ello.

Se pueden reconocer diferentes pasos en la técnica ideal de reparación de un nervio: ${ }^{4}$

Preparación: Identificar los cabos nerviosos, proximal y distal con sus diferentes fascículos. En ocasiones es una tarea de gran dificultad debido a la fibrosis del área quirúrgica. El cirujano debe viabilizar los cabos, liberarlos de fibrosis, resecar áreas necróticas, seccionar neuromas y eliminar posibles compresiones, entre otros.

Aproximación: Presentar las extremidades a reparar, eliminar la tensión de las mismas en el sitio de sutura, evitar rotaciones de los cabos y evaluar la necesidad de la utilización de injerto nervioso interpuesto.

Mantenimiento: Realizar una sutura con nylon monofilamento con aguja redonda atraumática para que los cabos no se separen en el postquirúrgico. ${ }^{2}$ También es posible utilizar técnicas alternativas como la colocación de cola de fibrina, el uso de neurotubos, láser u otras técnicas desarrolladas a continuación.

Dentro de la cirugía hay recomendaciones que pueden favorecer a una mejor identificación nerviosa, como por ejemplo comenzar la disección en un área lejos de cicatrices o fibrosis, donde la anatomía no se encuentre distorsionada de la normalidad. Luego de dicha identificación del tronco nervioso, el cirujano se dirige con cuidadosa disección hacia el neuroma o la contusión, es decir hacia la porción dañada. También la identificación de fascículos de diferente tamaño o situación en el espacio es crucial para una correcta coaptación nerviosa.

Asimismo, suele ser relevante la identificación de la vasa nervorum que transcurre en sentido longitudinal. Dichos vasos epineurales resultan una guía extremadamente útil al momento de reconstruir nervios seccionados, ya que dan una idea de la orientación rotacional en la que debe ser reparado el nervio. ${ }^{42}$ Tratando de consolidar topográficamente la continuidad de esos vasos se aseguraría en parte la correcta orientación de los fascículos nerviosos subyacentes, más allá de que los vasos puedan o no volver a anastomosarse entre sí. Este concepto es válido en los primeros tiempos de la lesión nerviosa, ya que luego las deformidades producidas por los neuromas y el tejido cicatrizal circundante son manifiestas e impiden reconocer la correcta orientación de los fascículos dada por los vasos epineurales. ${ }^{4}$

En los nervios motores que no se encuentren con sección completa y conserven al menos un mínimo de su función, es primordial la identificación mediante el neuroestimulador, elemento indispensable en la cirugía de nervios periféricos.

No obstante todo lo anteriormente expuesto resulta fundamental un detallado conocimiento anatómico de la región a abordar, irremplazable en cualquier tipo de cirugía general como en la reparación nerviosa en particular. 


\section{Coaptación simple sin tensión}

\section{Sutura del nervio}

La sutura simple de un nervio constituye la técnica clásica de reconstrucción luego de un daño, y por lo tanto, todas las demás técnicas de reparación nerviosa deberán demostrar no ser inferiores con respecto a ella. ${ }^{55}$ Se reconocen dos tipos de anastomosis: término-terminal y término lateral.

\section{Término-terminal}

\section{Puntos epineurales}

Como ya fue mencionado, en el primer paso luego del abordaje hay que realizar la identificación de los cabos, que en ocasiones suele ser dificultoso si hay gran fibrosis en los tejidos circundantes, para lo cual técnicamente conviene ir desde el lado "sano", o sea de una región cercana al sitio de la injuria pero que los tejidos posean conservada su anatomía normal, hacia el sitio "enfermo", que consiste en el sitio mismo del daño, donde tanto los planos como las estructuras anatómicas se ven distorsionados por la propia reacción del organismo ante un traumatismo. Posterior a la disección de las estructuras vecinas de los extremos seccionados del nervio hay que verificar la viabilidad de los mismos, mediante resección de los neuromas y todo tejido desvitalizado o fibrótico, y constatar que en dichos cabos se encuentren aptos para la correcta neurotización.

Acto seguido y no menos importante, el cirujano debe asegurarse de que ambos extremos puedan ser coaptados sin tensión alguna, ya que de lo contrario nos encontraríamos frente a una situación más compleja en cuanto a la técnica de su reparación y con un pronóstico en principio menos auspicioso que una sutura simple sin tensión; problemática de la que se ocupa en parte esta tesis.

De la misma forma se debe tratar de lograr una correcta alineación de los mismos, evitando las rotaciones y que cada axón se enfrente a su correspondiente tubo endoneural en el cabo distal de la sutura. Si bien esto es algo imposible de realizar, hay ciertos elementos que nos guían para la realización de una alineación aproximada y que cada grupo axonal se contacte con su segmento distal lo más parecido a su relación anatómica previa a la injuria. Entre ellos, al momento de realizar una sutura con puntos epineurales, se encuentra la presencia de la vascularización longitudinal del nervio, ya descripta anteriormente.

Cuando se encuentren reunidas las condiciones de contar con cabos vitales y sin tensión en su aproximación, y a la vez la alineación sea aceptable, se procederá a realizar puntos de sutura epineurales con una aguja redonda atraumática, que evita lesionar la estructura nerviosa, siendo de elección como material un monofilamento de nylon. Éste produce menos reacción de fibrosis que los polifilamentos, al ser un material más inerte. Son utilizados de un grosor relativo de entre 8.0 y 11.0 , dependiendo del diámetro del nervio a reparar. 
Es de destacar que deben utilizarse la menor cantidad de puntos posible que aseguren una correcta coaptación de los extremos, ya que cada punto en sí mismo produce una reacción inflamatoria que resulta en fibrosis y se torna un obstáculo para el pasaje del brote axonal. Asimismo, si no hay un correcto afrontamiento de los cabos, muchos de los axones en crecimiento pueden tomar un curso erróneo y nunca llegar a su órgano blanco, perdiéndose en los tejidos de fibrosis circundantes.

Una vez terminada la neurorrafia, es de suma relevancia constatar de que la misma no sufra compresiones externas de huesos, articulaciones o ligamentos entre otros; y que al realizar movilizaciones normales de los miembros, el nervio recién reconstruido no se vea sometido a los efectos deletéreos de la tensión por estiramiento. Por lo general luego de la cirugía se indica inmovilización del miembro por un lapso variable de entre 2 y 6 semanas, dependiendo de la localización del nervio y el riesgo de su sometimiento a tensión. ${ }^{4}$

En la actualidad se encuentran en desarrollo numerosas sustancias que son agregadas al sitio de sutura con el fin de promover el crecimiento de los axones, como son el receptor de la proteína tirosina fosfatasa sigma ${ }^{61}$, el monofosfato de adenosina cíclico $^{62}$, o hasta el uso experimental de células madre. ${ }^{63}$

\section{Puntos perineurales (fascículos)}

En los nervios que no sean monofasciculares es posible la realización de las suturas por separado de sus fascículos, para lo cual se extrae el epineuro de la parte más próxima al extremo seccionado y se sutura el perineuro de los fascículos concordantes entre proximal y distal.

Al momento de realizar dicha sutura, existe un elemento ya mencionado anteriormente, que tal vez tome más relevancia que en el caso de la neurorrafia con puntos epineurales: la concordancia en tamaño de los diferentes fascículos del nervio en cuestión. Si existen pocos fascículos de tamaño dispar resultará más sencillo realizar la identificación y la posterior sutura entre sí, mientras que si nos enfrentamos a la reconstrucción de un nervio polifascicular la situación se torna compleja. Más aún si se trata de un nervio mixto, ya que al momento de realizar su reconstrucción de nada servirá afrontar un extremo proximal motor con uno distal sensitivo y viceversa.

Existe escasa literatura que afirma que hay una leve superioridad de resultados clínicos de la sutura perineural frente a la epineural ${ }^{2}$, aunque en muchas ocasiones, dependiendo el nervio valorado, esto resulta impracticable desde el punto de vista técnico.

\section{Término-lateral}

La anastomosis término-lateral se encuentra descripta como tratamiento de las lesiones nerviosas en las cuales no se cuenta con un cabo proximal viable o este se encuentra en situación en extremo distante, lo cual al requerir el uso de injertos nerviosos excesivamente largos, brinda pobres o nulos resultados. 
En la anastomosis término-lateral se realiza la coaptación del extremo distal del nervio a reparar con un segmento de nervio periférico donante que permanece intacto, deseando lograr la reinervación.

La mayor ventaja de esta técnica reside en la preservación de la función del nervio donante y la abolición del uso de injerto.

Si bien han sido observados histológicamente el crecimiento axonal hacia el sitio denervado, y la recuperación funcional, los estudios experimentales han presentado resultados controvertidos: algunos trabajos demuestran solo recuperación motora o sensitiva limitada, por lo cual son necesarios más estudios para la consideración de esta técnica como una alternativa conveniente al momento de reparar un nervio. ${ }^{2}$

\section{Colas de fibrina}

En busca de nuevos métodos de reparación nerviosa, técnicamente más sencillos, se han ponderado diversos materiales que logren mantener unidos los cabos nerviosos y permitir así una correcta neurotización entre el segmento proximal y su correspondiente distal, evitando el uso de microsuturas. Entre ellos fue desarrollado el cianocrilato con el objetivo de "pegar" los cabos, cuyo uso fue desestimado debido a la gran reacción inflamatoria y posterior fibrosis que produce en los distintos tejidos. Por lo anteriormente expuesto, las colas de fibrina ofrecen una adecuada coaptación de los cabos nerviosos, sin impedir su neurotización y con un mejor perfil de biocompatibilidad. ${ }^{2}$

La cola de fibrina consta de dos componentes, uno con fibrinógeno, factor XIII y apoproteína bovina; mientras que el segundo contiene trombina y cloruro de calcio. Ambos son cargados en un sistema de doble jeringa y al ser instilados se mezclan inmediatamente antes de su contacto con el tejido, presentando la particularidad de fraguado rápido. ${ }^{64}$

En la actualidad es utilizado corrientemente en nuestro medio, como método adyuvante luego de una neurorrafia con puntos de sutura o bien como único método de unión entre ambos cabos, especialmente en los casos en los cuales resulte técnicamente dificultoso (Vg. Profundidad del campo operatorio, escaso diámetro del nervio), resultando además ser un procedimiento más rápido. ${ }^{65}$ Existe bibliografía que sostiene que el uso de cola de fibrina posee un mejor alineamiento de las fibras nerviosas y una mejor regeneración axonal. ${ }^{2,64,66,67}$

\section{Láser como técnica de coaptación sin tensión}

Existen técnicas de coaptación nerviosa sin sutura mediada por laser que sueldan entre sí los cabos nerviosos, como el activador de albúmina sérica bovina y chitosan, presentando este último una temperatura de activación menor al de albúmina bovina, lo cual produciría un menor riesgo de daño

térmico de los axones. ${ }^{2,68}$ Estas técnicas necesitan estudios a largo plazo para comprobar su eficacia y demostrar que poseen buenos resultados clínicos en humanos. 


\section{Injertos interpuestos}

En aquellas situaciones en las que se cuente con un gran defecto por pérdida de sustancia nerviosa, resultará imposible la reparación mediante una sutura simple o con alguno de los métodos anteriormente expuestos. En esos casos será necesario interponer un segmento de nervio que cumpla la función de conductor de los axones desde el cabo proximal hacia el lejano segmento distal; y así poder alcanzar al órgano blanco para lograr su reinervación. En la actualidad la técnica de injerto autólogo es la elección al momento de reparar un nervio con gran pérdida de sustancia. (Fig. 5)

Existe una variedad de nervios que pueden ser utilizados como donantes para la reconstrucción de otros nervios a los cuales se desea priorizar su función. Generalmente los nervios utilizados como injertos suelen ser puramente sensitivos, y si bien existen varios de ellos, el empleado con mayor frecuencia es el nervio sural ${ }^{42,69}$, exceptuando los casos en que su utilización esté contraindicada, como por ejemplo infección activa en su trayecto. Otros nervios utilizados como donantes son el braquial cutáneo interno en el antebrazo y la rama terminal del nervio interóseo posterior. ${ }^{4}$

En la técnica de reparación nerviosa mediante injerto interpuesto, los axones que brotan del cabo proximal no solo deben sortear las dificultades ya descriptas de un sitio de sutura, sino que también deben hacerlo en la unión entre el injerto y el cabo distal, antes de llegar al órgano que se pretende reinervar. ${ }^{70,71}$

Cuando se utiliza un injerto como por ejemplo el nervio sural, que en ocasiones brinda numerosas ramas colaterales a lo largo de su recorrido, el mismo debe orientarse de manera invertida, suturando su extremo distal al cabo proximal y viceversa; de esta manera nos aseguramos de que todos los axones que atraviesen el primer sitio de sutura tengan la posibilidad de llegar al sitio distal, y no tomen la dirección de una rama y se extravíen en tejidos no seleccionados para reinervar.

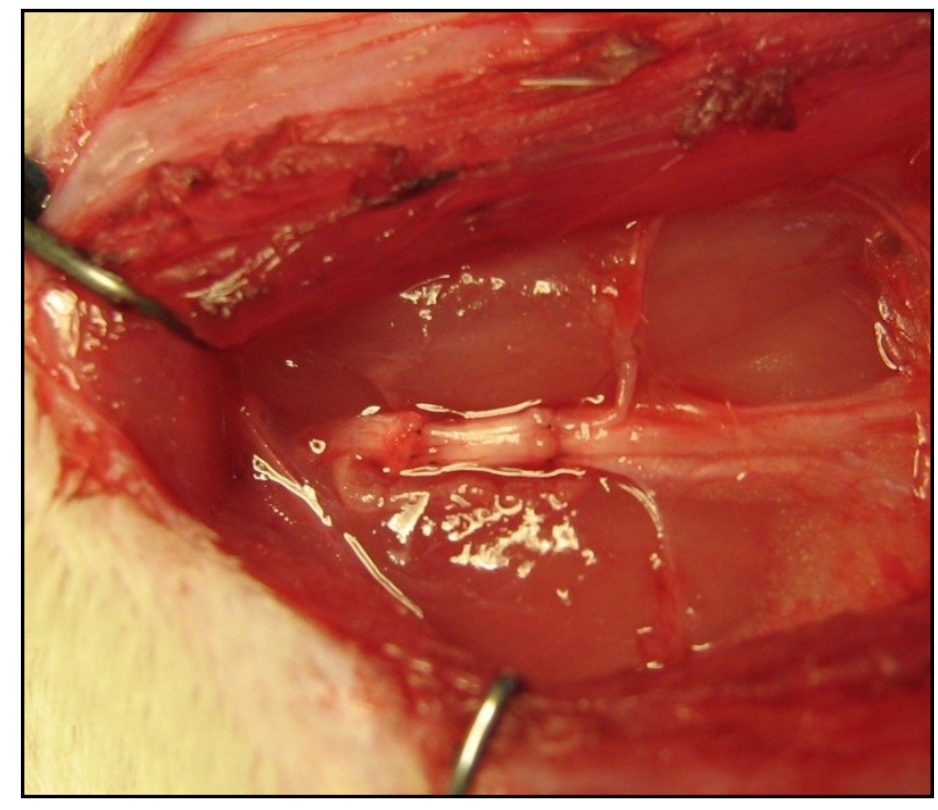

Fig. 5: Injerto autólogo interpuesto en tronco de nervio ciático de rata Wistar. 


\section{Neurotubos}

Como su denominación lo indica, son segmentos tubulares de los más variados materiales ${ }^{72-75}$, como la silicona o ácido poliglicólico, que son interpuestos entre los dos cabos de un nervio lesionado. Su empleo es relativamente simple desde el punto de vista técnico. ${ }^{76}$

Debido a su reacción como elemento extraño y al tejido granulomatoso producido, se han ideado nuevos materiales biodegradables que pasado cierto tiempo se desintegran y solo queda el nervio reparado. ${ }^{4}$ No obstante, por su elevado costo y su difícil adquisición, solo son utilizados en ciertos centros, y tampoco existe fuerte evidencia que su uso sea claramente superior a las técnicas clásicas de reconstrucción del sistema nervioso periférico. Además se ha demostrado la aparición de irritación crónica, inflamación y compresión nerviosa. ${ }^{42}$ Por otro lado, es limitada la extensión de defecto nervioso que pueden reparar, no encontrándose demostrada su utilidad clínica en intervalos mayores a $3 \mathrm{~cm} .{ }^{77}$

Actualmente se encuentran en fase experimental estudios de bioingeniería en los cuales se colocan sustancias dentro del neurotubo, que contienen factores que estimulan el crecimiento axonal y medios de soporte para el crecimiento de estos últimos, como cultivos de células de Schwann ${ }^{78}$, factor de crecimiento nervioso, ácido acetilsalicílico y factor neurotrófico ciliar por solo citar algunos ejemplos. $^{4,42,79}$

\section{Sutura a tensión}

Como se ha descripto previamente, la sutura simple de un nervio es la técnica de elección ante una sección del mismo. No obstante, en numerosas ocasiones existe una pérdida de sustancia nerviosa que debe ser solucionada, con el objetivo de que los axones que se lesionaron en el momento de la injuria regeneren y alcancen el órgano blanco.

Cuando el intento de aproximación entre los cabos es dificultoso debido a que supera la elasticidad fisiológica del nervio, se produce una excesiva tensión en el sitio de sutura primaria, lo cual impide la regeneración del axón. La sutura a tensión en el sitio mismo de reparación compromete un adecuado riego sanguíneo y favorece la formación de fibrosis y adhesiones a los tejidos vecinos, siendo estos efectos deletéreos y acompañados de un peor resultado funcional. ${ }^{42,71,80}$

Para evitar esto son utilizados los injertos nerviosos autólogos como técnica clásica, pese a que poseen numerosas desventajas ya expuestas que convendría evadir, como mayor tiempo operatorio, pérdida de sensibilidad, neuromas dolorosos, cicatrices en el territorio del nervio donante y la necesidad de que el brote axonal deba atravesar dos sitios de sutura. ${ }^{70,71}$ Asimismo es reconocido que la coaptación directa de los extremos nerviosos posee mejores resultados que los injertos interpuestos, y sobre todo que la sutura simple con tensión, que suele tener escasa o nula recuperación. ${ }^{22}$

Para prescindir del uso de injertos puede desarrollarse la técnica de sutura a tensión mediante puntos epineurales distales (PED), que consiste en la colocación de puntos de anclaje epineurales que disminuyen el efecto deletéreo de la tensión. Como es de esperar, esta técnica solo puede ser utilizada 
en defectos pequeños, aunque lo suficientemente grandes como para impedir una sutura epineural clásica.

\section{Diseño experimental general}

Los animales fueron divididos aleatoriamente en 4 grupos ( $A, B, C$ y D) de 10 ratas cada uno. Se realizó solo una técnica quirúrgica de neurorrafia por animal, utilizando al miembro inferior derecho y dejando el miembro contralateral inalterado ${ }^{21,54}$ como lo indican las normas internacionales de uso y cuidado de animales de laboratorio. ${ }^{81}$

Bajo anestesia general se le realizó el abordaje al nervio ciático derecho según técnica ${ }^{8,9}$ (ver adelante) y se efectuó una sección trasversal en ángulo recto en la porción media de dicho nervio.

En el grupo A (control) se realizó una sutura simple con puntos epineurales de nylon 10.0 bajo magnificación con microscopio quirúrgico. En el grupo B se realizó exéresis de $2 \mathrm{~mm}$ de nervio y posterior técnica de sutura mediante puntos epineurales distales (PED) con nylon 8.0 en los puntos distantes y sutura simple con nylon 10.0 en el sitio mismo de la neurorrafia. (Fig. 1) En el grupo $C$ se realizó la exéresis de $4 \mathrm{~mm}$, y al grupo $D$ de $6 \mathrm{~mm}$, para luego ser reparados con las mismas técnicas de anastomosis que el grupo B. Los segmentos extirpados se conservaron en formol buffer para su posterior análisis.

\begin{tabular}{ccc}
\hline Grupo & Brecha a Reparar $(\mathrm{mm})$ & Técnica Utilizada \\
\hline A & 0 & Sutura Simple \\
B & 2 & PED \\
C & 4 & PED \\
D & 6 & PED \\
\hline
\end{tabular}

Posteriormente a la cirugía los animales se mantuvieron con manta térmica hasta su total recuperación, se colocaron en jaulas individuales y se administraron analgésicos (tramadol 10mg/kg vía subcutánea) la primer semana del postoperatorio. ${ }^{64}$

A los 30, 60 y 90 días luego de la cirugía se realizaron las mediciones funcionales mediante las impresiones plantares de ambos miembros inferiores.

Los animales fueron reoperados bajo anestesia general para su estudio una vez cumplidos 90 días de la cirugía inicial. Se realizaron las mediciones electrofisiológicas y se tomaron las muestras para histopatología. Finalmente los animales fueron sacrificados por sobredosis anestésica. ${ }^{44,54,64}$ 


\section{Hipótesis}

- Que ante la ausencia de 2 milímetros de tejido nervioso periférico la sutura con puntos epineurales distales no evidencia diferencias significativas con la neurorrafia termino-terminal sin tensión analizada por evaluación funcional mediante huellas plantares, electrofisiología e histopatología en la rata Wistar.

- Que la sutura con puntos epineurales distales de cuatro milímetros de pérdida de tejido nervioso, si bien tendrá un resultado inferior ante la sutura simple sin tensión, la anastomosis será viable; analizado por evaluación funcional mediante huellas plantares, electrofisiología e histopatología en la rata Wistar.

- Que la sutura con puntos epineurales distales de seis milímetros de pérdida de tejido nervioso resultará una neurorrafia no viable en la rata Wistar.

\section{Objetivos}

\section{Generales}

En la reparación de los nervios periféricos, cuando se ejerce tensión por falta de tejido, se afecta tanto la velocidad de conducción como el número de axones viables, hasta llegar a un punto crítico de irreversibilidad con pérdida de función, aún con suturas simples satisfactorias. La eliminación de la tensión del sitio de sutura mediante puntos epineurales ha sido descripta en décadas anteriores, la propuesta general del presente trabajo es analizar en forma prospectiva la viabilidad de una reparación nerviosa en un modelo experimental, mediante técnicas microquirúrgicas con diferentes grados crecientes de pérdida de tejido nervioso periférico.

\section{Específicos}

- Desarrollar un modelo experimental que permita el estudio de la reparación del sistema nervioso periférico en condiciones de diferentes longitudes de falta de tejido.

- Demostrar que la sutura a tensión con puntos epineurales distales elimina la tensión en el sitio de sutura término terminal, permitiendo la funcionalidad de dicha anastomosis, que estaría predestinada al fracaso si se intentase una sutura primaria simple con tensión.

- Comparar diferentes grupos con pérdida de sustancia creciente para evidenciar el comportamiento de la viabilidad de la anastomosis nerviosa en tensión.

- Determinar el límite de pérdida de tejido nervioso periférico que pueda ser reparado con puntos epineurales distales exitosamente, y establecer la magnitud de ausencia de tejido que amerite el injerto. 


\section{Materiales y métodos}

\section{Animales}

Se utilizaron 40 ratas Wistar adultas (4 meses de edad), endocriadas, en su totalidad hembras. Las mismas se alojaron en el Laboratorio de Trasplante de Órganos, Tejidos y Células de la Facultad de Ciencias Médicas de la Universidad Nacional de la Plata, en una sala acondicionada con temperatura constante de $25 \circ \mathrm{C}$ y ciclo luz/oscuridad $12 \mathrm{hs} / 12 \mathrm{hs}^{41,82}$

Las ratas fueron adquiridas en el Bioterio de la Facultad de Ciencias Veterinarias de la Universidad Nacional de La Plata y trasladadas al bioterio de nuestro laboratorio, donde se dejó transcurrir una semana antes del procedimiento quirúrgico para que las mismas se aclimaten al nuevo medio, con el fin de reducir el estrés de los animales y limitar su influencia en los resultados. ${ }^{83}$

Fueron alimentadas ad-libitum durante toda su estadía únicamente con alimento balanceado ${ }^{21,41,84}$ y dispuestas en jaulas de no más de 3 animales. ${ }^{82}$ Dentro de las mismas se colocó un colchón de viruta de madera que fue recambiada cada 2 días y un segmento de cañería plástica opaca donde podían ocultarse simulando una madriguera. La dipsia fue proporcionada mediante agua corriente de red en botellas con picos especiales para tal fin, su contenido se renovó a diario y se verificó rigurosamente que nunca se encuentren vacías.

En cada recambio de viruta y limpieza de la jaula un médico veterinario realizó una revisión integral de cada animal buscando cualquier signo de patología.

Durante todo el experimento los animales fueron tratados respetando las normas nacionales e internacionales de ética y bienestar animal, siendo supervisados y evaluados estrechamente por un profesional veterinario. ${ }^{81}$

\section{Instrumental Quirúrgico}

El instrumental microquirúrgico constó de pinzas rectas tipo Dumont №1 y №3 y una pinza curva tipo Dumont №7. Para determinados momentos de delicadeza y precisión se utilizó una pinza recta tipo Dupont №5. Para la sección transversal de los nervios, así como para el corte de los hilos, fue utilizada una tijera recta de microcirugía tipo Castroviejo. Los separadores quirúrgicos fueron construidos con agujas tipo butterfly $25 \mathrm{G}$.

Para la realización de hemostasia por compresión y limpieza del campo quirúrgico se utilizaron hisopos de algodón. 


\section{Microscopio}

Fue utilizado un microscopio quirúrgico binocular tipo Galileo, con aumentos de $12 \mathrm{X}$ y oculares de $10 \mathrm{X}$ o 15X, con distancia focal de $250 \mathrm{~mm}$. El mismo se encuentra equipado con cámara de video para su proyección a monitor. (Fig. 6)

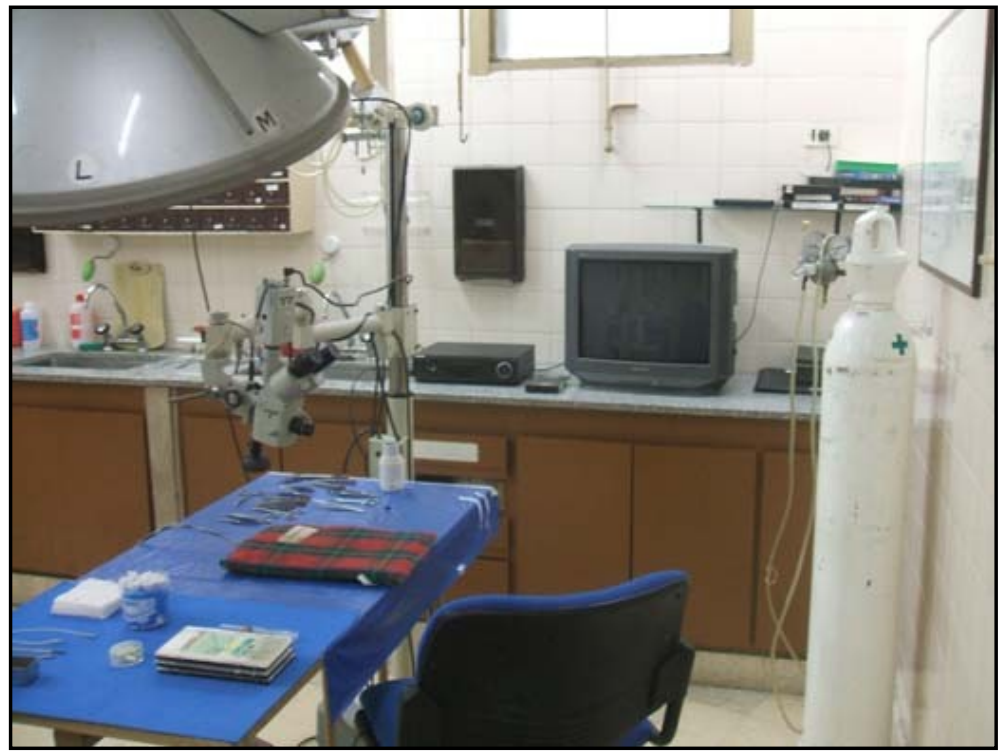

Fig. 6: Quirófano Experimental del Laboratorio - Programa de Trasplante de Órganos y Tejidos. Facultad de Ciencias Médicas. Universidad Nacional de La Plata

\section{Anestesia}

Como protocolo anestésico los roedores fueron inducidos por vía inhalatoria con sevoflurano dentro de una campana oscura con un lugar para que el animal se oculte y disminuya su estrés, con una pequeña ventana para su observación; se utilizó $1 \mathrm{ml}$ aerozolizado por la inyección enérgica con una aguja 25G dentro de la campana. Luego se realizó la inyección intraperitoneal de drogas, vía utilizada en la mayoría de los laboratorios de experimentación con roedores. Se utilizó el hemiabdomen izquierdo en su porción media y lateral para la inyección, de manera de evitar al ciego, muy desarrollado en los roedores. Se emplearon las siguientes drogas anestésicas por vía intraperitoneal: ketamina / diazepam / atropina 75, 10 y $0,04 \mathrm{mg} / \mathrm{kg}$ respectivamente, realizándose el mantenimiento solo con ketamina, por la misma vía. $^{64,70}$

\section{Preparación quirúrgica}

Una vez anestesiados los animales, la región de interés fue rasurada con máquina eléctrica. La posición fue fijada con cinta adhesiva y luego se efectuó la antisepsia de piel.

No fueron utilizados antibióticos como profilaxis prequirúrgica. ${ }^{84}$ 
Como camilla quirúrgica se empleó una base acrílica rectangular que excedió las dimensiones del animal y se colocó por debajo una almohadilla térmica, con el fin de preservar la temperatura corporal y así evitar la hipotermia operatoria. A continuación se protegieron las córneas con ungüento oftálmico.

En ningún abordaje se utilizaron realces infracorporales, con el objetivo de evitar lesiones articulares y/o ligamentarias que podrían producirse por la hiperextensión más allá de los límites anatómicos, fácilmente ocasionados bajo anestesia general.

La cabeza y el cuello siempre se ubicaron en posición neutra y extendida para facilitar el pasaje de los gases, asimismo se lateralizó la lengua con el mismo fin. Mediante una pequeña campana que abarcó el hocico, se le administró oxígeno durante el acto quirúrgico.

\section{Abordaje}

La posición quirúrgica empleada fue en decúbito dorsal, la cabeza quedó extendida sobre el plano de la camilla quirúrgica, los miembros superiores fueron fijados con cinta adhesiva remedando unos pequeños grilletes y luego se aseguraron al plano dejando algunos centímetros de libertad. Esto permitió adecuados movimientos respiratorios, que se imposibilitarían si ambos miembros superiores se fijasen firmemente al plano. Esto evitó la hipoxia que se produciría por inmovilidad torácica.

El miembro inferior contralateral al que se abordó, se asentó firmemente en extensión y abducción al plano quirúrgico por encima del tobillo. Se reparó que no comprima demasiado al mismo y produzca isquemia en sitios distales.

Posteriormente se arqueó delicadamente la cola fijándola con cinta adhesiva en su tercio distal, en el plano lateral al abdomen. De esta manera no sobresalió de la camilla, evitando lesiones de la misma y molestias al cirujano, quien se situó en posición caudal al animal.

Ulteriormente se transpuso a través de la línea media el miembro que se deseó abordar, y se fijó junto a su par a nivel maleolar. De esta manera quedó expuesta la totalidad de la región glútea elegida. (Fig. 7)

Previo al rasurado anteriormente mencionado de la región de interés, se realizó en este momento la antisepsia de piel. Se palpó la cresta ilíaca y los músculos de la región glútea, y se procedió a realizar una incisión cutánea comenzando inferior y anterior a la cresta ilíaca. Luego se progresó en forma de semiluna hacia posterior, con leve concavidad hacia la zona distal del miembro. Se realizó divulsión del tejido celular subcutáneo y se identificó al músculo glúteo. ${ }^{85}$ (Fig. 8) 


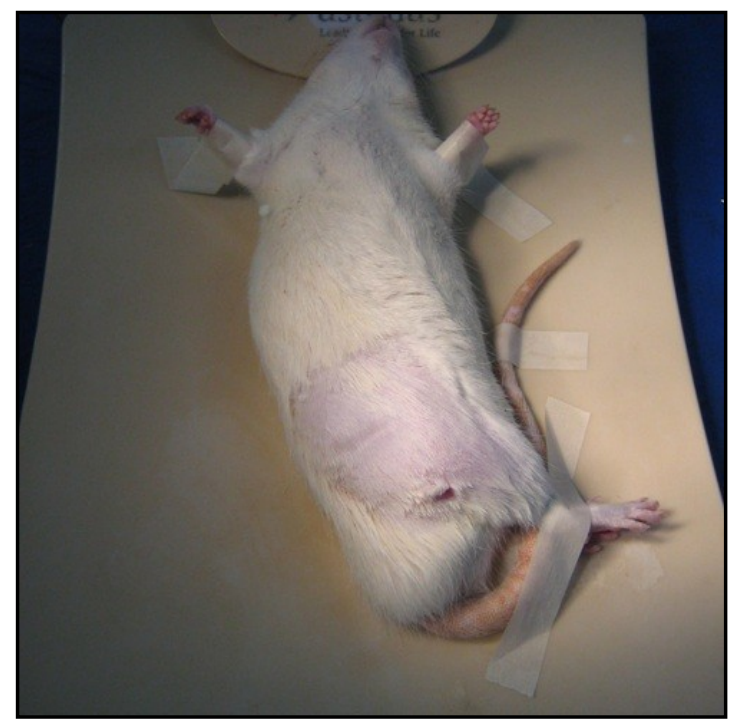

Fig. 7: Posición Quirúrgica de la rata Wistar.

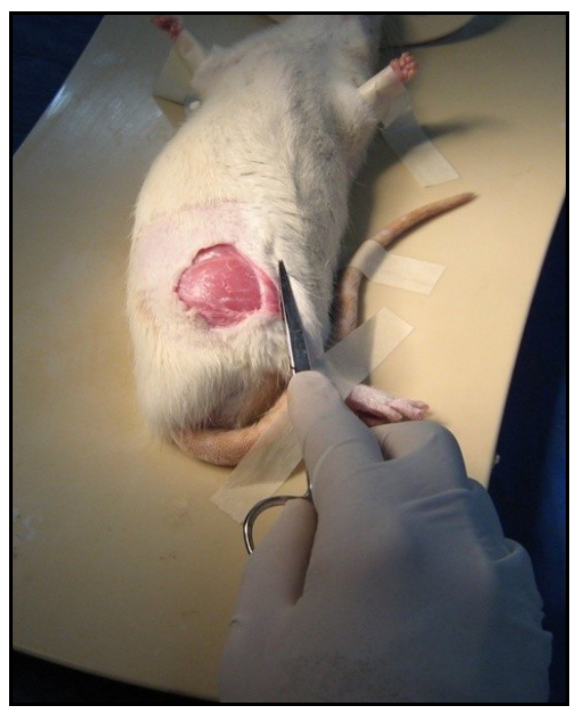

Fig. 8: Exposición de músculo glúteo.

A continuación se dividió imaginariamente a dicho músculo en tres tercios y se divulsionó al mismo en el sentido de las fibras musculares en la unión del tercio superior con los dos tercios inferiores, atendiendo con especial cuidado evitar la lesión de nervio ciático que se encontrará en situación inmediata y profunda a la aponeurosis posterior del mencionado músculo. ${ }^{86-88}$ (Fig. 9) Se colocaron separadores fabricados con agujas $25 \mathrm{G}$ tipo mariposa, cortando sus orejuelas y doblando la aguja en forma de gancho, para ampliar el campo quirúrgico. Se dispusieron dos separadores superiores y dos inferiores en los labios de la sección muscular, y se aseguraron distalmente con cinta adhesiva a la camilla quirúrgica y no a la mesa de trabajo, ya que esto último nos impediría rotar libremente al animal si se requiriese un cambio de angulación en el acto quirúrgico. Dichos separadores se orientaron de manera transversal al nervio, ya que si se colocasen en sentido longitudinal producirían un estiramiento del mismo, y por ende más tensión.

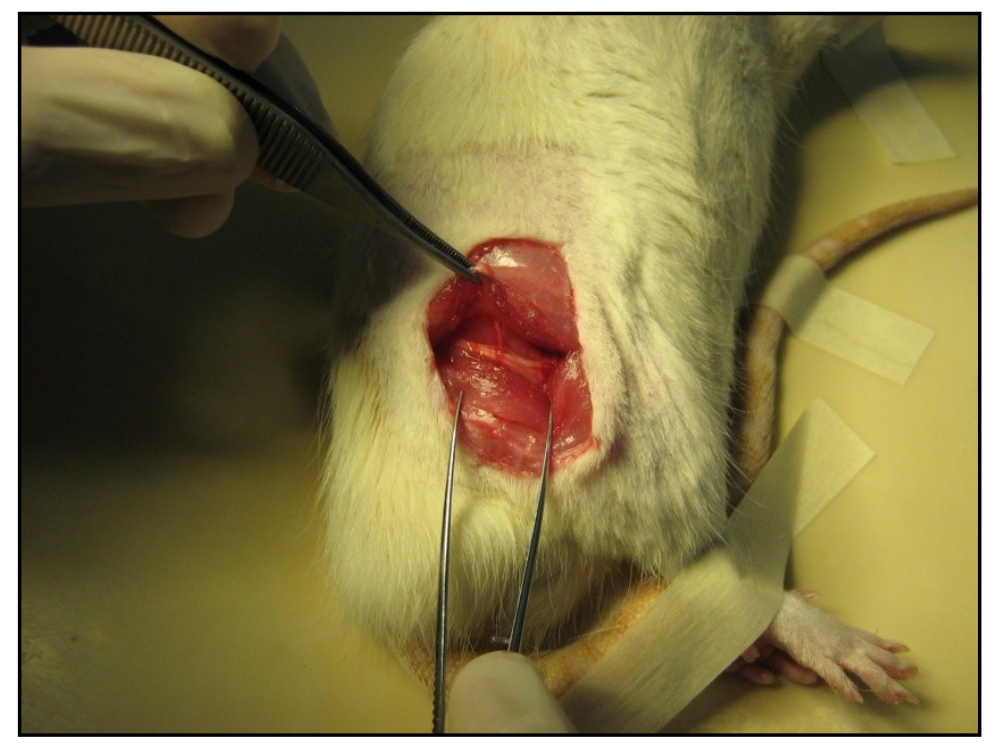

Fig. 9: Exposición de Nervio Ciático. 
Por último se colocaron finas gasas húmedas en solución fisiológica tibia en los bordes del campo quirúrgico, lo que protege a los tejidos circundantes de la desecación, cumple función hemostática e impide el ingreso de pelos al campo quirúrgico. (Fig. 10) En este momento se colocó el microscopio quirúrgico con fines de magnificación e iluminación, y comenzó la disección de los tejidos conectivos para individualizar al nervio ciático.

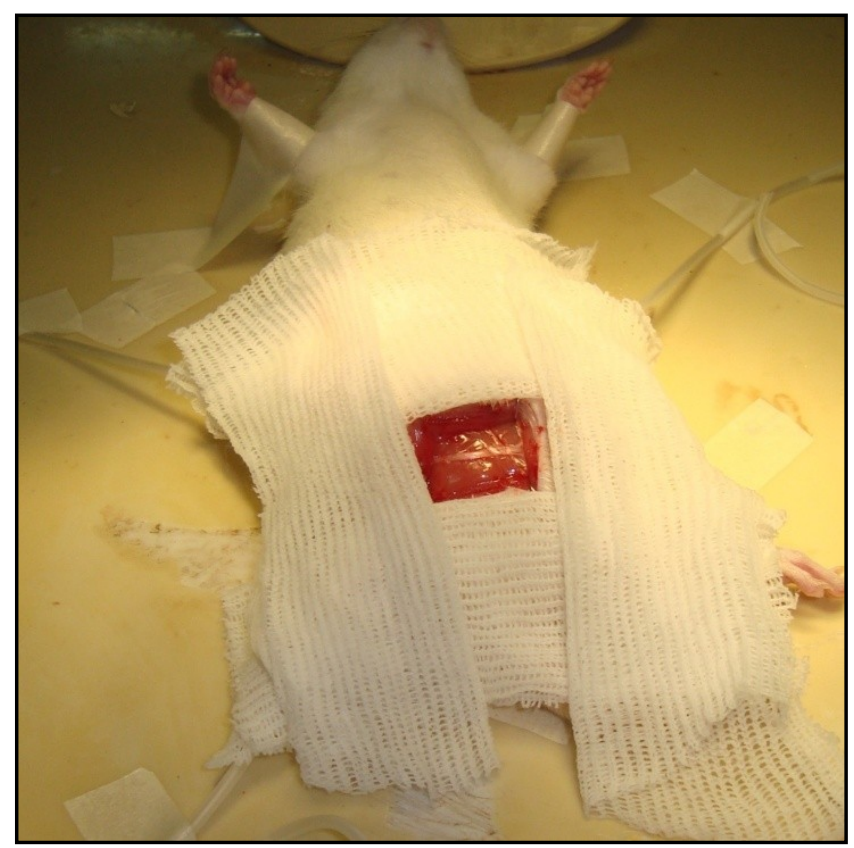

Fig. 10: Fin del abordaje.

\section{Técnica quirúrgica}

Bajo magnificación se realizó la disección del nervio ciático separándolo de los tejidos conectivos adyacentes mediante maniobras romas de divulsión, rodeándolo en los 360 respetando minuciosamente no comprometer su irrigación mediante la vasa nervorum. (Fig. 11)

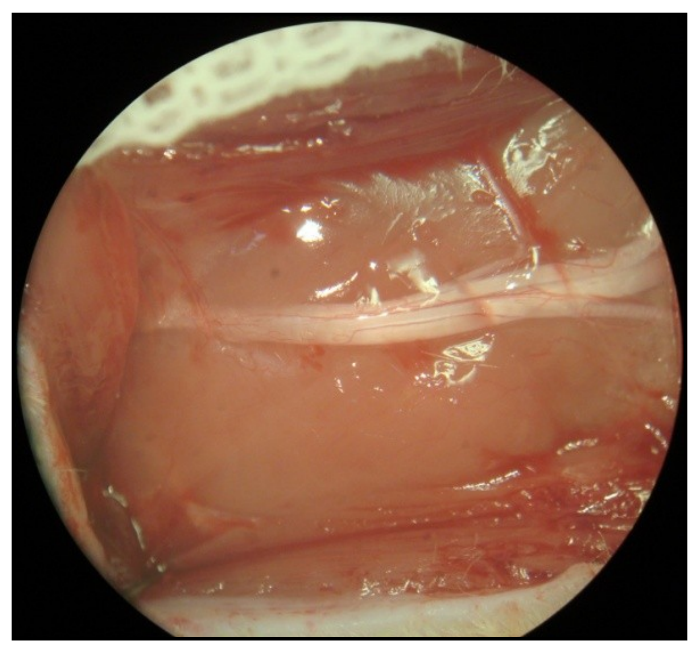

Fig. 11: Vista bajo magnificación del nervio ciático. 
Posterior a esto y dependiendo del grupo realizado, se obró de la manera siguiente:

Grupo A: Se ubicó la parte medial de la exposición del nervio en el centro del campo quirúrgico magnificado, se realizó la sección transversal a 90 mediante una microtijera, se verificó la totalidad del corte y se evidenció la retracción natural del tejido. Posteriormente se inspeccionaron cuidadosamente los cabos nerviosos, su orientación rotacional y características más finas, para luego realizar la neurorrafia con nylon 10.0, mediante dos o tres puntos epineurales.

Grupos B, C y D: Luego de centrar la posición de la zona nerviosa a seccionar se realizó la medición mediante un calibre de precisión de 2, 4 o $6 \mathrm{~mm}$ dependiendo el grupo en cuestión. Luego se realizaron marcas con la microtijera en el epineuro de manera de no caer en un error de distancia a seccionar por la retracción natural de nervio. (Fig. 12)
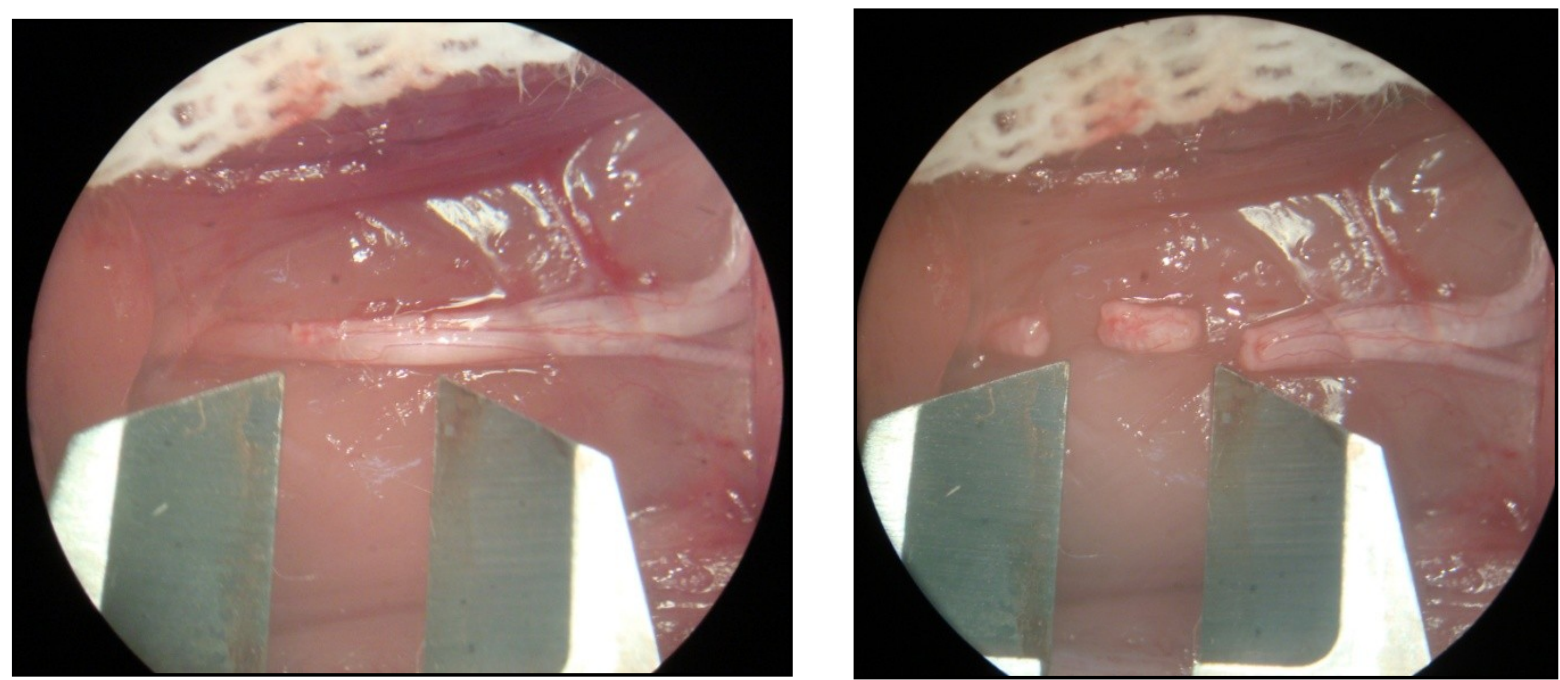

Fig. 12: Medición de 4mm y marcas del Epineuro. Fig. 13: Sección nerviosa y retracción de los cabos.

Se retiró el calibre del campo quirúrgico y se procedió a seccionar a 90ํe el nervio en su totalidad, primeramente en sitio proximal, de manera de no exponer al animal a dos secciones nerviosas, ya que cada una de ellas dispararía mediadores de dolor pese a estar bajo anestesia general. Luego de seccionar en el sitio distal, la pequeña muestra de escasos milímetros fue enviada a su análisis mediante técnicas de histopatología. (Fig. 13)

Se observó las mismas características que para el grupo A al momento de preparar los cabos para su síntesis y se procedió a exponer la cara posterior de los mismos. Se colocaron aquí los puntos de nylon 8.0 atendiendo a que solo sea interesado el epineuro, con una distancia aproximada de $3 \mathrm{~mm}$ del extremo, en ambos cabos nerviosos, para luego realizar un nudo con tres o cuatro vueltas, de manera que resistan la extensión que producirá el nervio, realizando finalmente su fijación con un nudo en sentido opuesto. En este momento se observó como los extremos se aproximaron entre sí, permaneciendo sin tensión inmediata, ya que la tensión se encuentra más allá del sitio del cual se toma 
el epineuro para la aproximación de los extremos. Luego se procedió a realizar la sutura de los extremos nerviosos con nylon 10.0, del mismo modo que el grupo A. (Fig. 14)

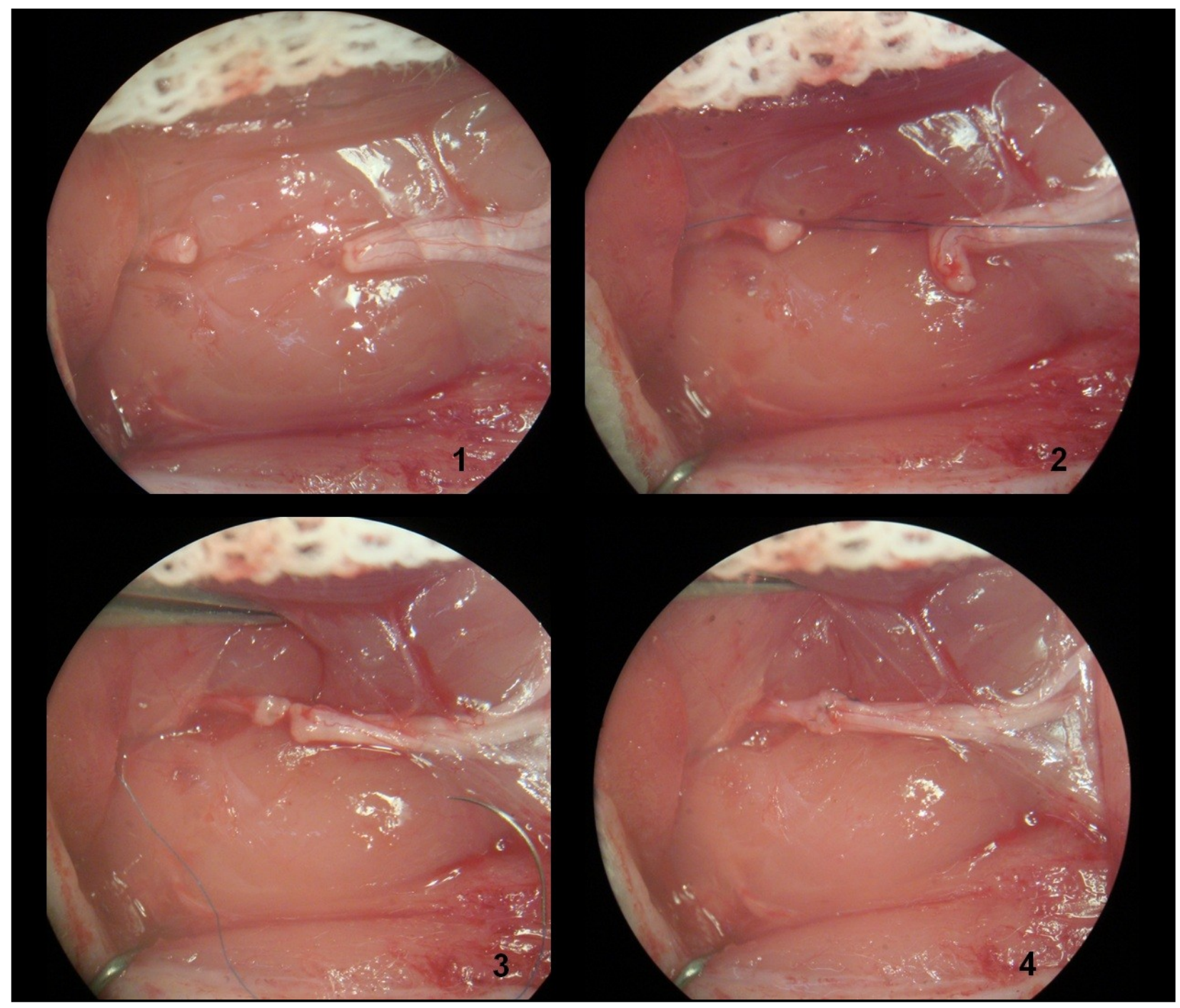

Fig. 14: Pasos de la Técnica de PED: 1.Defecto de tejido luego de resección de 4mm (Grupo C) 2.Inicio del PED 3.Fin del PED y afrontamiento de los cabos 4. Realización de la neurorrafia.

\section{Cierre quirúrgico}

Se valoró integralmente la neurorrafia atendiendo a la correcta coaptación de sus extremos, la ausencia de rotaciones o la presencia de tejido conectivo en el sitio mismo del futuro brote axonal. Sin evidencia de posibles compresiones externas o hemorragias activas, se procedió al cierre de la herida quirúrgica. Para lo cual se retiraron los separadores y se aproximaron manualmente los bordes musculares, se examinó nuevamente la posibilidad de hemorragias ocultas por la tensión generada por los separadores 
y se realizó el cierre cutáneo en monoplano con sutura simple continua de nylon 3.0. Se efectuó una nueva asepsia cutánea y el animal se liberó delicadamente de las fijaciones de cinta adhesiva.

\section{Postquirúrgico}

Se trasladó al animal a un ambiente con luz tenue, calefaccionado y sin otros animales en la misma jaula hasta su recuperación completa de la anestesia. ${ }^{64}$ Se verificó que en todo momento que no le falte agua o alimentos, y que su herida quirúrgica no sufra dehiscencias o infecciones. Se realizó analgesia durante las primeras $72 \mathrm{hs}$ postquirúrgicas con tramadol $10 \mathrm{mg} / \mathrm{kg}$ por vía subcutánea.

No se realizaron inmovilizaciones postoperatorias de los miembros intervenidos en concordancia con la bibliografía. 89,90

\section{Determinaciones}

\section{Evaluación funcional mediante huellas plantares}

Para la realización de las impresiones plantares fue desarrollado en el presente estudio un corredor de madera de $15 \mathrm{Cm}$ de ancho por $200 \mathrm{~cm}$ de largo, con una altura de $20 \mathrm{~cm}$ para que el animal no sea distraído de su trayecto hasta el final, donde se encuentra un sitio atractivo para el animal: relativamente pequeño y de luminosidad reducida, donde la rata se sintiera mayormente protegida. El piso del corredor posee gran firmeza para que no se deformen las huellas y el mismo se tapiza con papel intercambiable del mismo ancho que el corredor pero de gran longitud (rollo continuo), de manera de eliminar papeles superpuestos que modifiquen distancia intra o inter huellas. La construcción no cuenta con techo, de manera de observar al roedor en todo momento. (Fig. 15)

Los animales son tomados delicadamente de las jaulas, sus miembros inferiores son sumergidos en tinta negra no tóxica y depositados en el inicio del corredor; dejando las impresiones de sus huellas posteriores durante su marcha hasta su introducción en el recipiente oscuro. ${ }^{2,4,91}$

Las medidas que se obtuvieron, del miembro Normal $(N)$ como del Experimental (E), fueron las siguientes:

Longitud de la huella (LH): desde el extremo posterior del talón hasta la porción más distal del dedo medio.

Distancia entre el Primer y el Quinto dedo (D1-5): la separación entre los mismos

Distancia entre el Segundo y el Cuarto dedo (D2-4): la disociación entre los dedos intermedios

Distancia entre la huella del miembro abordado y la del miembro contralateral y viceversa (DPO): se toma la extremidad anterior de cada huella y se miden las extensiones de sus pasos. 


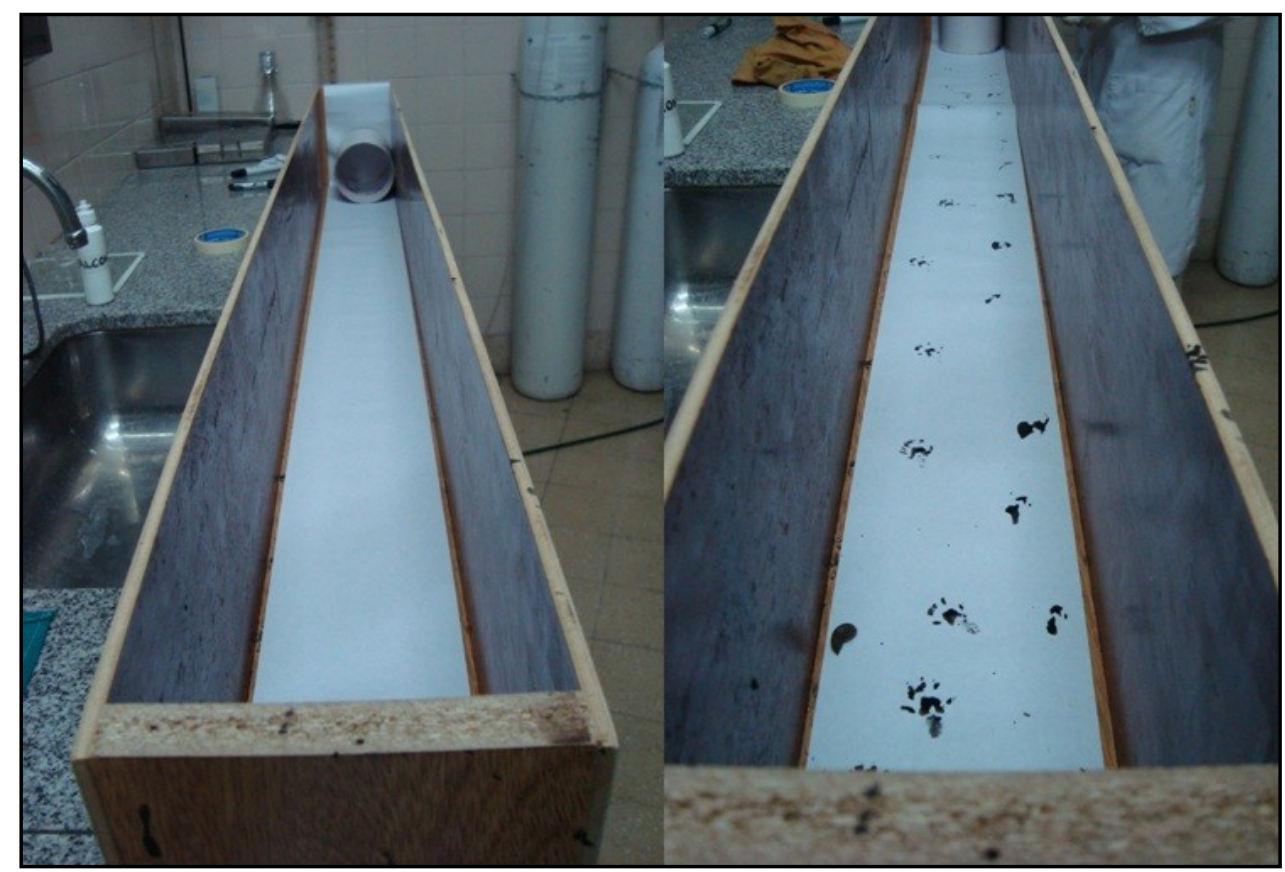

Fig. 15: Corredor para las impresiones plantares (izquierda). Luego del paso de un animal (derecha).

Todas las longitudes son obtenidas de ambos miembros inferiores, del operado (lado derecho) y del que se mantiene intacto (lado izquierdo). (Fig. 16)

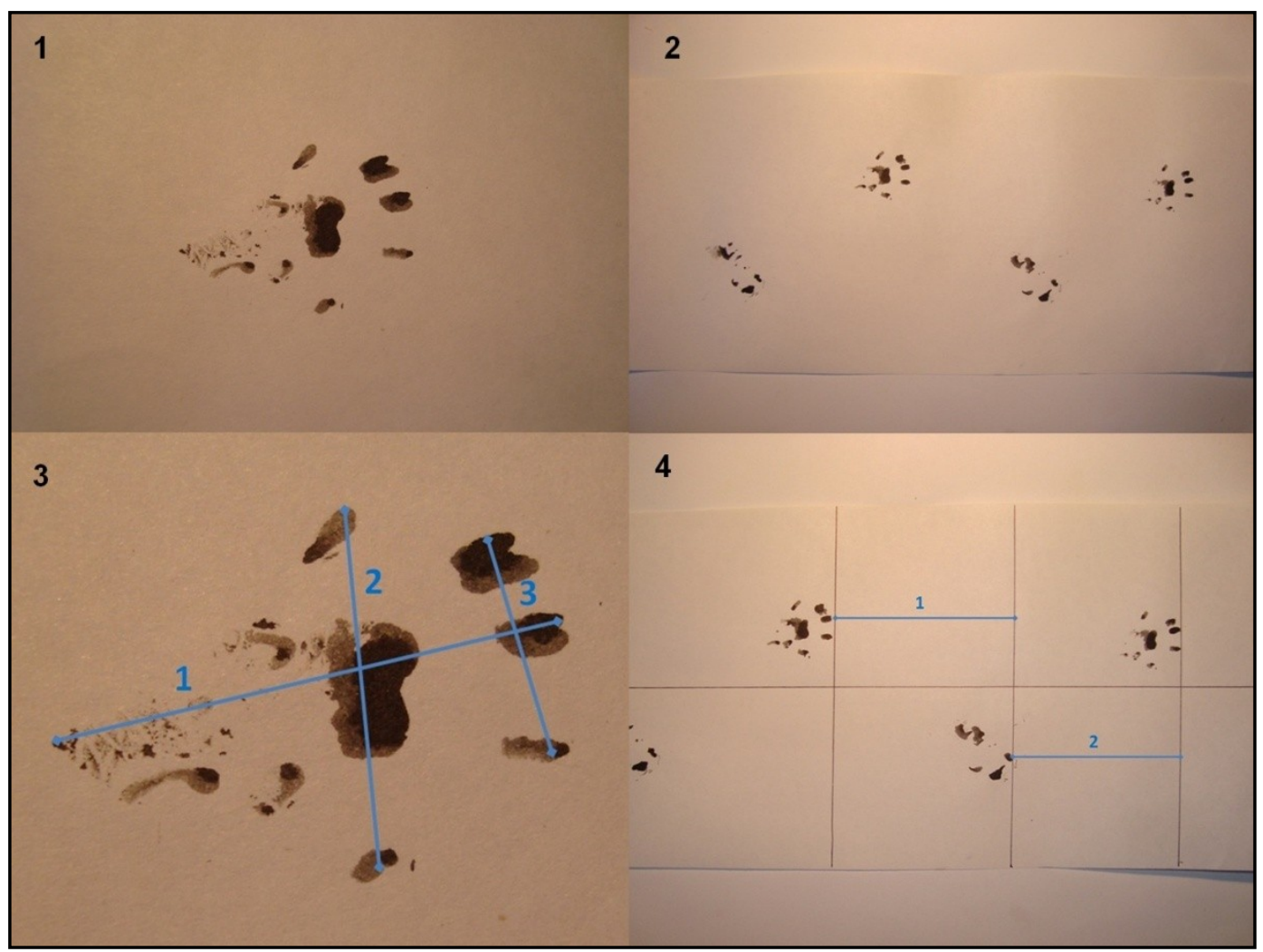

Fig. 16: Mediciones de huellas: 1. Huella Plantar 2. Huellas en la marcha 3.Mediciones intra-huella 4.Mediciones inter-huellas 
El Índice de Función Ciático (IFC) se calcula mediante una fórmula matemática derivada empiricamente en la cual se comparan las cuatro medidas ya descriptas, las cuales se asume que son igualmente importantes y se multiplica por un factor de corrección, siendo su resultado en porcentaje. La cifra obtenida ronda la unidad, tomando como valor normal $0 \%$ con una variabilidad de $+-11 \%$, y cuyo límite inferior $(-100 \%)$ representa la pérdida total de la función. ${ }^{92}$

$$
I F C=\frac{D P O E-D P O N}{D P O N}+\frac{L H N-L H E}{L H E}+\frac{D 1-5 E-D 1-5 N}{D 1-5 N}+\frac{D 2-4 E-D 2-4 N}{D 2-4 N} \times \frac{220}{4}
$$

Esta fórmula fue descripta inicialmente por de Medinaceli ${ }^{92}$ y modificada por numerosos autores, entre ellos Bain. ${ }^{41}$

El índice de función ciático, como ya se mencionó, se calculó en tres oportunidades, la primera a los 30 días post quirúrgicos, la segunda a los 60 y la última a los 90 días, previo a las determinaciones electrofisiológicas. Se observó la evolución de la recuperación funcional en cada grupo.

\section{Electrofisiología}

A los 90 días postoperatorios fue realizado el análisis por electrofisiología de la conducción nerviosa y se realizó la extracción de la muestra para histopatología.

Previa anestesia general y abordaje al nervio ciático derecho como se describió previamente, se dispusieron 2 electrodos separados entre sí por una distancia de $30 \mathrm{~mm}$, uno fue ubicado en el nervio y otro en el músculo. Los registros fueron realizados mediante un eletroneuromiógrafo portátil de dos canales (Medtronic). (Fig. 17)

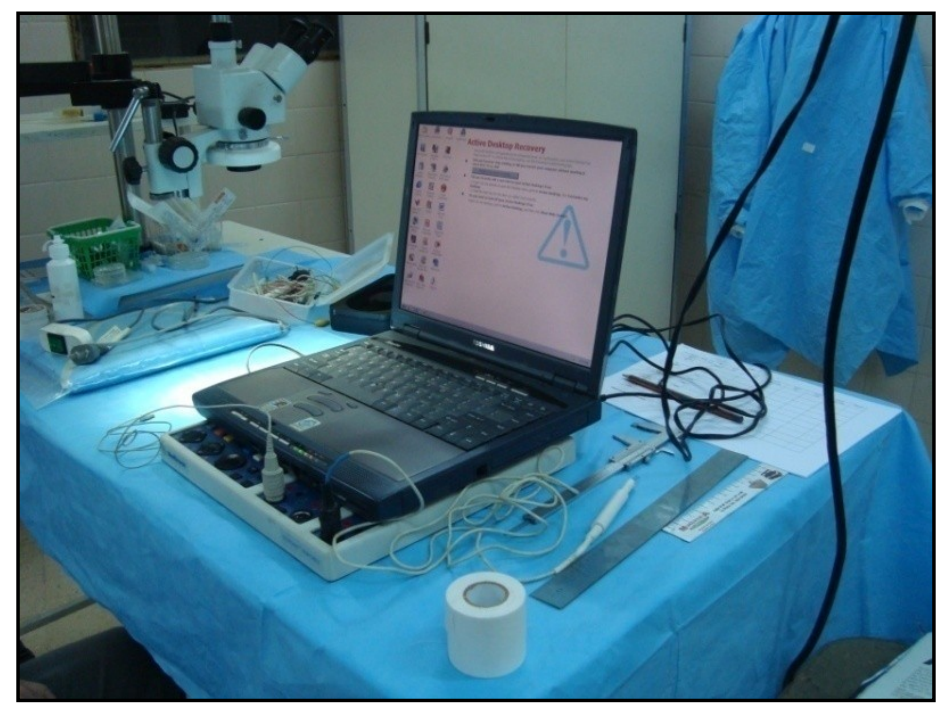

Fig. 17: Electromiógrafo utilizado en el experimento. 
El electrodo de estímulo utilizado consistió en una aguja coaxial con 0,30 mm de diámetro por $25 \mathrm{~mm}$ de largo, con gauge (G) 30 y un área de registro de $0,019 \mathrm{~mm}^{2}$, mientras que el electrodo de registro consistió en una aguja monopolar de acero inoxidable con diámetro de 0,40 mm por $25 \mathrm{~mm}$ de largo, con $26 \mathrm{G}$ y de extremo recto. (Fig. 18)

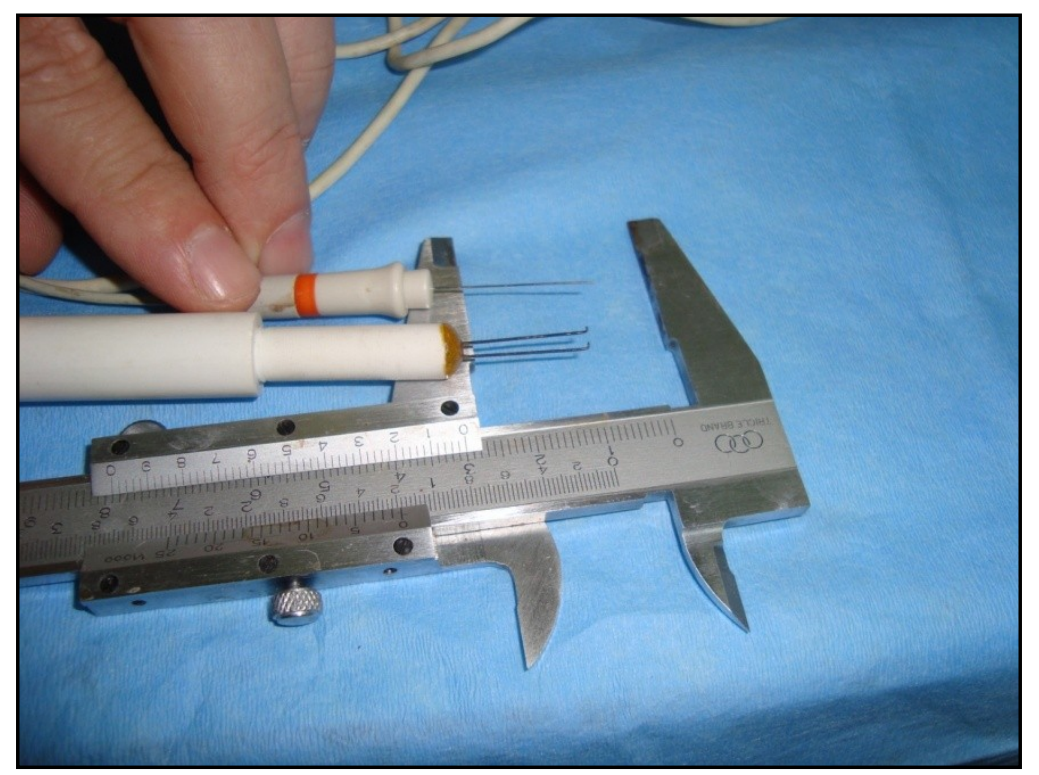

Fig. 18: Electrodos de estímulo y de registro.

El electrodo de registro se ubicó en el segmento proximal a la neurorrafia, se midió una distancia de 30 $\mathrm{mm}$ con un calibre y se posicionó el electrodo de tierra que recepcionó los registros. Este último se insertó mediante punción transcutánea en el interior del músculo gastrocnemio, en el tercio distal de la pata derecha. (Fig. 19)

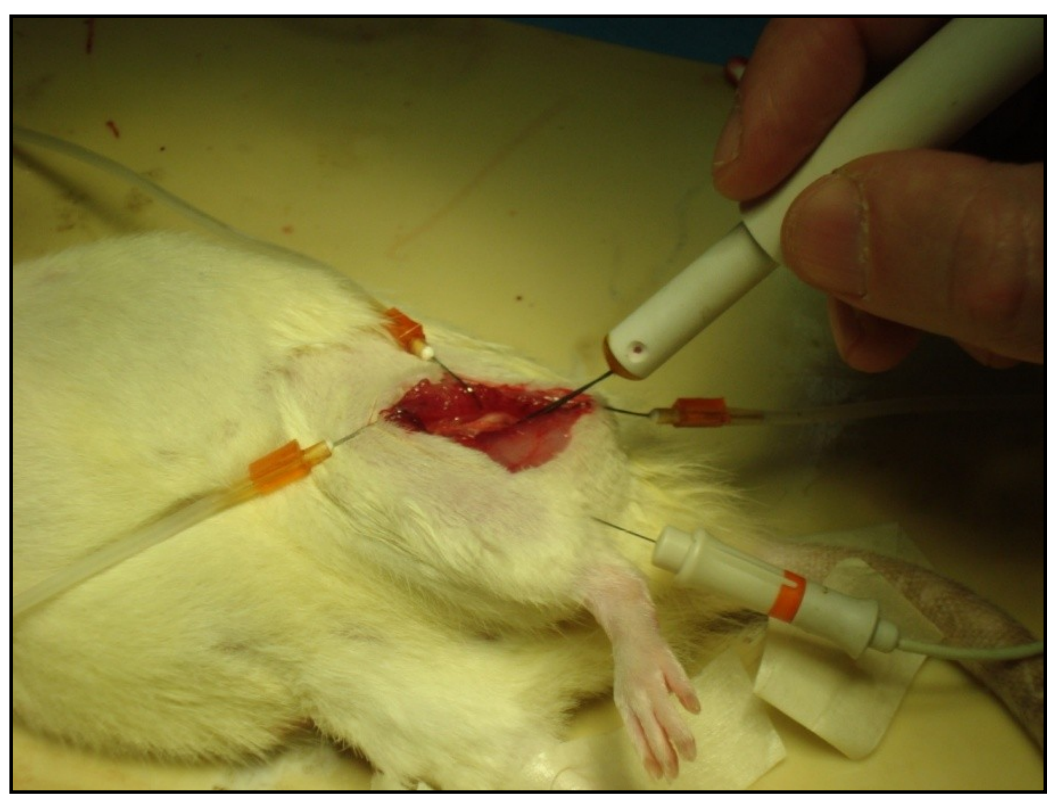

Fig. 19: Realización de estimulación y registro por electrodos. 
Se aplicaron estímulos supramáximos de corta duración (1 ms) para generar un potencial de acción motor. Para determinar la corriente supramáxima de estimulación, los valores de la misma fueron aumentados gradualmente, de 0,1 a 0,1 miliamperios (mA), hasta que la amplitud de los dos últimos potenciales se mantuvo inalterada. A partir del registro de dicho potencial, denominado PAM, fueron estimadas las latencias y amplitudes máximas del mismo, denominadas LATM y AMPTM. La velocidad de conducción fue determinada dividiendo la latencia por la distancia de $30 \mathrm{~mm}$ entre los electrodos, y fue denominada VCM. ${ }^{8,9}$

Esta determinación permitió analizar cuantitativamente la viabilidad de la neurorrafia mediante su conducción eléctrica.

En el miembro inferior izquierdo se realizaron las mismas determinaciones electrofisiológicas que para el derecho, para lo que se cambió de posición general al animal y se abordó al nervio ciático izquierdo según la técnica ya descripta. Se colocó un electrodo de registro en el músculo gastrocnemio izquierdo por punción y se ubicó al electrodo de estímulo sobre el nervio a 30mm de distancia hacia proximal.

Todos los registros electrofisiológicos fueron realizados por un investigador independiente de la unidad de nervios periféricos del servicio de neurocirugía del Hospital das Clínicas, Universidad de São Paulo, Brazil. $^{8}$

\section{Histopatología}

En el momento de la cirugía inicial, en los grupos en los cuales se extrajo un segmento del nervio (grupo B: $2 \mathrm{~mm}$ de tejido, y grupo C: $4 \mathrm{~mm}$ ), este se conservó en formol buffer y posteriormente se sometió a las técnicas histopatológicas descriptas a continuación para la realización del conteo axonal.

En la segunda cirugía a los 90 días, luego de realizada la electrofisiología y aún bajo anestesia general, se extrajo un segmento nervioso de $10 \mathrm{~mm}$ con centro en la neurorrafia; para su estudio histológico y conteo axonal en todos grupos. Posteriormente se realizó la exéresis en forma completa el sitio mismo de neurorrafia con $4 \mathrm{~mm}$ de extensión, $2 \mathrm{~mm}$ proximal y $2 \mathrm{~mm}$ distal, de manera de asegurar el correcto análisis ambos segmentos libres de los cambios propios del tejido cicatrizal.

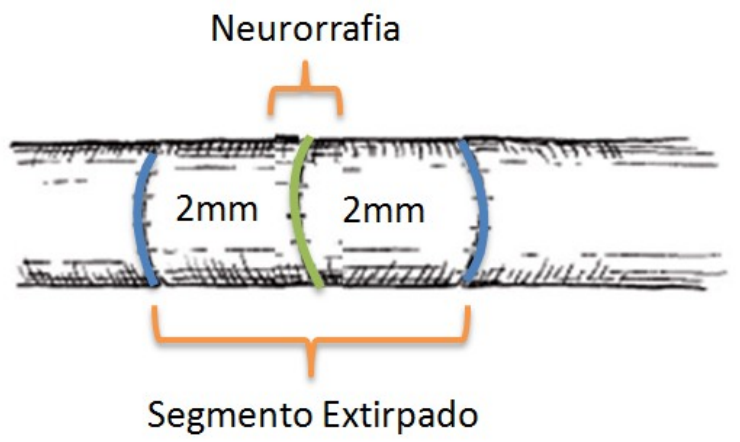


Inmediatamente luego de su extracción, las muestras fueron sumergidas en formol buffer en un tubo de Eppendorf cuidadosamente nomenclado, con el fin de preservar los tejidos de manera fidedigna e inalterada hasta su análisis microscópico.

\section{Técnica de Histoquímica:}

El tejido de muestra fue deshidratado en concentraciones ascendentes de alcohol, partiendo desde 960 hasta llegar al alcohol absoluto (100). y luego en xylol, para culminar en una impregnación en parafina para su ulterior inclusión.

Se realizaron cortes con micrótomo de un espesor de 3.5 micrones y se colorearon con la técnica de hematoxilina - eosina, para posteriormente realizar un montaje con bálsamo de Canadá. ${ }^{93,94}$

Técnica de Inmunohistoquímica:

Partiendo de la muestra incluida en parafina se realizaron cortes de 3 micrones de espesor con micrótomo El material se dispuso en un portaobjeto positivado y se agregó el control positivo para la constatación de la correcta realización de la técnica.

Se colocó en estufa a 59ㄷ por 12 horas y dichas secciones histológicas fueron desparafinadas. Luego fueron hidratadas con alcoholes descendentes hasta llegar al agua destilada.

Se realizó la recuperación con microondas para la exposición del antígeno con buffer citrato 10X con PH de 6 , y posteriormente se efectuó la inhibición de la peroxidasa endógena mediante una incubación al $3 \%$ en agua bidestilada por 20 minutos.

Mediante la utilización de cámara húmeda se incubó la muestra con anticuerpo primario S100 para células de Schwann por el lapso de 6 hs. ${ }^{95,96}$

Se ejecutó el sistema de detección basado en la técnica tradicional de Avidina - Biotina por 4 horas a temperatura ambiente y posteriormente se procedió al revelado con DAB. Se realizó la contra coloración con hematoxilina, luego su deshidratación y posteriormente se efectuó el montaje con bálsamo de Canadá. (Fig. 20)

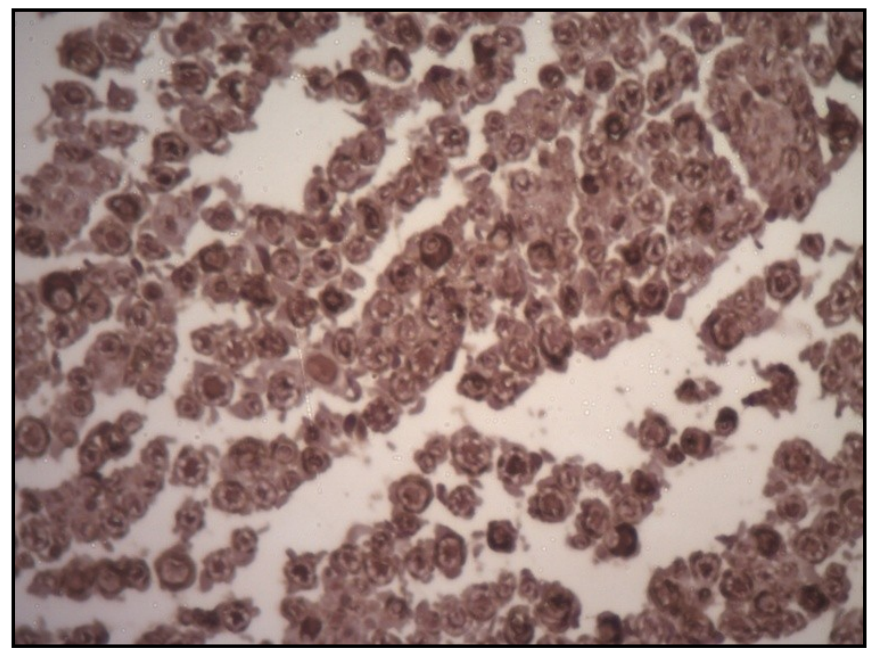

Fig. 20: Axones de Nervio Ciático a 40X.

Técnica de Inmunohistoquímica S100. 
Una vez procesados la totalidad de los tejidos, se observaron los 220 portaobjetos con microscopio de luz y se repitieron 5 de ellos por errores técnicos esperados en muestras delgadas, como pliegues o dobleces del material, siendo de difícil manejo por el escaso tamaño del mismo.

Un investigador independiente, especialista consultor en anatomía patológica y jefe del servicio de patología del Hospital de Alta Complejidad El Cruce S.A.M.I.C., evaluó la totalidad de las muestras histopatológicas analizando los axones, la morfología y el intersticio celular en busca de fibrosis.

Luego se procedió a la obtención de microfotografías con un microscopio con cámara de fotos especialmente adaptada para ese uso. Las imágenes fueron digitalizadas y cuidadosamente nomencladas para evitar sesgos de numeración. (Fig. 21)

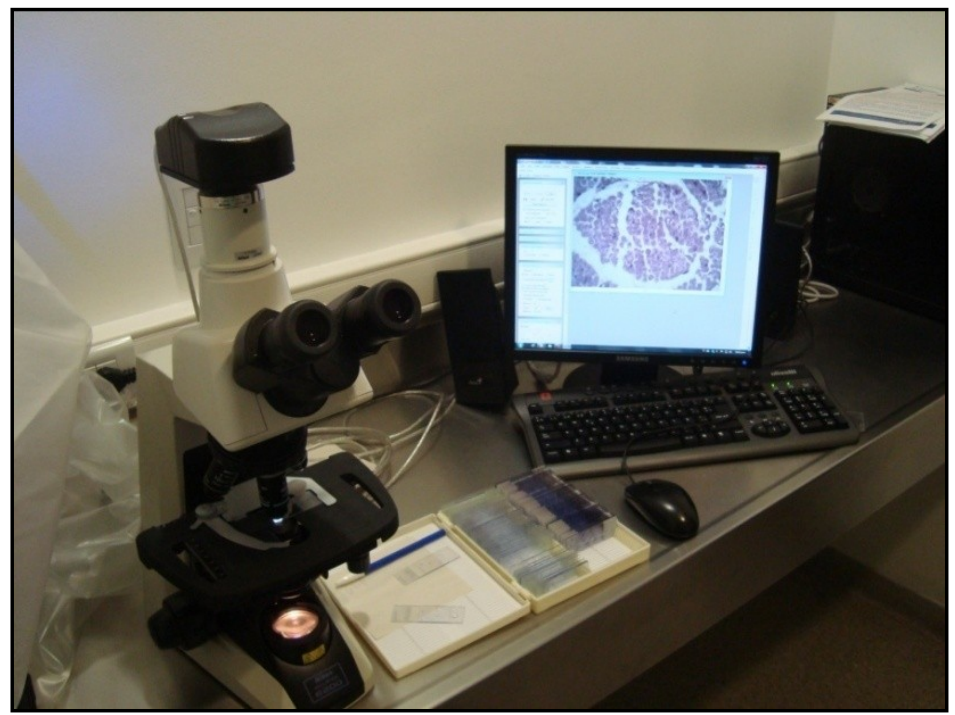

Fig. 21: Realización Microfotografías.

Posteriormente se seleccionaron 3 aéreas representativas dentro de la totalidad del epineuro en la que se realizó el conteo manual de los axones mielínicos, excluyendo las células de Schwann, vasos sanguíneos con sus eritrocitos, los pequeños axones amielínicos y otras células. ${ }^{97}$ (Fig. 22) Para esto último fue utilizado el programa Sigma Scan Pro, SPSS Inc. Los datos obtenidos fueron tabulados en una planilla de hoja de cálculo, siendo determinado el índice de regeneración para cada nervio operado.

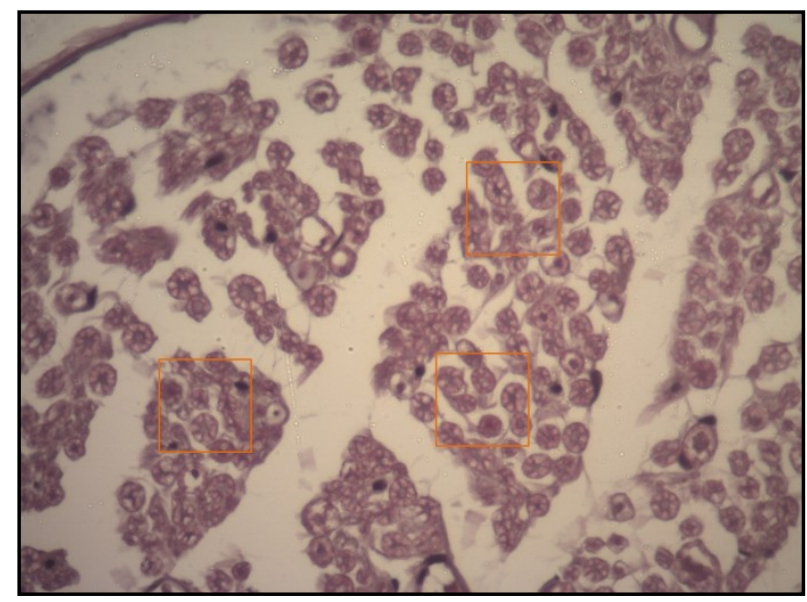

Fig. 22: Selección de cuadros dentro del nervio (Aumento 40X. Hematoxilina-Eosina). 
Este índice es el cociente entre el total de los axones computados en el segmento distal de neurorrafia (numerador), sobre el conteo de los axones en el segmento proximal (denominador). ${ }^{8,29}$

\section{$\underset{\text { Regendice de }}{\text { Ínación }}=\frac{\text { Axones en cabo distal }}{\text { Axones en cabo proximal }}$}

\section{Análisis Estadístico}

Los resultados de las tres determinaciones fueron tabulados en hojas de cálculo, obteniéndose la media aritmética y el desvío estándar de cada uno de los grupos. Posteriormente los datos particulares fueron cargados al programa Prism 5 de GraphPad Software Inc. y los diferentes grupos fueron confrontados mediante Análisis de la Varianza (ANOVA) y al ser significativos se compararon entre sí mediante el test de Tukey. Con el mismo programa se realizaron los gráficos pertinentes. Un valor de $p<0.05$ se consideró significativo. El análisis del conteo axonal del segmento extirpado en la primera cirugía y el segmento proximal de la neurorrafia extraído en el segundo procedimiento quirúrgico, fue realizado mediante una prueba de t de Student pareado.

\section{$\underline{\text { Resultados }}$}

Los grupos A, B y C fueron realizados sin inconvenientes, alcanzándose resultados satisfactorios.

En lo referente al grupo $D$, de $6 \mathrm{~mm}$ de exéresis de sustancia nerviosa, se intentó realizar la técnica de PED en 3 animales, obteniendo por resultado el impedimento de realizar un punto epineural distante efectivo que acerque los cabos nerviosos entre sí; lo suficiente como para realizar la neurorrafia. Este inconveniente fue debido al desgarro del epineuro por la extrema tensión.

Por lo anteriormente expuesto se decidió interrumpir la realización de dicho grupo, ya que no existían posibilidades de obtener una neurorrafia funcional, y por ende, los resultados de todas las determinaciones serían nulos.

Al inicio del experimento los animales fueron pesados en una balanza digital, cuyo promedio general fue de 183.23g. Al tercer mes y antes de realizar la cirugía, los animales fueron nuevamente pesados, siendo su media aritmética de $220.53 \mathrm{~g}$. En el lapso de tiempo entre la primer cirugía y el fin del experimento aumentaron su masa corporal un $21.86 \%$, con una ganancia promedio de $40 \mathrm{~g}$.

Ningún animal presentó signos clínicos de patología alguna hasta el fin del experimento, siendo evaluados periódicamente por un profesional veterinario. No hubo casos de automutilaciones de los miembros operados.

Se produjo el óbito de un animal durante la inducción anestésica, siendo el mismo reemplazado para mantener la $\mathrm{N}$ homogénea en los grupos. 
En lo referente a los resultados netamente quirúrgicos, no fueron evidenciadas dehiscencias de las heridas ni infecciones postquirúrgicas. Salvo una excepción, ni la piel ni el músculo presentaron grandes áreas de fibrosis; en todos los reabordajes se logró localizar y aislar de los tejidos circundantes al nervio

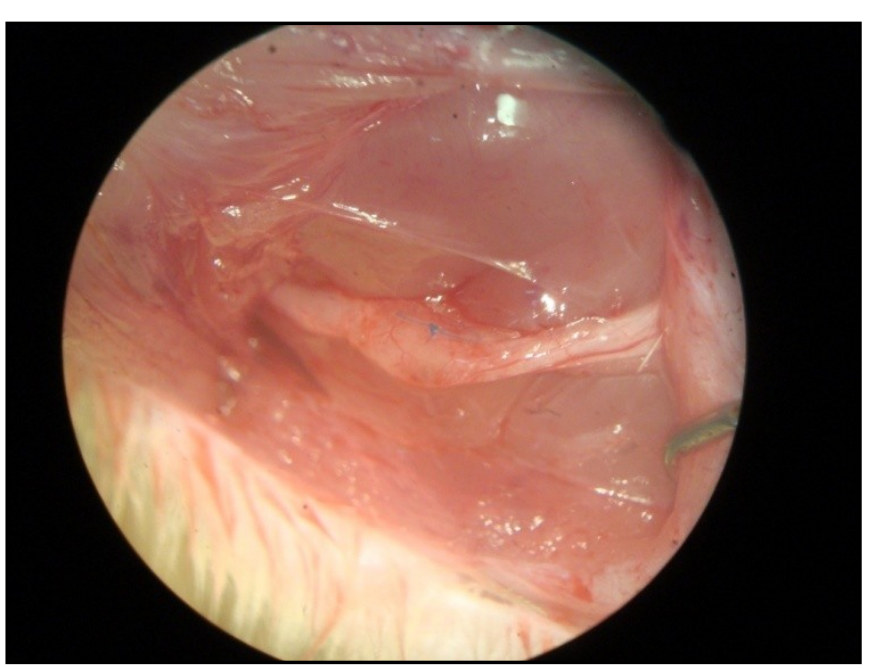
ciático y sus ramas terminales, sin producir daño a su estructura. La excepción fue la rata número 2 del grupo $C(4 \mathrm{~mm})$ que presentó en el re abordaje a los 90 días gran adherencia y fibrosis de la sutura nerviosa a los tejidos vecinos; no obstante, el nervio pudo individualizarse sin lesiones.

Si bien la gran mayoría de los nervios poseían pequeñas dilataciones fusiformes globales 0 localizadas en ciertas áreas de la neurorrafia, un animal del grupo de $4 \mathrm{~mm}$ presentó un neuroma en continuidad. (Fig. 23)

Fig. 23: Neuroma en continuidad.

( 3 meses posterior a la primer cirugía)

Todos los casos en los cuales se realizó técnica de PED requirieron un solo punto epineural distal con nylon 8.0, siendo este realizado en la cara posterior del nervio. En toda la casuística de los grupos de 2 y $4 \mathrm{~mm}$, la neurorrafia con nylon 10.0 fue consumada mediante 3 puntos de sutura. En el grupo control sin tensión, la anastomosis nerviosa fue realizada en cinco casos con 3 puntos, y en la otra mitad tan solo con 2 puntos.

\section{Evaluación funcional mediante huellas plantares}

Fue calculado el IFC de cada animal, que reúne ambos miembros inferiores en un solo valor, a los 30, 60 y 90 días luego de la cirugía inicial, siendo la medición de los 90 días la previa al fin del experimento. Por esto contamos con la medición evolutiva de cada animal a lo largo de su recuperación funcional. 


\begin{tabular}{|c|c|c|c|c|c|}
\hline \multirow[t]{2}{*}{ Marcha 1er mes } & & Marcha 2do mes & & Marcha 3er mes & \\
\hline & IFC & & IFC & & IFC \\
\hline \multirow[t]{10}{*}{ Control } & -71.33 & Control & -28.31 & Control & -19.01 \\
\hline & -41.10 & & -31.70 & & -34.99 \\
\hline & -31.48 & & -22.78 & & -5.39 \\
\hline & -23.16 & & -59.48 & & -41.62 \\
\hline & -50.28 & & -48.79 & & -41.57 \\
\hline & -27.39 & & -48.66 & & -33.17 \\
\hline & -65.29 & & -48.94 & & -22.12 \\
\hline & -64.47 & & -35.07 & & -21.93 \\
\hline & -13.82 & & -34.90 & & -10.21 \\
\hline & -26.02 & & -37.49 & & -22.24 \\
\hline Promedio & -41.43 & Promedio & -39.61 & Promedio & -25.22 \\
\hline Desvío Estándar & 20.28 & Desvío Estándar & 11.40 & Desvío Estándar & 12.39 \\
\hline & & & & & \\
\hline \multirow[t]{10}{*}{$2 \mathrm{~mm}$} & -29.88 & $2 \mathrm{~mm}$ & -53.04 & $2 \mathrm{~mm}$ & -16.92 \\
\hline & -33.38 & & -64.80 & & -38.31 \\
\hline & -49.07 & & -35.23 & & -11.12 \\
\hline & -68.06 & & -67.41 & & -31.11 \\
\hline & -35.68 & & -40.21 & & -39.65 \\
\hline & -63.36 & & -23.48 & & -37.08 \\
\hline & -50.96 & & -17.34 & & -22.05 \\
\hline & -34.27 & & -59.02 & & -33.97 \\
\hline & -65.08 & & -25.53 & & -31.17 \\
\hline & -68.12 & & -37.96 & & -14.61 \\
\hline Promedio & -49.79 & Promedio & -42.40 & Promedio & -27.60 \\
\hline Desvío Estándar & 15.62 & Desvío Estándar & 17.84 & Desvío Estándar & 10.54 \\
\hline & & & & & \\
\hline \multirow[t]{10}{*}{$4 \mathrm{~mm}$} & -55.03 & $4 \mathrm{~mm}$ & -58.58 & $4 \mathrm{~mm}$ & -44.91 \\
\hline & -45.07 & & -51.74 & & -53.60 \\
\hline & -40.76 & & -51.30 & & -29.61 \\
\hline & -57.23 & & -47.97 & & -75.49 \\
\hline & -77.90 & & -65.58 & & -56.18 \\
\hline & -87.55 & & -52.75 & & -52.20 \\
\hline & -33.39 & & -66.85 & & -57.10 \\
\hline & -91.02 & & -52.36 & & -51.88 \\
\hline & -92.99 & & -65.76 & & -50.30 \\
\hline & -63.29 & & -61.02 & & -75.64 \\
\hline Promedio & -64.42 & Promedio & -57.39 & Promedio & -54.69 \\
\hline Desvío Estándar & 21.80 & Desvío Estándar & 7.04 & Desvío Estándar & 13.49 \\
\hline
\end{tabular}

Fueron computados los promedios y los desvíos estándar de cada grupo en cada medición, obteniéndose un gráfico de líneas en el cual cada grupo inició con un parámetro determinado y luego fue mejorando a los largo de los días.

Al inicio, el grupo con mejor IFC fue el control, seguido por el de $2 \mathrm{~mm}$ y por último el de $4 \mathrm{~mm}$. Al segundo mes las posiciones fueron mantenidas, no obstante los grupos de 2 y $4 \mathrm{~mm}$ tuvieron una mejoría del IFC de alrededor de un 7\%. Luego se produjeron cambios dispares, el grupo de $4 \mathrm{~mm}$ solo mejoró un $2,7 \%$, mientras que los grupos control y $2 \mathrm{~mm}$ mantuvieron un crecimiento casi paralelo de alrededor de un $15 \%$ del IFC. 


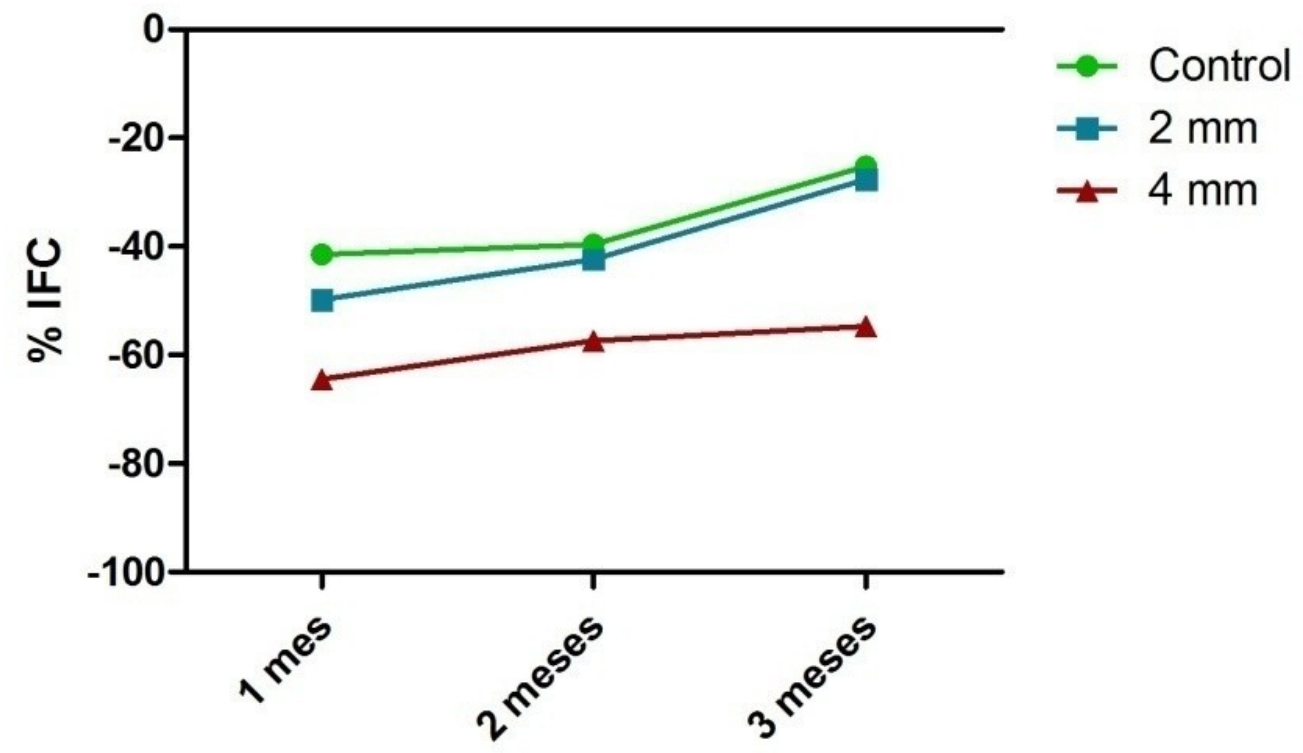

Ulteriormente se examinaron los datos obtenidos únicamente en el tercer mes, ponderado como el mejor resultado funcional alcanzado, y se realizó un análisis de varianza (ANOVA). Este reveló diferencias altamente significativas con una $p=0.0001$. A continuación se realizó el test de Tukey que evidenció diferencias significativas $(p<0.05)$ entre el grupo de $4 \mathrm{~mm}$ y el resto de los grupos, no así entre los grupos control y $2 \mathrm{~mm}$.

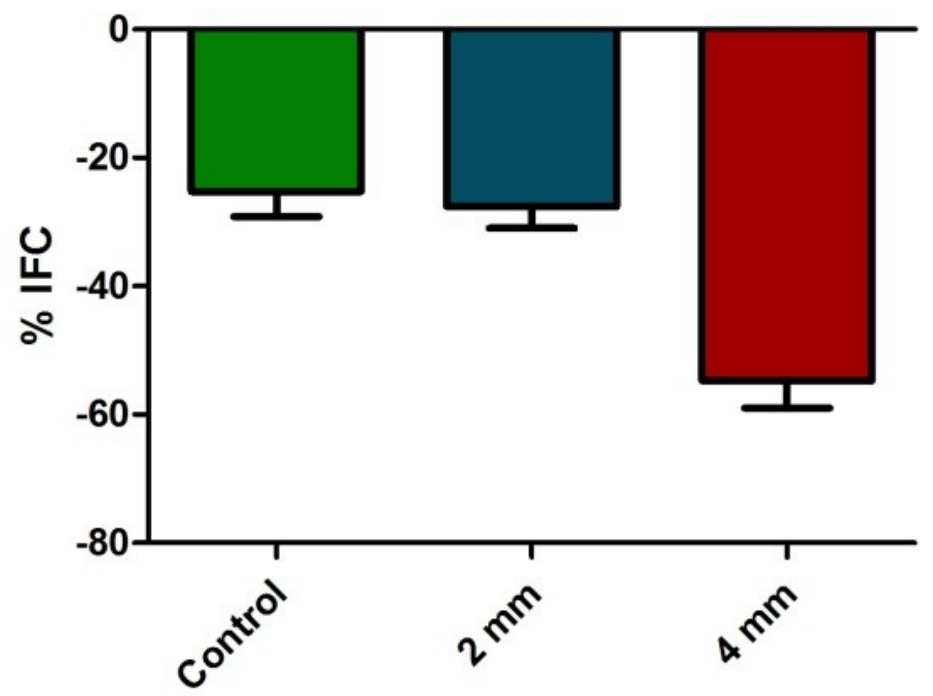

Grupos 


\section{Electrofisiología}

Todos los nervios intervenidos mostraron conducción de los impulsos eléctricos con un promedio total de $10.68 \mathrm{~mm} / \mathrm{seg}$, mientras que los miembros izquierdos, reservados como un control dentro del mismo animal, fueron en el orden de $18.03 \mathrm{~mm} / \mathrm{seg}$. Por lo que existió en este estudio una diferencia de $7.35 \mathrm{~mm} / \mathrm{seg}$ entre un nervio seccionado y reconstruido con cualquier técnica, y la velocidad de los nervios control.

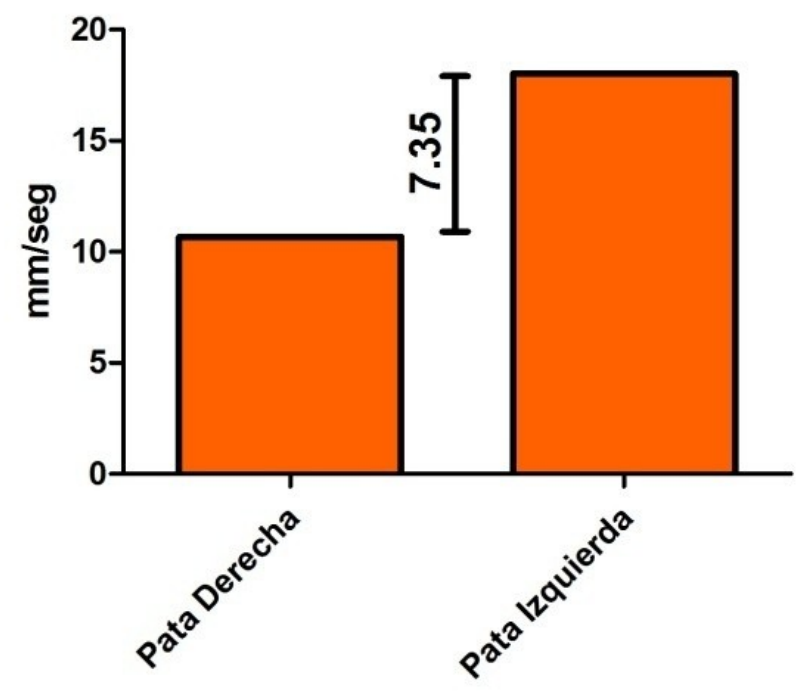

Los registros electromiográficos fueron analizados inicialmente dentro de cada animal, para lo cual se calculó la diferencia existente entre la velocidad de conducción (expresada en $\mathrm{mm} / \mathrm{seg}$ ) del miembro abordado quirúrgicamente (derecho), y su correspondiente control de miembro izquierdo; el cual se mantuvo inalterado a lo largo del experimento.

Posteriormente la cifra obtenida fue analizada en conjunto con el resto de los integrantes del mismo grupo, calculándose las medias aritméticas y los desvíos estándar. El promedio más bajo lo obtuvo el grupo de $4 \mathrm{~mm}$, mientras que el más alto lo alcanzó el grupo control.

\begin{tabular}{|c|c|c|c|}
\hline \multirow[t]{11}{*}{ Electrofisiología } & Control & $2 \mathrm{~mm}$ & $4 \mathrm{~mm}$ \\
\hline & -13.62 & -4.73 & -18.96 \\
\hline & -6.33 & -3.00 & -12.86 \\
\hline & -8.16 & -7.30 & -7.61 \\
\hline & -0.59 & -2.50 & -7.68 \\
\hline & -3.97 & -9.46 & -10.64 \\
\hline & 1.79 & -9.50 & -14.91 \\
\hline & -7.47 & -4.91 & -7.62 \\
\hline & -8.31 & -5.15 & -14.62 \\
\hline & -0.63 & -1.39 & -8.45 \\
\hline & -1.37 & -8.05 & -12.56 \\
\hline Promedio & -4.87 & -5.60 & -11.59 \\
\hline Desvío Estándar & 4.73 & 2.88 & 3.87 \\
\hline
\end{tabular}


Los 3 grupos fueron confrontados entre sí mediante un ANOVA, lo cual arrojó un resultado altamente significativo con una $p=0.001$. Posteriormente se realizó el test de Tukey para comparación múltiple, el cual mostró diferencias significativas ( $p<0.05$ ) entre el grupo control y el de $4 \mathrm{~mm}$, y entre el grupo de $2 \mathrm{~mm}$ y el de $4 \mathrm{~mm}$. No se hallaron diferencias estadísticamente significativas entre el grupo control y el de $2 \mathrm{~mm}$.

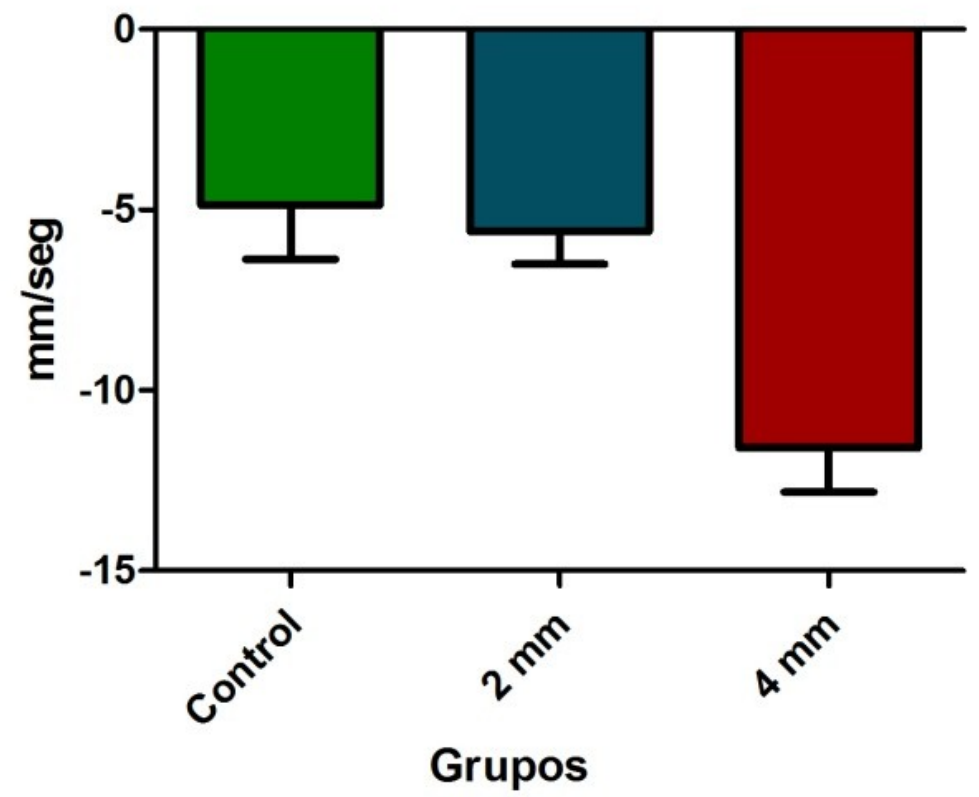

\section{Histopatología}

Como se refirió en material y métodos, cada muestra fue procesada con técnica de hematoxilina-eosina y con inmunohistoquímica S100, por lo cual se obtuvieron como resultado dos conteos de axones de la misma muestra de tejido. A fin de poseer un conteo más fidedigno, fue realizado un promedio entre ambos resultados.

Posteriormente se calculó el índice de regeneración axonal (IR) y se dispuso en una hoja de cálculo para obtener los promedios generales de cada grupo y su desvío estándar. 


\begin{tabular}{|r|r|r|r|}
\hline Histopatología & & & \\
\hline Promedio axonal HE - S100 & IR control & IR $2 \mathrm{~mm}$ & IR $4 \mathrm{~mm}$ \\
& 0.78 & 0.74 & 0.73 \\
& 0.69 & 0.78 & 0.77 \\
& 0.77 & 0.62 & 0.72 \\
& 0.91 & 0.87 & 0.73 \\
& 0.68 & 0.8 & 0.65 \\
& 0.81 & 0.78 & 0.78 \\
& 0.74 & 0.97 & 0.63 \\
& 0.95 & 0.96 & 0.63 \\
& 0.88 & 0.77 & 0.64 \\
\hline Promedio & 0.93 & 0.73 & 0.53 \\
\hline Desvío Estándar & 0.81 & 0.80 & 0.68 \\
\hline & 0.10 & 0.11 & 0.08 \\
\hline
\end{tabular}

El mayor promedio de IR obtenido fue el del grupo control, con un pasaje de axones a través de la neurorrafia del $81.4 \%$, mientras que el menor valor fue hallado en el grupo de $4 \mathrm{~mm}$ con un IR promedio de $68.1 \%$.

A continuación fue realizado un ANOVA que evidenció una $p=0.007$, considerándose como altamente significativa. El test de comparación múltiple de Tukey demostró diferencias significativas $(p<0.05)$ entre los grupos control y $2 \mathrm{~mm}$ respecto al grupo de $4 \mathrm{~mm}$. $Y$ no demostró diferencias estadísticamente significativas entre el grupo control y el de $2 \mathrm{~mm}$.

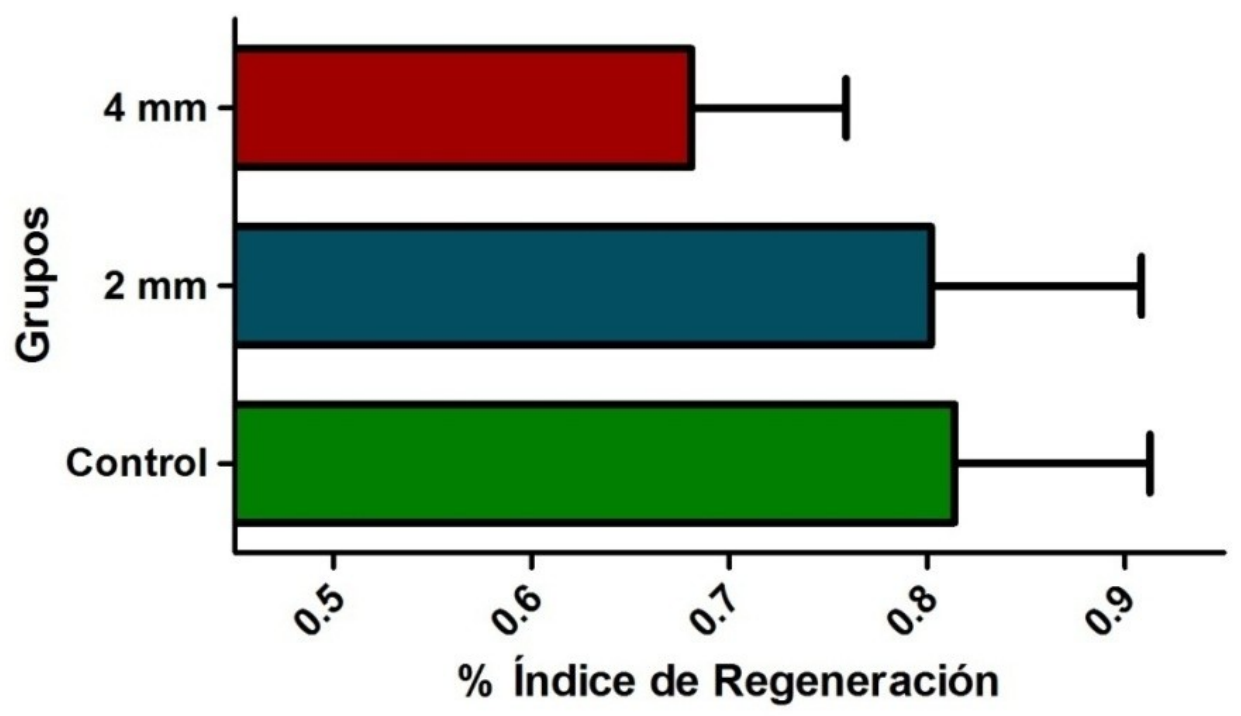


A la porción de nervio extraída en la primera cirugía de los grupos de $2 \mathrm{~mm}$ y $4 \mathrm{~mm}$, se le realizó un conteo axonal del mismo modo que para el resto de las muestras. El resultado fue comparado con el conteo axonal de la porción proximal a la neurorrafia del mismo nervio a los 3 meses de la cirugía, mediante una prueba de $\mathrm{t}$ de Student pareado. Este análisis estadístico demostró que no existieron diferencias significativas $(p=0.69)$.

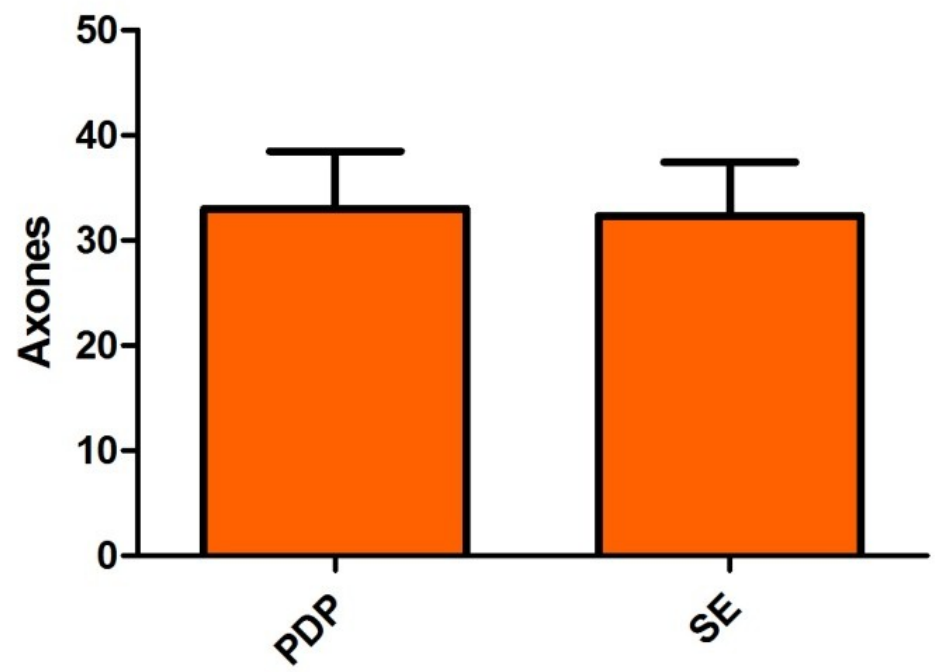

El investigador independiente que evaluó las muestras histopatológicas no evidencio áreas de fibrosis en ningún fragmento del tejido nervioso, sea tanto en la porción proximal o distal del miembro operado, así como en el control del miembro contralateral.

\section{Discusión}

Para la confección de este estudio fueron utilizados nervios ciáticos de ratas adultas Wistar, hembras endocriadas. La literatura científica internacional consultada, arroja como resultado que es el modelo más utilizado para experimentación quirúrgica en el SNP. ${ }^{84}$ Su ventaja principal es la rápida y eficiente regeneración nerviosa. Además la rata de laboratorio es un animal definido en su carga genética y microbiológica, por lo cual respeta el concepto de reactivo biológico y es además relativamente de bajo costo. La nula variabilidad en la especie seleccionada reduce las diferencias entre individuos por ser animales isogénicos o endocriados. ${ }^{88}$ Por otro lado operativamente requiere de escasa cantidad de operadores para su manejo.

La elección de utilizar hembras se basó en los reportes de Weber RA y col. donde describe que poseerían una menor tasa de automutilaciones. De suceder esto último, se eliminaría la posibilidad de la realización de la evaluación de la marcha mediante las impresiones plantares, ya que nos faltarían parámetros para realizar las mediciones necesarias para el cálculo del índice de función ciática. 21,80,98 
En nuestro estudio no existieron automutilaciones, en paralelismo con otros reportes en los cuales no encontraron ningún caso de este comportamiento, resultante de la anestesia en miembros desnervados y su posterior autofagia. 22,88

Si bien es indistinta la utilización del nervio ciático derecho o izquierdo, se ha utilizado el derecho en todos los animales en concordancia con otros experimentos. ${ }^{70,71,97}$ Es importante asimismo realizar el abordaje de un solo miembro por animal, con el fin de que el contralateral inalterado contribuya con la recuperación funcional del miembro abordado, resultando esta muy dificultosa si son operados ambas extremidades debido al enorme déficit que sufre el animal. Asimismo esto último no cumpliría con las normas internacionales de uso y cuidado de animales de laboratorio. ${ }^{81}$

Para la evaluación final del experimento se fijó el lapso temporal máximo de 90 días, en similitud con otras investigaciones con nervios periféricos en ratas, que oscilan entre los 2 y los 4 meses. ${ }^{84,90}$

En lo referente a la anestesia, creemos que la inducción mediante éter sulfúrico debe ser abandonada debido a su potente acción inflamatoria sobre las vías aéreas, lo que produce aumento de secreciones respiratorias pudiendo llevar al animal a hipoxia y paro respiratorio por obstrucción. No obstante insistimos fuertemente en la necesidad de la inducción inhalatoria, ya que disminuye notablemente el estrés del animal, lo que conllevara a una menor dosis de drogas intraperitoneales y de mantenimiento posterior si fuera necesario. Por lo anteriormente expuesto utilizamos en la inducción anestésica sevoflurano.

La vía intraperitoneal es de elección en numerosos experimentos en la rata de laboratorio, así como las drogas utilizadas. ${ }^{88}$ La ketamina produce una desorganización funcional del sistema nervioso central y bloquea la actividad refleja a nivel espinal, sin afectar al sistema motor. ${ }^{71}$

Este experimento tuvo una tasa menor de óbito por causas anestésicas en comparación con otros reportes. Tampoco se registraron necrosis distales $\mathrm{u}$ óbitos por causas desconocidas en el postoperatorio alejado. ${ }^{84,90}$

La utilización de modelos experimentales quirúrgicos ha facilitado la investigación y el desarrollo de técnicas, procedimientos y terapéuticas médico-quirúrgicas extrapolables a la práctica clínica para dar respuesta a problemas médicos concretos. Muchos de estos experimentos requieren técnicas macro y microquirúrgicas para abordar el órgano en estudio. En el caso de la experimentación y el entrenamiento microquirúrgico en nervios periféricos, es importante respetar la anatomía para preservar las estructuras en forma adecuada, minimizar el tiempo operatorio y evitar que se agreguen factores externos al experimento que pudieran comprometer o alterar sus resultados, como por ejemplo la presencia de un hematoma infectado producido por una pobre técnica quirúrgica, la inadecuada exposición del nervio que induzca a un exceso de manipulación del mismo o que dificulte, por su reducida exposición, la técnica misma de sutura nerviosa. Del mismo modo una excesiva e innecesaria exposición del nervio en estudio generalmente conlleva una mayor incisión cutánea, una mayor disección muscular y muchas veces el sacrificio de estructuras vasculares, lo que repercute directamente sobre el animal al adicionarle un excedente de morbilidad que trasciende al experimento en sí, lindando con el tema no menor del sufrimiento de un ser vivo. 
El abordaje aquí descripto a pesar de ser realizado sin coagulación eléctrica, posee escasas o nulas hemorragias intraoperatorias. Esto es debido a que si se respetan los planos naturales se minimiza el daño tisular, no se seccionan vasos de importancia, y el único elemento sangrante es la piel y en ocasiones el músculo, cuya hemostasia se logra adecuadamente por compresión con hisopo y la posterior colocación de gasas embebidas en solución fisiológica tibia.

En lo referido al nervio ciático mayor de la rata, se encuentra otra vía descripta en la literatura para su abordaje; partiendo de una posición en decúbito ventral con los cuatro miembros extendidos y fijados con cinta adhesiva a la camilla quirúrgica, se realiza la incisión en piel, se divulsiona al tejido celular subcutáneo y se diseca el borde superior del músculo glúteo; mediante tracción inferior con separadores se permite exponer el nervio ciático. Aquí se colocan dos separadores inferiores en el borde superior del músculo y otro superior en los tegumentos. ${ }^{88,99}$

Si bien el abordaje utilizado en la presente tesis con disección longitudinal de las fibras del músculo glúteo es más traumático y menos anatómico, permite una excelente exposición del nervio. Por otra parte, si se realiza disección roma para separar las fibras musculares, no se lesionan vasos y las hemorragias son mínimas. Su contraparte respeta al máximo la anatomía, pero implica la gran dificultad del trabajo en profundidad.

A pesar de que no fueron utilizados antibióticos como profilaxis prequirúrgica no se registraron infecciones de las heridas, hecho ya reportado por otros autores en la literatura. ${ }^{84,100,101}$

Tampoco evidenciamos contracturas crónicas de los miembros abordados, producidas por anquilosis articulares o por reinervación fallida, producida por la pérdida de la ruta original de los axones, y que involucra a músculos agonistas y antagonistas a la vez. Esto se traduciría en deformidades y la imposibilidad de contar con la evaluación de la marcha como lo demuestran ampliamente Dellon y Mackinnon. ${ }^{89,91}$

En lo referente a la técnica misma de la neurorrafia de los PED, fue utilizado un hilo de nylon más grueso (8.0) que para la coaptación de los cabos, ya que este debe soportar la tensión diseminada hacia los extremos nerviosos, librando de tensión al sitio por donde atravesará el brote axonal. De caso contrario, si utilizásemos el nylon 10.0 que destinamos a la neurorrafia en sí, este podría seccionarse y llevar la tensión al lugar donde brotará en nuevo axón, predestinando la reconstrucción nerviosa al fracaso. ${ }^{22}$

Creemos que por las características del nervio ciático de la rata Wistar alcanza con un solo PED de nylon 8.0 para aproximar los cabos nerviosos, sea con un déficit de sustancia nerviosa de 2 o $4 \mathrm{~mm}$. También es recomendable la realización de dicho PED en la parte posterior del nervio, ya que moviliza y presenta los cabos nerviosos hacia anterior, permitiendo realizar la neurorrafia de una manera más sencilla. (Fig. 24) Si efectuásemos el PED tanto en la porción superior o inferior del nervio, y sobre todo en la cara anterior, éste punto dificultaría la realización de la neurorrafia, al dirigir los extremos nerviosos hacia una situación distante. 


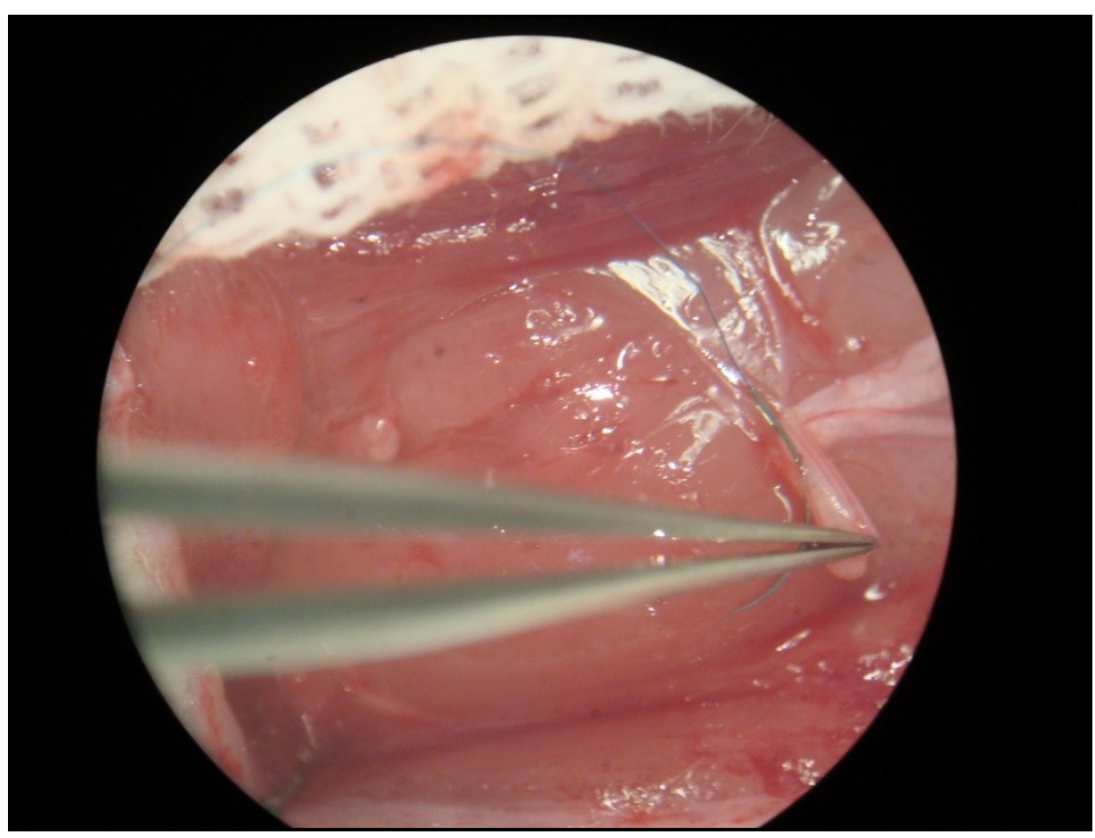

Fig. 24: Realización de PED en cara posterior.

En el presente trabajo las neurorrafias pudieron realizarse sin inconvenientes técnicos en todos los casos. No obstante se evidenció que el grupo control sin tensión requirió un $25 \%$ menos de puntos de sutura para su correcta confrontación primaria de los cabos, sin tener en cuenta los PED.

La evaluación funcional se realizó mediante huellas, electrofisiología e histopatología. Estos parámetros son las tres determinaciones utilizadas más frecuentemente en la investigación del sistema nervioso periférico, en especial del nervio ciático en la rata de laboratorio. ${ }^{88,91}$

El análisis de las huellas fue descripto inicialmente por de Medinaceli en $1982^{92}$, vinculando cuatro mediciones mediante una fórmula matemática que incluye al miembro contralateral. Esta determinación reviste importancia mayúscula, ya que requiere de la coordinación por parte del animal de las porciones más distales de su economía, garantizando la presencia de conexiones complejas motoras y sensitivas, ponderando la recuperación funcional del miembro reinervado. ${ }^{84}$

Esta evaluación nos permite la valiosa observación de la funcionalidad del miembro afectado por la cirugía y su comparación permanente con su contralateral no operado, de manera evolutiva a lo largo del experimento. Cuenta con la enorme ventaja de no ser un procedimiento invasivo y suprime las manipulaciones repetidas del nervio a estudiar, previniendo nuevas inflamaciones y mayor tejido de fibrosis. ${ }^{91}$

En nuestro experimento se nos plantea la dificultad de que el animal dentro del corredor (a pesar de ser lo suficientemente angosto) podía realizar una marcha levemente oblicua hacia izquierda o derecha, lo que nos llevaría a realizar un sesgo de medición si tomáramos el eje longitudinal del corredor como línea media para cuantificar la distancia entre las huellas izquierdas y las derechas. Para evitar este inconveniente, atendimos a la dirección global de la marcha del animal y trazamos su eje medio. Se 
tomó esto último como base, y se realizó todas las mediciones de las impresiones plantares, en especial la distancia entre huellas, que es la que se vería mayormente sesgada si no tratáramos la línea de eje medio. (Fig. 25)

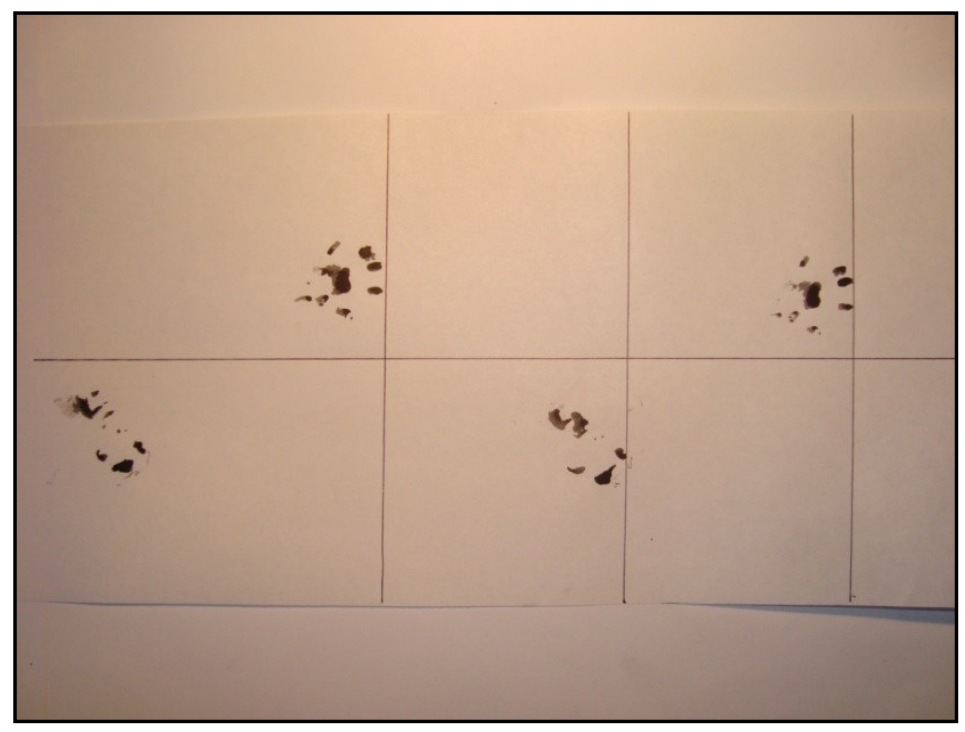

Fig. 25: Trazado de línea media en la marcha.

Oliveira et ál. realizan una crítica a la medición del índice de función ciática, argumentando que dicha medición en ninguno de sus experimentos fue 0 (cero), valor que es tomado como normalidad, incluso en animales en los cuales no se realizó ningún procedimiento. No obstante su utilización se ha generalizado y su uso es regla al momento de realizar determinaciones para evaluar la recuperación de un nervio ciático en la rata. ${ }^{84}$

Las determinaciones electrofisiológicas constan de la realización de un estímulo eléctrico en un área del cabo proximal y su correspondiente registro en el músculo, es decir a través de la neurorrafia. Las pruebas fueron realizadas con un eletroneuromiógrafo portátil de dos canales (Medtronic) y operado por un investigador que desconocía la pertenencia a uno u otro grupo de cada animal, el investigador involucrado posee amplia experiencia en realizar dichas mediciones y es autor de numerosos trabajos de investigación en ratas del SNP. ${ }^{8,64,88,99,102,103}$ En mayor o menor grado todos los nervios operados mostraron continuidad de los estímulos a través de la neurorrafia.

La comparación de las velocidades de conducción nerviosa del miembro operado con las del miembro contralateral nos brinda una excelente relación entre la variable y su control dentro de cada animal, eliminando variaciones inter individuales al cotejar a dos nervios con la misma función dentro del mismo individuo.

En la realización del conteo axonal en las muestras histológicas nos encontramos con la dificultad de que ciertas muestras se encontraban con su tejido formando "islas", mientras que otros contenían toda su extensión compacta. Esto puede deberse en parte a la hidratación y deshidratación de la muestra, resultado íntimo de la técnica histológica en sí. 
Si realizáramos el conteo axonal en estos preparados caeríamos en un error por técnica, ya que en un preparado con su tejido compacto contaríamos más axones que en otro preparado en el cual se encuentre con muchas "islas".

Para evitar este sesgo de conteo visualizamos a la muestra histológica más disgregada y buscamos la mayor extensión posible que se encuentre con tejido compacto dentro de esta "isla". Esa área fue triplicada y adaptada a diferentes partes del preparado histológico.

Estas tres áreas fueron transpoladas a la totalidad de los preparados histológicos observándose la correcta adaptación.

Esto llevó a realizar un conteo axonal en áreas netamente con tejido compacto, eliminando el sesgo de conteo. $^{97}$

Para la mejor individualización de los axones, además de la clásica técnica de hematoxilina-eosina, se realizó la inmunohistoquímica S100 que marca las células de Schwann que envuelven los axones; dicho anticuerpo fue descubierto en el año 1982 por Stefansson y colaboradores. ${ }^{31}$

La correlación entre el segmento de nervio extirpado en la primera cirugía y la porción proximal a la neurorrafia de la última cirugía muestra que no hay cambios estadísticamente significativos, lo que manifestaría una concordancia entre el número de axones presentes en el nervio intacto y los hallados en el mismo nervio luego de tres meses de la injuria.

La ausencia de fibrosis en las muestras analizadas se debe a que las mismas son distantes al sitio mismo de neurorrafia, lugar donde se produce la cicatriz fibrosa que debe sortear el brote axonal para iniciar su migración hacia el órgano blanco.

En la década de 1970 Millesi recomendaba la utilización de injertos nerviosos en todos aquellos casos en los que se contara con una pérdida de sustancia de más de $2 \mathrm{~cm}$, obteniendo buenos resultados en su serie de lesiones de nervios ulnar, radial y mediano. ${ }^{19,104,105}$

Como es esperable, la extracción total de un nervio para la utilización como injerto va acompañada de la pérdida total de su función hacia distal de su sección, por lo cual la utilización de nervios sensitivos se acompaña de anestesia en la topografía de su distribución.

Otra comorbilidad agregada son las extensas cicatrices ocasionadas si se decide su extracción a cielo abierto exponiendo todo su trayecto. Es posible utilizar incisiones escalonadas para evitar o disminuir este problema. Si bien se encuentra descripta la extracción por vía endoscópica del nervio sural en infantes para el tratamiento de la parálisis braquial obstétrica, la misma es escasamente realizada en nuestro medio. ${ }^{106,107}$

También se describe la formación de un neuroma en el extremo nervioso seccionado, que puede producir dolor postoperatorio mediato, en ocasiones de difícil tratamiento; y que puede requerir una nueva cirugía para su resolución. ${ }^{2}$ 
El injerto es una fuente escasa de factores tróficos, a diferencia de un cabo distal bien irrigado; así como también es distinto en número de fibras y diámetro al nervio a reparar. ${ }^{42}$

Como en todo procedimiento quirúrgico, la vascularización juega un papel primordial, ya que el injerto requiere de un adecuado aporte sanguíneo para llevar a cabo su función. La vascularización del injerto suele provenir de los tejidos adyacentes inmediatos a él, así como del crecimiento de la vasa nervorum de los cabos que se intenta reparar. Los injertos libres, que son los mayoritariamente utilizados en la práctica quirúrgica actual, no poseen vasos que nutran su estructura, sino que estos deben desarrollarse como neovascularización de tejidos aledaños como se mencionó anteriormente. Dicha irrigación puede retrasarse por la formación de fibrosis propias de la cirugía, el nervio desarrollar necrosis central y finalmente fracasar la regeneración o no llegar a un resultado óptimo. ${ }^{2}$

En vistas a lo argumentado, para evitar la falta de riego sanguíneo se han desarrollado injertos nerviosos vascularizados. Este procedimiento resulta técnicamente demandante y conlleva un mayor tiempo quirúrgico para su realización, por lo que algunos autores solo recomiendan su utilización en casos en los cuales exista un riesgo incrementado de necrosis del implante, como en injertos largos o con tejidos del lecho quirúrgico con gran fibrosis. El modelo mayoritariamente utilizado es el nervio cubital. . $^{2,108-110}$

Otra desventaja de la utilización de injertos es la imposibilidad de contar con suficiente tejido al momento de reparar extensos defectos ocasionados por una abundante pérdida de sustancia. Además es necesario tener presente que el injerto a utilizar debe ser por lo menos 10 o 20 por ciento más largo que el defecto a reparar, a modo de evitar tensión en los sitios de sutura, sea por la reacomodación de los tejidos en el post operatorio o por flexiones imprevistas de las articulaciones.

Con el objetivo de solucionar lo anteriormente expuesto se desarrollaron injertos heterólogos o xenoinjertos. Su utilización se encuentra acompañada de inmunosupresión, por lo menos hasta que el injerto sea reemplazado por tejidos propios al completarse el crecimiento axonal. Entre los fármacos utilizados en estos casos se encuentran la ciclosporina y el tacrolimus. Este último, además de evitar el rechazo del injerto, ha mostrado efectos neuroprotectores y neurorregenerativos. No obstante, los xenoinjertos aún no cuentan con gran evidencia clínica favorable a su utilización ${ }^{42}$, por lo que en la actualidad es muy infrecuente que sean empleados. ${ }^{2}$

Existen descriptos otros métodos de reemplazo de ausencia de tejido nervioso con otros tejidos tales como venas ${ }^{111,112}$, arterias ${ }^{113}$ o músculo ${ }^{114}$, que servirían de guía a los axones para arribar al extremo distal sin la interposición deletérea del tejido de fibrosis ${ }^{42}$, no obstante poseen resultados controvertidos. $^{71}$

La reparación del SNP bajo tensión injuria los vasos intraneurales, lo que debilita el riego sanguíneo, siendo su resultante el incremento del tejido cicatrizal e impidiendo el avance del brote axonal. ${ }^{104}$ Esas dificultades deben ser ponderadas con la utilización de injertos y sus desventajas, en especial la necesidad de que el brote axonal atraviese dos sitios de neurorrafias. ${ }^{80}$

En una lesión con sección completa del nervio o grado III de Seddon, aunque no haya pérdida de sustancia los cabos comienzan su retracción entre unos pocos días y semanas. Asimismo, la presencia de 
neuromas que deban ser resecados hasta encontrar un extremo con axones viables y sin fibrosis suele dejar un segmento de pérdida de sustancia generada por el propio cirujano. ${ }^{115}$

Milessi expuso que el SNP humano tiene una capacidad de elongación del $20 \%$, limite en el cual comienza a afectarse su capacidad de conducción. ${ }^{19}$

Un estudio experimental en ratas pone de manifiesto que el flujo sanguíneo disminuye un $50 \%$ luego de una elongación del $8 \%$ del nervio luego de 30 minutos de tensión sostenida, mientras que un estiramiento del $15 \%$ lo reduciría hasta un $80 \%$ con mínima restitución luego de la relajación. ${ }^{22,116}$ La tensión crece de manera exponencial a medida que aumenta el defecto a reparar. ${ }^{80}$

Se sostiene que la técnica de PED elimina los efectos deletéreos de la tensión en el sitio de coaptación íntima de los cabos nerviosos, ya que traslada dicha tensión hacia proximal y distal del nervio utilizando la elasticidad natural del mismo.

Fue de Medinacelli en 1991 quien detalló esta divergencia de tensión hacia los extremos distantes de los bordes de sutura, en vez de donde se realizará el crecimiento axonal a través del sitio dañado. ${ }^{22}$

Las técnicas de eliminación de la tensión en el sitio primario de anastomosis mediantes puntos distantes que aprovechen la elasticidad natural del propio tejido y acerquen los cabos han sido descriptas en cirugía vascular, por ejemplo las técnicas de aortopexia como resolución de la coartación de aorta en neonatos. $^{117}$

Como se encuentra descripto en la bibliografía, en los PED suele utilizarse una sutura de mayor calibre que la reservada para una neurorrafia propiamente dicha, ya que los PED deben ejercer una mayor fuerza de aproximación. A modo de ejemplo, en el nervio ciático de la rata Wistar adulta se utiliza nylon monofilamento 8.0 para colocar el PED, mientras que para una neurorrafia común se utiliza $10.0 .^{22}$

La distancia en la cual debe utilizarse esta técnica o la de injertos no se encuentra ponderada en la bibliografía, aunque se recomienda que ante la ausencia de una pequeña porción del nervio y en vista de una reparación con muy leve tensión, es preferible realizar una anastomosis simple que a colocar un injerto interpuesto. ${ }^{70,80}$ No obstante, cuando hay mayor pérdida de tejido y se prevé que la sutura a tensión no va a resultar viable, puede realizarse PED.

Cuando se intenta realizar la técnica de PED con una pérdida de sustancia extensa, y el epineuro se desgarra por la extrema tensión, resulta dificultoso un adecuado afronte de los cabos nerviosos y por ende no se logrará una correcta neurorrafia. Esto llevará a un pobre o nulo resultado funcional y sería aconsejable la utilización de un injerto interpuesto.

Si bien la técnica de PED en la rata Wistar da por resultado neurorrafias funcionantes, investigaciones clínicas cuidadosas serían requeridas antes de la utilización en humanos. 


\section{Conclusiones}

- El nervio ciático de la rata Wistar es un modelo válido para el estudio de la reconstrucción microquirúrgica del SNP con diferentes grados de tensión.

- La realización de una neurorrafia con $6 \mathrm{~mm}$ de pérdida de tejido no es viable con la técnica de puntos epineurales distales en el nervio ciático la rata Wistar.

- En defectos de tejido nervioso menores a $4 \mathrm{~mm}$, la técnica de puntos epineurales distales es capaz de resultar en neurorrafias funcionalmente útiles, analizadas por evaluación funcional mediante huellas plantares, electrofisiología e histopatología.

- La reparación del nervio ciático mediante técnica de puntos epineurales distales en defectos de $2 \mathrm{~mm}$, no evidencia diferencias estadísticamente significativas con la neurorrafia terminoterminal sin tensión, analizada mediante los métodos que se han citado anteriormente. 


\section{$\underline{\text { Referencias bibliográficas }}$}

1. Robinson LR. Traumatic injury to peripheral nerves. Muscle Nerve. 2000;23(6):863-73.

2. Chimutengwende-Gordon $\mathrm{M}, \mathrm{Khan} \mathrm{W}$. Recent advances and developments in neural repair and regeneration for hand surgery. Open Orthop. J. 2012;6:103-7.

3. Thorsén F, Rosberg H-E, Steen Carlsson K, Dahlin LB. Digital nerve injuries: Epidemiology, results, costs, and impact on daily life. J. Plast. Surg. Hand Surg. 2012. p. 184-90.

4. Dahlin LB. Techniques of peripheral nerve repair. Scand. J. Surg. 2008;97(4):310-6.

5. Eser F, Aktekin LA, Bodur H, Atan C. Etiological factors of traumatic peripheral nerve injuries. Neurol. India. 2009;57(4):434-7.

6. Flores LP. The importance of the preoperative clinical parameters and the intraoperative electrophysiological monitoring in brachial plexus surgery. Arq. Neuropsiquiatr. 2011;69(4):6549.

7. Siqueira MG, Martins RS. Surgical treatment of adult traumatic brachial plexus injuries: an overview. Arq. Neuropsiquiatr. 2011;69(3):528-35.

8. Bustamante J, Socolovsky M, Emmerich J, Pennini MG, Lausada N, Domitrovic L, et al. Efectos de la eliminación de la tensión mediante puntos epineurales: estudio comparativo empleando diferentes técnicas de sutura en un modelo animal. Rev Arg Neuroc. 2009;23:71-6.

9. Bustamante J, Socolovsky M, Martins RS, Emmerich J, Pennini MG, Lausada N, et al. Effects of eliminating tension by means of epineural stitches: a comparative electrophysiological and histomorphometrical study using different suture techniques in an animal model. Arq. Neuropsiquiatr. 2011;69(2B):365-70.

10. Schmidhammer R, Zandieh S, Hopf R, Mizner I, Pelinka L, Kroepfl A, et al. Alleviated tension at the repair site enhances functional regeneration: the effect of full range of motion mobilization on the regeneration of peripheral nerves--histologic, electrophysiologic, and functional results in a rat model. J Trauma. 2004;56(3):571-84.

11. Radtke C, Vogt PM. Peripheral nerve regeneration: a current perspective. Eplasty. 2009;9:e47.

12. Bochdansky $\mathrm{T}$, Hertz $\mathrm{H}$, Poigenfürst J. Effects of flexed position of the wrist joint after flexor tendon sutures on the median nerve. Unfallchirurgie. 1993;19(5):303-6.

13. Zlowodzki M, Chan S, Bhandari M, Kalliainen L, Schubert W. Anterior transposition compared with simple decompression for treatment of cubital tunnel syndrome. A meta-analysis of randomized, controlled trials. J. Bone Joint Surg. Am. 2007;89(12):2591-8.

14. Danoff JR, Lombardi JM, Rosenwasser MP. Use of a pedicled adipose flap as a sling for anterior subcutaneous transposition of the ulnar nerve. J. Hand Surg. Am. 2014;39(3):552-5. 
15. Zimmerman RM, Jupiter JB, González Del Pino J. Minimum 6-year follow-up after ulnar nerve decompression and submuscular transposition for primary entrapment. J. Hand Surg. Am. 2013;38(12):2398-404.

16. Bourrel P. Technique of nerve suture. Med Trop. 1982;42(2):221-2.

17. Millesi H. The nerve gap. Theory and clinical practice. Hand Clin. 1986;2(4):651-63.

18. Stevens WG, Hall JD, Young VL, Weeks PM. When should nerve gaps be grafted? An experimental study in rats. Plast. Reconstr. Surg. 1985;75(5):707-13.

19. Saleh M, Mafi $P$, Hindocha $S$, Dhital M. Advances of peripheral nerve repair techniques to improve hand function: a systematic review of literature. Open Orthop. J. 2012;6:60-8.

20. Oktay MF, Askar I, Yildirim A, Gurlek A, Akkus M, Topcu I, et al. Effects of antineoplastic agents on the peripheral nerves under a surgical tissue expansion procedure: An experimental study. Microsurgery. 2006;26(6):473-9.

21. Arnaoutoglou CM, Sakellariou A, Vekris M, Mitsionis GI, Korompilias A, loakim E, et al. Maximum intraoperative elongation of the rat sciatic nerve with tissue expander: Functional, neurophysiological, and histological assessment. Microsurgery. 2006;26(4):253-61.

22. Kechele PR, Bertelli JA, Dalmarco EM, Frode TS. The mesh repair: tension free alternative on dealing with nerve gaps-experimental results. Microsurgery. 2011;31(7):551-8.

23. Belkas JS, Shoichet MS, Midha R. Peripheral nerve regeneration through guidance tubes. Neurol. Res. 2004;26(2):151-60.

24. De Ruiter GCW, Malessy MJA, Yaszemski MJ, Windebank AJ, Spinner RJ. Designing ideal conduits for peripheral nerve repair. Neurosurg. Focus. 2009;26(2):E5.

25. Meek MF, Coert JH. US Food and Drug Administration /Conformit Europe- approved absorbable nerve conduits for clinical repair of peripheral and cranial nerves. Ann. Plast. Surg. 2008;60(4):466-72.

26. Hobson MI. Increased vascularisation enhances axonal regeneration within an acellular nerve conduit. Ann. R. Coll. Surg. Engl. 2002;84(1):47-53.

27. Janjua RM, Fernandez J, Tender G, Kline DG. Submuscular transposition of the ulnar nerve for the treatment of cubital tunnel syndrome. Neurosurgery. 2008;63(4 SUPPL.).

28. Charles YP, Coulet B, Rouzaud JC, Daures JP, Chammas M. Comparative Clinical Outcomes of Submuscular and Subcutaneous Transposition of the Ulnar Nerve for Cubital Tunnel Syndrome. J. Hand Surg. Am. 2009;34(5):866-74.

29. Jiang B, Shibata M, Matsuzaki H, Takahashi HE. Proximal nerve elongation vs. nerve grafting in repairing segmental nerve defects in rabbits. Microsurgery. 2004;24(3):213-7. 
30. Friedman $\mathrm{AH}$. An eclectic review of the history of peripheral nerve surgery. Neurosurgery. 2009;65(4 Suppl):A3-A8.

31. Powers CJ, Friedman AH. A brief history of surgery for peripheral nerve sheath tumors. Neurosurg. Focus. 2007;22(6):E1.

32. Battiston B, Papalia I, Tos P, Geuna S. Chapter 1: Peripheral nerve repair and regeneration research: a historical note. Int Rev Neurobiol. 2009;87:1-7.

33. Socolovsky M, Bortz J. Historia de la cirugía de los nervios periféricos, con especial interés en la influencia que tuvieron en ella los conflictos armados. Rev Arg Neuroc. 2005;19(4):237-42.

34. Seddon H. Three types of nerve injury. Brain. 1943;66(4):237-88.

35. Seddon H. A classification of nerve injuries. Br Med J. 2(4260):237-9.

36. Socolovsky M. Estudio anatómico y microquirúrgico del abordaje transmuscular a la porción proximal del nervio ciático mayor. 2010. p. 7-10. Facultad de Medicina. Universidad de Buenos Aires.

37. Burnett MG, Zager EL. Pathophysiology of peripheral nerve injury: a brief review. Neurosurg. Focus. 2004;16(5):E1.

38. Wang S, Yaszemski MJ, Knight AM, Gruetzmacher JA, Windebank AJ, Lu L. Photo-crosslinked poly(epsilon-caprolactone fumarate) networks for guided peripheral nerve regeneration: material properties and preliminary biological evaluations. Acta Biomater. 2009;5(5):1531-42.

39. Geuna S, Nicolino S, Raimondo S, Gambarotta G, Battiston B, Tos P, et al. Nerve regeneration along bioengineered scaffolds. Microsurgery. 2007;27(5):429-38.

40. Amado S, Rodrigues JM, Luís AL, Armada-da-Silva PAS, Vieira M, Gartner A, et al. Effects of collagen membranes enriched with in vitro-differentiated N1E-115 cells on rat sciatic nerve regeneration after end-to-end repair. J. Neuroeng. Rehabil. 2010;7:7.

41. Bain J, Mackinnon S HD. Functional evaluation of complete sciatic, peroneal, and posterior tibial nerve lesions in the rat. Plast. Reconstr. Surg. 1989;83(1):129-38.

42. Flores AJ, Lavernia CJ, Owens PW. Anatomy and physiology of peripheral nerve injury and repair. Am. J. Orthop. 2000;29(3):167-73.

43. Geneser F. Histología. 2da ed. Panamericana EM, editor. 1990. p. 283-5.

44. Asato $\mathrm{F}$, Butler $\mathrm{M}$, Blomberg $\mathrm{H}$, Gordh $\mathrm{T}$. Variation in rat sciatic nerve anatomy: implications for a rat model of neuropathic pain. J. Peripher. Nerv. Syst. 2000;5(1):19-21.

45. Koka R, Hadlock TA. Quantification of functional recovery following rat sciatic nerve transection. Exp. Neurol. 2001;168(1):192-5. 
46. Thil MA, Duy DT, Colin IM, Delbeke J. Time course of tissue remodelling and electrophysiology in the rat sciatic nerve after spiral cuff electrode implantation. J. Neuroimmunol. 2007;185(12):103-14.

47. Andrei Biro, Oana Grosu, George Dinlegan1, Vasile Ibre CC. The Repair of a 10 Milimeter Defect in the Rat Sciatic Nerve with Collagen Tube. Timisora Med. j. 2005;2(1):1-7.

48. Fine EG, Decosterd I, Papaloïzos M, Zurn AD, Aebischer P. GDNF and NGF released by synthetic guidance channels support sciatic nerve regeneration across a long gap. Eur. J. Neurosci. 2002;15(4):589-601.

49. Clavijo-Alvarez JA, Nguyen VT, Santiago LY, Doctor JS, Lee WPA, Marra KG. Comparison of biodegradable conduits within aged rat sciatic nerve defects. Plast. Reconstr. Surg. 2007;119(6):1839-51.

50. Francel PC, Smith KS, Stevens FA, Kim SC, Gossett J, Gossett C, et al. Regeneration of rat sciatic nerve across a LactoSorb bioresorbable conduit with interposed short-segment nerve grafts. J. Neurosurg. 2003;99(3):549-54.

51. Karimi M, Biazar E, Keshel SH, Ronaghi A, Doostmohamadpour J, Janfada A, et al. Rat sciatic nerve reconstruction across a $30 \mathrm{~mm}$ defect bridged by an oriented porous PHBV tube with Schwann cell as artificial nerve graft. ASAIO J. 2014;60(2):224-33.

52. Kovacic U, Bajrović F, Sketelj J. Recovery of cutaneous pain sensitivity after end-to-side nerve repair in the rat. J. Neurosurg. 1999;91(5):857-62.

53. Bélanger E, Henry FP, Vallée R, Randolph MA, Kochevar IE, Winograd JM, et al. In vivo evaluation of demyelination and remyelination in a nerve crush injury model. Biomed Opt Express. 2011; 2(9):2698-708.

54. Chlebicki CA, Lee AD, Jung W, Li H, Liaw L-H, Chen Z, et al. Preliminary investigation on use of high-resolution optical coherence tomography to monitor injury and repair in the rat sciatic nerve. Lasers Surg. Med. 2010;42(4):306-12.

55. Menovsky T, Beek JF. Laser, fibrin glue, or suture repair of peripheral nerves: a comparative functional, histological, and morphometric study in the rat sciatic nerve. J. Neurosurg. 2001;95(4):694-9.

56. Spinner RJ, Poliakoff MB, Tiel RL. The origin of "Saturday night palsy"? Neurosurgery. 2002;51(3):737-741; discussion 741.

57. Fernandez E, Pallini R, Talamonti G. Sleep palsy (Saturday-night palsy) of the deep radial nerve. Case report. J. Neurosurg. 1987; 66(3):460-1.

58. Sunderland S. A classification of peripheral nerve injuries producing loss of function. Brain. 1951;74(4):491-516. 
59. Robla-Costales J, Socolovsky M, Masi G Di, Domitrovic L, Campero A, Fernández-Fernández J, et al. Técnicas de reconstrucción nerviosa en cirugía del plexo braquial traumatizado Parte 1 : Transferencias nerviosas extraplexuales. Neurocirugia (Astur). 2011;22(6):507-20

60. Robla-Costales J, Socolovsky M, Masi G Di, Domitrovic L, Campero A, Fernández-Fernández J, et al. Técnicas de reconstrucción nerviosa en cirugía del plexo braquial traumatizado Parte 2 : Transferencias nerviosas intraplexuales. Neurocirugia (Astur). 2011;22(6):521-34.

61. McLean J, Batt J, Doering LC, Rotin D, Bain JR. Enhanced rate of nerve regeneration and directional errors after sciatic nerve injury in receptor protein tyrosine phosphatase sigma knockout mice. J. Neurosci. 2002;22(13):5481-91.

62. Borin A, Toledo RN, Lee P, Ricardo J, Testa G, Laércio O. facial nerve regeneration in rats. 2008;74:675-83.

63. Liu G-B, Cheng Y-X, Feng Y-K, Pang C-J, Li Q, Wang Y, et al. Adipose-derived stem cells promote peripheral nerve repair. Arch. Med. Sci. 2011 Aug;7(4):592-6.

64. Martins RS, Siqueira MG, Silva CF da, Godoy BO de, Plese JPP. Electrophysiologic assessment of regeneration in rat sciatic nerve repair using suture, fibrin glue or a combination of both techniques. Arq. Neuropsiquiatr. 2005;63(3A):601-4.

65. Knox CJ, Hohman MH, Kleiss IJ, Weinberg JS, Heaton JT, Hadlock TA. Facial nerve repair: fibrin adhesive coaptation versus epineurial suture repair in a rodent model. Laryngoscope. 2013;123(7):1618-21.

66. Nunes e Silva D, Silva ACMBA, Aydos RD, Viterbo F, Pontes ERJC, Odashiro DN, et al. Nerve growth factor with fibrin glue in end-to-side nerve repair in rats. Acta Cir Bras. 2012;27(4):32532.

67. Silva DN e, Coelho J, Frazílio F de O, Odashiro AN, Carvalho P de TC de, Pontes ERJC, et al. End-toside nerve repair using fibrin glue in rats. Acta Cir. Bras. 2010;25(2):158-62.

68. Lauto A, Foster L, Avolio A, Sampson D, Raston C, Sarris M, et al. Sutureless nerve repair with laser-activated chitosan adhesive: a pilot in vivo study. Photomed. Laser Surg. 2008;26(3):22734.

69. Tallis R, Staniforth P, Fisher TR. Neurophysiological studies of autogenous sural nerve grafts. J. Neurol. Neurosurg. Psychiatry. 1978;41(8):677-83.

70. Maeda T, Hori S, Sasaki S, Maruo S. Effects of tension at the site of coaptation on recovery of sciatic nerve function after neurorrhaphy: evaluation by walking-track measurement, electrophysiology, histomorphometry, and electron probe X-ray microanalysis. Microsurgery. 1999;19(4):200-7. 
71. Arnaoutoglou CM, Sakellariou A, Vekris M, Mitsionis GI, Korompilias A, loakim E, et al. Maximum intraoperative elongation of the rat sciatic nerve with tissue expander: functional, neurophysiological, and histological assessment. Microsurgery. 2006;26(4):253-61.

72. Nectow AR, Marra KG, Kaplan DL. Biomaterials for the Development of Peripheral Nerve Guidance Conduits. Tissue Eng. Part B Rev. 2012. p. 40-50.

73. Hsiang S-W, Tsai C-C, Tsai F-J, Ho T-Y, Yao C-H, Chen Y-S. Novel use of biodegradable casein conduits for guided peripheral nerve regeneration. J. R. Soc. Interface. 2011. p. 1622-34.

74. Gu X, Ding F, Yang Y, Liu J. Construction of tissue engineered nerve grafts and their application in peripheral nerve regeneration. Prog. Neurobiol. 2011. p. 204-30.

75. Hazer DB, Bal E, Nurlu G, Benli K, Balci S, Öztürk F, et al. In vivo application of poly-3hydroxyoctanoate as peripheral nerve graft. J. Zhejiang Univ. Sci. B. 2013;14(11):993-1003.

76. Device SS, Management S. Reconstruction of the human median nerve in the forearm with the neurotube. 2007; 53(12):839-46.

77. Moore AM, Kasukurthi R, Magill CK, Farhadi HF, Borschel GH, Mackinnon SE. Limitations of conduits in peripheral nerve repairs. Hand (N. Y). 2009;4(2):180-6.

78. Hedayatpour A, Sobhani A, Bayati V, Abdolvahhabi M-A, Shokrgozar M-A, Barbarestani M. A method for isolation and cultivation of adult Schwann cells for nerve conduit. Arch. Iran. Med. 2007;10(4):474-80.

79. Mohammadi R, Amini K, Abdollahi-Pirbazari M, Yousefi A. Acetyl Salicylic Acid Locally Enhances Functional Recovery After Sciatic Nerve Transection in Rat. Neurol. Med. Chir. (Tokyo). 2013;53(12):839-46.

80. Scherman P, Kanje M, Dahlin LB. Bridging short nerve defects by direct repair under tension, nerve grafts or longitudinal sutures. Restor. Neurol. Neurosci. 2004;22(2):65-72.

81. National Research Council. Guide for the Care and Use of Laboratory Animals. Lab. Anim. 1996. p. 248.

82. Tschan CA, Keiner D, Müller HD, Schwabe K, Gaab MR, Krauss JK, et al. Waterjet dissection of peripheral nerves: an experimental study of the sciatic nerve of rats. Neurosurgery. 2010;67(2 Suppl Operative):368-76.

83. Robla Costales J, Dominguez Páez J, Bustamante J, Socolovsky M. Técnicas Modernas en Microcirugía de los Nervios Periféricos. Journal Ed. 2014.

84. Oliveira EF, Mazzer N, Barbieri CH, Selli M. Correlation between functional index and morphometry to evaluate recovery of the rat sciatic nerve following crush injury: experimental study. J. Reconstr. Microsurg. 2001;17(1):69-75. 
85. Sun W, Sun C, Zhao H, Lin H, Han Q, Wang J, et al. Improvement of sciatic nerve regeneration using laminin-binding human NGF-beta. PLoS One. 2009;4(7):e6180.

86. Christensen D, Idänpään-Heikkilä JJ, Guilbaud G, Kayser V. The antinociceptive effect of combined systemic administration of morphine and the glycine/NMDA receptor antagonist, (+)-HA966 in a rat model of peripheral neuropathy. Br. J. Pharmacol. 1998;125(8):1641-50.

87. Vrinten DH, Gispen WH, Groen GJ, Adan RA. Antagonism of the melanocortin system reduces cold and mechanical allodynia in mononeuropathic rats. J. Neurosci. 2000;20(21):8131-7.

88. Martins RS, Siqueira MG, da Silva CF, Plese JPP. Correlation between parameters of electrophysiological, histomorphometric and sciatic functional index evaluations after rat sciatic nerve repair. Arq Neuropsiquiatr. 2006;64(3B):750-6.

89. Dellon AL, Mackinnon SE. Sciatic nerve regeneration in the rat. Validity of walking track assessment in the presence of chronic contractures. Microsurgery. 1989;10(3):220-5.

90. Terzis J, Faibisoff B, Williams B. The nerve gap: suture under tension vs. graft. Plast. Reconstr. Surg. 1975;56(2):166-70.

91. Brown CJ, Evans PJ, Mackinnon SE, Bain JR, Makino AP, Hunter DA, et al. Inter- and intraobserver reliability of walking-track analysis used to assess sciatic nerve function in rats. Microsurgery. 1991;12(2):76-9.

92. De Medinaceli L, William F, Wtatt R. An index of the functional condition of rat sciatic nerve based on measurements made from walking tracks. Exp. Neurol. 1982;77:634-43.

93. Chakravarthy Marx S, Kumar P, Dhalapathy S, Prasad K, Marx CA. Microanatomical and immunohistochemical study of the human lateral antebrachial cutaneous nerve of forearm at the antecubital fossa and its clinical implications. Clin. Anat. 2010;23(6):693-701.

94. Ma X, Yang Z, Li X, Ma J, Zhang Y, Guo H, et al. A study on biomechanical properties of chemically extracted acellular peripheral nerve. Zhongguo Xiu Fu Chong Jian Wai Ke Za Zhi. 2010;24(11):1293-7.

95. Whitlock EL, Myckatyn TM, Tong AY, Yee A, Yan Y, Magill CK, et al. Dynamic quantification of host Schwann cell migration into peripheral nerve allografts. Exp. Neurol. 2010;225(2):310-9.

96. Kim Y tae, Haftel VK, Kumar S, Bellamkonda R V. The role of aligned polymer fiber-based constructs in the bridging of long peripheral nerve gaps. Biomaterials. 2008;29(21):3117-27.

97. Kaplan S, Geuna S, Ronchi G, Ulkay MB, von Bartheld CS. Calibration of the stereological estimation of the number of myelinated axons in the rat sciatic nerve: A multicenter study. J. Neurosci. Methods. 2010;187(1):90-9.

98. Weber RA, Proctor WH, Warner MR, Verheyden CN. Autotomy and the sciatic functional index. Microsurgery. 1993;14(5):323-7. 
99. Martins R. Avaliação da eficácia do reparo na regeneração do nervo ciático do rato com utilização de sutura, adesivo de fibrina ou combinação das duas técnicas. Universidade de São Paulo; 2004. p. 87-8.

100. Yan H, Zhang F, Kolkin J, Wang C, Xia Z, Fan C. Mechanisms of nerve capping technique in prevention. PLoS One. Public Library of Science; 2014;9(4).

101. Mohammadi R, Amini K, Abdollahi-Pirbazari M, Alireza Y. Acetyl Salicylic Acid Locally Enhances Functional Recovery after Sciatic Nerve Transection in Rat. Neurol Med Chir. 2013;53:839-46.

102. Martins RS, Siqueira MG, Da Silva CF, De Godoy BO, Pereira Plese JP. Electrophysiologic assessment of regeneration in rat sciatic nerve repair using suture, fibrin glue or a combination of both techniques. Arq. Neuropsiquiatr. 2005;63(3 A):601-4.

103. Martins RS, Teodoro WR, Simplício H, Capellozi VL, Siqueira MG, Yoshinari NH, et al. Influence of suture on peripheral nerve regeneration and collagen production at the site of neurorrhaphy: An experimental study. Neurosurgery. 2011;68(3):765-72.

104. Millesi H, Meissl G, Berger A. Further experience with interfascicular grafting of the median, ulnar, and radial nerves. J. Bone Joint Surg. Am. 1976;58(2):209-18.

105. Berger A, Millesi H. Nerve grafting. Clin. Orthop. Relat. Res. 1978;(133):49-55.

106. Capek L, Clarke HM. Endoscopically assisted sural nerve harvest in infants. Semin. Plast. Surg. 2008;22(1):25-8.

107. Van Ouwerkerk WJ. Endoscopy-assisted sural nerve harvest in infants. Childs. Nerv. Syst. 1999;15(4):192-195; discussion 196.

108. Hattori Y, Doi K, Ikeda K, Pagsaligan JM. Vascularized ulnar nerve graft for reconstruction of a large defect of the median or radial nerves after severe trauma of the upper extremity. J. Hand Surg. Am. 2005;30(5):986-9.

109. Hattori Y, Doi K. Vascularized ulnar nerve graft. Tech. Hand Up. Extrem. Surg. 2006. p. 103-6.

110. Terzis JK, Kostopoulos VK. Vascularized ulnar nerve graft: 151 reconstructions for posttraumatic brachial plexus palsy. Plast. Reconstr. Surg. 2009;123(4):1276-91.

111. Risitano G, Alcontres FSD. Ulnar nerve repair by end-to-side neurorrhaphy on the median nerve with interposition of a vein : an experimental study. 2007; 58(2):209-18.

112. Lavasani M, Gehrmann S, Gharaibeh B, Clark KA, Kaufmann RA, P??ault B, et al. Venous graftderived cells participate in peripheral nerve regeneration. PLoS One. 2011;6(9).

113. Mohammadi R, Mehrtash M, Nikonam N, Mehrtash M, Amini K. Ketoprofen combined with artery graft entubulization improves functional recovery of transected peripheral nerves. J. Cranio-Maxillofacial Surg. 2013; 58(2):209-18. 
114. Bertelli JA, Taleb M, Mira J-C, Ghizoni MF. The course of aberrant reinnervation following nerve repair with fresh or denatured muscle autografts. J. Peripher. Nerv. Syst. 2005;10(4):359-68.

115. Robla Costales J, Domínguez Páez M, Bustamante JL SM. Técnicas Modernas en Microcirugía de los Nervios Periféricos. Ed. Journal. ISBN 9789871981625. 2014.

116. Clark WL, Trumble TE, Swiontkowski MF, Tencer AF. Nerve tension and blood flow in a rat model of immediate and delayed repairs. J. Hand Surg. Am. 1992;17(4):677-87.

117. Vazquez-Jimenez JF, Sachweh JS, Seipelt R, Seghaye MC, Messmer BJ. Aortopexy reduces anastomosis stress after repair of coarctation. Ann. Thorac. Surg. 2001;72(1):294-5. 


\section{Agradecimientos}

A mis padres y hermana por el todo. A mi esposa e hijo por ser el motor de la vida.

A Mariano Socolovsky por su grandeza desinteresada y aliento permanente desde antes de recibirme de médico.

A Natalia Lausada por iniciarme en la microcirugía y brindarme la calidez de formar parte de su familia de investigación.

A los Dres Alberto Fontana y Clemente Raimondi, profesores titulares de cátedras, por los cimientos de mi carrera.

A Tate Lambre por las oportunidades brindadas, pasadas y presentes.

A Juan Emmerich por su acompañamiento permanente, desde mi inicio en la neuroanatomía hasta la neurocirugía.

Al gran Fidel Sosa por sus enseñanzas intra y extra neuroquirúrgicas, y la visión del paciente como un todo.

A Pablo Rubino por contagiarme de su obsesión para realizar siempre una cirugía lírica y limpísima.

A Eduardo Salas por su temple y sabias decisiones frente a las cirugías complejas, sin descuidar el afecto con los pacientes.

A Osvaldo Tropea por su apoyo incondicional y cariño durante mi residencia.

A Facundo Rodríguez por demostrarme que la velocidad y solidez deben formar parte de una cirugía.

A Carlos y Esteban Vogel por su inmensurable ayuda con la histopatología.

A Marcelo D’Agustini por su calidez y apoyo para publicar mi primer artículo internacional aún siendo alumno de medicina.

A mis compañeros de Laboratorio que me ayudaron en esta tesis con cariño (Pablo Stringa, Gustavo Zalazar, Claudio Ledesma, Gonzalo Irigoyen, Fernanda Raimondi).

A mis compañeros de la cátedra de anatomía, por su amistad y entusiasmo por la disección.

A mis compañeros de residencia y neurocirujanos (Mario Espeche, Leopoldo Luque, Juan Lafata, Miguel Mural, Maximiliano Nuñez, Romina Argañaraz, Mariano Pallavicini, Noel Almerares, Jorge Mandolesi, Marcelo Orellana) que compartieron conmigo mis primeros años de neurocirugía y mucho me enseñaron. 